Self-Care Activities of Low-Income Women in Midlife

BY

\title{
PATRICIA GREGORY
}

\author{
A Thesis \\ Submitted to the Faculty of Graduate Studies \\ Partial Fulfillment of the Requirements \\ for the Degree of
}

\section{MASTER OF NURSING}

Faculty of Nursing University of Manitoba

Winnipeg, Manitoba

(C) August, 1999 
National Library of Canada

Acquisitions and

Bibliographic Services

395 Wellington Street

Ottawa ON K1A ON4

Canada
Bibliothèque nationale du Canada

Acquisitions et services bibliographiques

395, rue Wellington OHawa ON K1A ON4 Canada
The author has granted a nonexclusive licence allowing the National Library of Canada to reproduce, loan, distribute or sell copies of this thesis in microform, paper or electronic formats.

The author retains ownership of the copyright in this thesis. Neither the thesis nor substantial extracts from it may be printed or otherwise reproduced without the author's permission.
L'auteur a accordé une licence non exclusive permettant à la Bibliothèque nationale du Canada de reproduire, prêter, distribuer ou vendre des copies de cette thèse sous la forme de microfiche/film, de reproduction sur papier ou sur format électronique.

L'auteur conserve la propriété du droit d'auteur qui protège cette thèse. $\mathrm{Ni}$ la thèse ni des extraits substantiels de celle-ci ne doivent être imprimés ou autrement reproduits sans son autorisation. 


\title{
THE UNIVERSITY OF MANTTOBA
}

FACULTY OF GRADUATE STUDIES

COPYRIGHT PERMISSION PAGE

Self-Care Activities of Low-Income Women in Midlife

BY

\section{Patricia Gregory}

\begin{abstract}
A Thesis/Practicum submitted to the Faculty of Graduate Studies of The University of Manitoba in partial fulfillment of the requirements of the degree

of
\end{abstract}

MASTER OF NURSING

PATRICIA GREGORYO1999

Permission has been granted to the Library of The University of Manitoba to lend or sell copies of this thesis/practicum, to the National Library of Canada to microfilm this thesis and to lend or sell copies of the film, and to Dissertations Abstracts International to publish an abstract of this thesis/practicum.

The author reserves other publication rights, and neither this thesis/practicum nor extensive extracts from it may be printed or otherwise reproduced without the author's written permission. 


\section{DEDICATION}

To Lisa, my daughter

who holds a very special place in my heart and is the passion of my life 


\section{ACKNOWLEDGMENTS}

I thank the following people for their knowledge, guidance and support in the completion of this thesis:

- the women who so willingly and candidly shared their stories. I hope that I have been able to adequately reflect the context of your lives.

- the school division administration, the teacher in the job re-entry program, and the outreach coordinator of the women's resource centre for their cooperation and assistance in facilitating the research process.

- my thesis committee for assisting me to develop knowledge and skill as a researcher.

Dr. Karen Chalmers for your expertise, attentiveness, and the unrelenting support you provided to me. Dr. Wanda Chernomas for you knowledge and experience in the areas of women's health and feminist method. Dr. Tuula Heinonen for your guidance in terms of the literature and your excitement about the project.

- To Bruce for your endurance and faith in my ability to achieve this goal.

- To Lisa, for your patience and understanding throughout this process and for your words of support and encouragement.

- To my mother and father for your encouragement and support in the pursuit of my goals. This project would not have been possible without your help. I want to thank you for your help in caring for Lisa, preparing meals and making sure all was well on the homefront.

- To Donna and Claire, and my other friends, classmates and colleagues for your unwavering support. 


\begin{abstract}
In Canada women born during the "baby boom" years from the late 1940 s to the mid 1960s make up the largest group of women. Many of these women are now entering midlife. Little is known about the self-care activities that women carry out to maintain functioning and development associated with midlife. Findings from the few studies that have been conducted, indicate that women think of midlife as a developmental stage, representing a time of change and transition, a time when women are attempting to come to terms with midlife and aging. The studies have included predominantly white, educated, employed and affluent women, thereby limiting knowledge about the experience of midlife, and self-care activities of low-income women The purpose of this study was to uncover the self-care activities that low-income women carry out to maintain functioning and for development at midlife in their particular environmental contexts. Knowledge of low-income women's self-care activities in midlife is critical for the development of health promotion strategies that are acceptable and relevant to lowincome women in the context of their daily lives. A qualitative ethnographic approach informed by feminist principles was used to uncover the self-care activities of lowincome women in midlife. The study was guided by Orem's Model of Self-Care and Bronfenbrenner's Ecology of Human Development Framework. Data were collected through the use of in-depth semi-structured interviews. Analysis was conducted using content analysis methods. The analysis revealed five major categories: (1) poverty: a consequence of circumstance rather than a way of life; (2) working towards a better future; (3) self-care: survival strategies; (4) midlife, a stage? Not really, just the continuity of life; and (5) it's connections I need. The self-care activities were found to be deeply embedded within the context of their daily lives.
\end{abstract}


Women did not think of midlife as a developmental stage, nor were they coming to terms with midlife and aging. Women were focused on issues related to the continuity of life. Focused on work, raising their children and maintaining the family as a foundation, the women used emotion focused activities to carry on in the face of adversity. The findings of this study were most consistent with the findings of studies on low income women, rather than the studies of women in midlife. Recommendations for nursing practice, nursing education, nursing research and policy were made. 
Table of Contents

\section{Chapter 1 Statement of the Problem}

Introduction

Problem Statement

Purpose of the Study

Significance of the Study

Conceptual Framework

Orem's model of self-care

Ecology of human development framework

Summary

$\begin{array}{lll}\text { Chapter } 2 \text { Literature Review } & 25\end{array}$

$\begin{array}{ll}\text { Midlife } & 27\end{array}$

Developmental theories 31

In Search of a Common Understanding of Menopause 33

The Multiple and Conflicting Perspectives 42

The Estrogen Dilemma 51

Alternative Approaches $\quad 55$

Self-Care $\quad 56$

Orem's model of self-care $\quad 58$

Other relevant models $\quad 62$

Self-care Activities of Women in Midlife: a Review of the Research 65

Definitions of Low-Income $\quad 74$

Poverty: A Determinant of Health 78

$\begin{array}{ll}\text { Women and Poverty } & 81\end{array}$

Socioeconomic Status and Menopause: A review of Research Findings 88

Summary 90

$\begin{array}{lll}\text { Chapter } 3 \text { Methodology } & 92\end{array}$

Introduction $\quad 92$

Approaches to Studying Women in midlife $\quad 92$

$\begin{array}{ll}\text { Research Design } & 97\end{array}$

$\begin{array}{ll}\text { Sampling } & 101\end{array}$

$\begin{array}{ll}\text { Recruitment and Access } & 103\end{array}$ 
$\begin{array}{ll}\text { Setting } & 106\end{array}$

$\begin{array}{ll}\text { Data Collection } & 107\end{array}$

Data Analysis 111

Measures to Enhance Methodological Rigor 113

$\begin{array}{ll}\text { Ethical Considerations } & 116\end{array}$

$\begin{array}{ll}\text { Limitations to the study } & 119\end{array}$

$\begin{array}{ll}\text { Summary } & 119\end{array}$

$\begin{array}{lll}\text { Chapter } 4 \text { Findings } & 121\end{array}$

Who Were the Women 121

$\begin{array}{ll}\text { A closer look } & 127\end{array}$

$\begin{array}{ll}\text { Themes } & 128\end{array}$

Poverty: A Consequence of Circumstance Rather Than a Way of Life 129

A breach of faith 131

No education, no skills, and no language $\quad 135$

Surviving the early years $\quad 136$

Working Towards a Better Future 137

The transition: a struggle in itself 138

The struggle continues 140

This is only one place on the journey 143

$\begin{array}{ll}\text { Self-care: Survival Strategies } & 145\end{array}$

I'm it, there is no one else, so I gotta keep going 146

Escaping it all 150

Social support, important, but only if I can trust 151

Focusing on the positive 156

Midlife, a Stage? Not Really, Just the Continuity of Life 157

Taking it in stride 157

Opening doors for my children 159

Maintaining the family as the foundation 160

It's Connections I Need 164

Who can I talk to, where do I go? 164

A sense of community 166

$\begin{array}{ll}\text { Summary } & 168\end{array}$

$\begin{array}{lll}\text { Chapter 5 Discussion } & 169\end{array}$

$\begin{array}{ll}\text { Introduction } & 169\end{array}$ 
Methodological Issues

Conceptual Frameworks

Midlife, a Stage? Not Really, Just the Continuity of Life

Taking it in stride

Opening doors for my children

A developmental stage?

The transition: a struggle in itself

The Struggle Continues

Self-Care: Survival Strategies

Escaping it all

Social support, important, but only if I can trust

Maintaining the Family as the Foundation

It's Connections I Need

Expectations Regarding the findings in this study as compared to

the findings in the literature

Recommendations for Practice

Recommendations for Education

Recommendations for Research

Recommendations for Policy

Conclusion

Reflection

\section{Appendices}
A NCW estimates of Statistics Canada's Low Income Cut-offs
B Letter Requesting Access 231
C Script for Recruiters 232
D Telephone Explanation to Potential Participants 233
E Script for Request of Participants to Identify Other Eligible Women 235
F Information Sheet for Potential Participants 236
G Demographic Questions $\quad 237$
H Interview Guide 238
I Consent Form 241
J Script for Request of Participants for the Verification of Findings 243 


\section{Tables and Figures}

Tables:

2.1 The Multiple and Conflicting Perspectives of Menopause

4.1 Age of Participants

4.2 Number of Children, Number of Children Living in Home

4.3 Age of Children Living in Home

4.4 Marital Status

4.5 Educational Level

4.6 Ethnic Origin

4.7 Employment status

125

4.8 Source of Household Income

4.9 Number of People Living in Household

126

4.10 Occupation

126

Figure:

4.1 Presentation of Themes and Categories 


\section{Chapter 1}

Statement of the Problem

\section{Introduction}

Self-care is considered essential to health; it contributes to human structural integrity, human functioning, and human development (Orem, 1995). Self-care is not a new concept, self-care has been a part of family life since the earliest documented civilizations (Woods, 1989). Orem defines self-care as "the voluntary regulation of one's own human functioning and development that is necessary for individuals to maintain life, health and well being" (p. 95).

Despite the fact that the large number of women born during the baby boom years are entering midlife, few studies have examined the self-care activities of women in midlife or menopause (Bernhard \& Sheppard, 1993; Hartweg, 1993). Findings from the literature indicate that middle-class women think of midlife as a developmental stage, as representing a time of change and transition, a time when women are attempting to come to terms with midlife and aging (Jones, 1994; Woods \& Mitchell, 1997). Women, were found to be developing a new aesthetic based on character and substance rather than one based on youthful beauty and appearance (Jones). They also became more accepting of themselves, and of older women in general as they themselves matured. Women identified that personal gcal attainment was important at this time of life (Dickson, 1994: Woods \& Mitchell, 1997). They were found to be returning to school, starting new careers, and buying homes. Many associated aging, and midlife issues with their experience of menopause (Dickson, 1994; Dosey \& Dosey, 1980; Jones, 1994). As Jones identifies, women were found to have internalized the biomedical perspective. Midlife represented a time of transition, a time of coming to terms with midlife and aging in 
general, and menopause was simply a marker. In addition to the self-care activities to manage the physical manifestations of menopause, women identified a wide variety of activities including the following: gaining knowledge to change the dread of menopause; accepting bodily changes; having faith; throwing themselves into their work; reading for diversion, changing style of dress to cover up their changing bodies; coloring their hair to avoid perception of somehow being less sexual; dieting and exercising in an attempt to hold on to their youth; taking better care of their bodies and taking vitamins and minerals to maintain well being during midlife, and health and quality of life in later years; among other activities.

Midlife is discussed partially in the context of menopause for two reasons, first, as the literature indicates women associate midlife with experience of menopause, and second, most of the research regarding midlife women has been conducted in the context of menopause. The focus of this study is on the self-care activities that low-income women carry out to maintain functioning and development associated with midlife in their particular environmental contexts. Midlife is considered to take into account the range of developmental transitions that women experience.

A major challenge is defining midlife. Some researchers have used age boundaries, others have based their definitions on women's reproductive capacity, and still others have based their definitions on women's role patterns (Woods \& Mitchell, 1997). Jacobson (1995) defined midlife as beginning between the ages of 35 and 40 up to age 65. Hartweg (1993) defined midlife as 40 to 59 years of age. Woods and Mitchell (1997) found that women enrolled in the Seattle Midlife Women's Health Study, most frequently defined midlife as an age range, such as 35 to 55 years, or 40 to 60 years. Common language for the discussion of menopause or reproductive capacity is also 
lacking. There is confusion in the literature in the use of terms such as premenopause, climacteric, perimenopause, and postmenopause (World Health Organization, 1981). Complicating the definition is that it is determined only in retrospect, one year without menstrual bleeding (Mansfield, Jogensen, \& Yu, 1989; Voda \& George, 1986). Neugarten (1968), using role patterns identified the following as midlife parameters: the launching of children; reaching a peak in one's occupation; menopause; grandparenthood; retirement; onset of chronic illness, and widowhood. The number of definitions indicate that there are limitations with each of them and that none fully describe midlife.

Jacobson (1995) identifies that the middle years may be classified differently, renamed and even lengthened in the future as the baby-boom generation ages. The babyboom generation (as defined in Canada, those bom between 1947 and 1966 [Foot, 1996]), has changed societal norms; this generation is expected to experience increasing productive longevity. Women from different cohorts, have lived in different worlds. The initial baby boomers are now entering their fifth decade. As Jacobson identifies, these women were raised differently from women now in later midlife. The oldest cohort of midlife baby boom women were in the forefront of the feminist movement, they were active participants in the sexual revolution and were the first generation to have access to the birth control pill (Faludi, 1991). They have put off marriage and childbearing and have smaller families than women had before them. This cohort has experienced a higher divorce rate, but are found to be remarrying and involved in blended families. Many are somewhat active in nontraditional careers. Household income is equal to that of their older counterparts, however, largely because they live in two-income households. This cohort was raised in front of the television set, with Dr. Spock's values in child-centered 
households, and have been called the "me-generation" demanding and getting what they want instantaneously (Faludi, 1991; Jones, 1980; Naisbitt, 1984). It is important however to keep in mind that the concept of "baby boomer" is a North American phenomenon. Many women in Canadian society may have immigrated to Canada and therefore may not have had the experiences associated with the baby boom generation as described above. Jacobson (1995) indicates that even 35 ycars of age, the age at which midlife is considered to begin, may be too young for this cohort of women, particularly considering that this cohort tended to delay marriage and childbearing. For the purposes of this study midlife is defined as women born between the years of 1947 and 1958 . Women were therefore, between the ages of 40 and 51 at the time of data collection. This age range also encompasses the average age at which women experience the menopausal transition. A major limitation with many of the studies in the area of midlife and menopause, is that the participants have been predominantly white, educated, employed, and affluent. Little, therefore is known about the experience of low-income women and their self-care activities in midlife. It is not known whether the self-care activities identified in previous studies are relevant to low-income women. Income is a well known determinant of health, it can positively or negatively affect the lives, health, and well-being of individuals, families and communities. Poor health is associated with lower position on the social hierarchy regardless of whether hierarchy is defined by education, income, or job classification (Rachlis \& Kushner, 1995). Women are disproportionately represented among Canada's poor (National Council of Welfare, 1998a). Increasingly poverty is being recognized as a health issue on women's health agendas. Nelson (1997) identifies that the combination of poverty and multiple role responsibilities may inhibit healthy behaviours and contribute to the poorer health outcomes experienced by low-income 
women. There is an assumption that self-care activities are health promoting. Graham (1989) illustrated the double edged sword of self-care activities of low-income women. Women in her study used smoking as a major coping strategy. When the demands of child care became too much to handle in a controlled manner, the women may have successfully coped with the situation, but the activity was not health promoting.

The proportion of women among Canada's poor has not changed despite the many legislative changes mandating affirmative action and pay equity that occurred during the 1980s. Women continue to be at higher risk of poverty than men (National Council of Welfare, 1990). Research is suggesting that health behaviour among lowincome groups is unlikely to be modified simply through individually targeted information and advice (Graham, 1987; Nelson, 1997). Graham suggests that health behaviour should not be thought of as indicative of free choice, easily amenable to change, but rather as a no-choice option for low-income people struggling to make ends meet. There is a need therefore, to develop strategies for health promotion which go beyond advice directed at individual lifestyle change, to address the experiences of living in poverty. (Daykin \& Naidoo, 1997). As Health and Welfare Canada, (1990) indicated in their report entitled The Active Health Report on Women, there is a "critical need to develop responses that are sensitive to the needs and life circumstances of different groups of women..." (p. 3).

Prior to developing health promotion strategies that are sensitive to the needs and life circumstances of low-income women in midlife, it is critical to identify the self-care activities that low-income women engage in, within the context of their environments. 


\section{Problem Statement}

The purpose of this study was to uncover the self-care activities of low-income women in midlife in terms of: (a) their perceived self-care needs in midlife; (b) sources of information and support to cope with this transition; (c) the conditions low-income midlife women seek to create or maintain through self-care activities; (d) how they come to decide which self-care activities should be utilized and which self-care activities are engaged upon; (e) the facilitating and limiting factors or conditions regarding self-care; and (f) suggestions low-income midlife women have for health professionals regarding the facilitation of interconnections with settings including the health care system that are required for development during this developmental stage. The central question guiding the study was, "what are the self-care activities that low-income women carry out in midlife?"

\section{Purpose of the Study}

In this study, the researcher sought information on self-care activities that lowincome women carried out at midlife in their particular environmental contexts. In response to the uncovering of self-care activities, recommendations for working with low-income women in midlife were made. The information required to develop the recommendations was collected through in-depth semi-structured interviews conducted with low-income women in midlife. More specifically, the data collection process was guided by the following questions:

1. How do low-income women in mid-life define self-care?

2. What are the perceived self-care needs of low-income women in midlife?

3. What sources of information do women use to assist them with the midlife transitions and self-care activities? 
4. To whom do low-income women in midlife go to for assistance and support in coping with this transition?

5. What conditions do low-income women in midlife seek to create or maintain through self-care activities?

6. How do low-income women in midlife decide which self-care activities should be utilized and how do they select the self-care activities they engage in?

7. What self-care activities are engaged in?

8. What are the facilitating and limiting factors or conditions regarding self-care?

9. How can health professionals facilitate the interconnections with settings including the health care system that are required for development during this developmental stage. Significance of the Study

The study findings are valuable to health care professionals working with lowincome women in midlife, particularly in light of the number of women approaching midlife. As Reissman (1990) asserts, it is not enough to increase access to services, rather, support strategies that are responsive and integrated are needed for low-income women and families.

Orem (1995) identifies that patterns of living, sociocultural orientations, family system factors, and social environmental circumstances affect self-care activities largely by circumscribing the needs and means of meeting those needs that are accepted and admitted as constituent components of a person's self-care agency. The care measures prescribed by culture and families, in addition to the sociocultural orientation to health and heaith care, all influence what will or will not be accepted by low-income women. As Orem asserts, self-care activities must be understood within the cultural context of social groups and with the total care systems of social group members. Health promotion 
strategies, therefore must be based on an understanding of what low-income women in midlife do to take care of themselves, within the context of their lives. Increased understanding of the self-care activities of low-income women in midlife and the ways in which these practices are integrated into the women's daily activities assist professionals to design health promotion strategies that are responsive and appropriate considering the demands and constraints of living in poverty at midlife.

In summary, the self-care activities of low-income women in midlife were important to uncover. Not only were they important to identify because the baby boomers are expanding the proportion of women entering this time of life, but also because of the links between poverty, health behaviour and health status. The understanding of the selfcare activities of low-income women in midlife and how they come to be practiced in the context of their unique life circumstances is critical for the development of health promotion strategies that are responsive, acceptable, and relevant to these women in the context of their daily lives.

\section{Conceptual Framework}

Conceptual frameworks serve to organize research findings into a coherent structure that assists in making the body of accumulated knowledge more accessible and useful to both practicing professionals and researchers who seek to build upon the knowledge base (Polit \& Hungler, 1995). Frameworks also help to stimulate research and extend the body of knowledge by providing both impetus and direction (Gunter, 1992).

Both Orem's Model of Self-Care (1995) and Bronfenbrenner's Ecology of Human Development framework (1979) guided this study. Bronfenbrenner's framework was needed to permit a broader contextual understanding of the self-care activities of lowincome women in midlife. The ecological framework guided the study particularly in 
terms of uncovering the social environmental circumstances in both the immediate and more remote environments that shaped low-income women's self-care activities in midlife.

\section{Orem's Model of Self-Care.}

The three interrelated theories proposed by Orem (1995) are: the theory of selfcare, the theory of self-care deficit, and the theory of nursing system. The theory of selfcare (Orem, 1995), framed this study as it was most consistent with the concepts of development and health promotion, therefore most relevant to this study. This theory includes the concepts of therapeutic self-care demand and self-care agency. The theory of self-care explains why individuals initiate self-care activities to meet self-care requisites. It considers the whole of experience and movement towards higher and higher integration through continued development which is reflective of women's experience during midlife transition as identified in the literature. The model also proposes that the conditions which people provide or maintain through self-care are related to development and functioning in life situations and therefore health. The idea that self-care is related to functioning in every day life situations is appropriate as it was within this context that the researcher studied the self-care activities of low-income women in midlife.

Orem (1995) defines self-care as a function that individuals carry out for themselves to maintain life, physical and psychosocial functioning, development compatible with conditions necessary for life, and for integrity of functioning and development. She describes self-care as learned and carried out continuously in time, and congruent with the regulatory requirements of the individual associated with their particular stage of growth and development, state of health, specific features of heaith, or developmental states, environmental factors, and levels of energy expenditure. In this 
study, the researcher sought information on self-care activities that low-income women carry out in midlife in their particular environmental contexts.

Orem (1995) presupposes that developing persons learn and exercise practical skills, manage themselves, and sustain themselves for continuing daily care with some degree of effectiveness. Self-care is considered to require the availability, procurement, preparation, and use of resources for determining what care is needed and for its provision. Orem identifies that available and known means of self-care are cultural. They are considered to vary within families, cultural groups and societies, hence the importance of studying the self-care activities of low-income women in midlife. Orem also presupposes that individuals' action repertoires and their preferences for taking action under certain conditions affect what persons do, and do not do, with respect to self-care within the context of stable or changing life situations. She also identifies experiences of persons in the provision of self-care enables them to accumulate and structure bodies of experiential knowledge about kinds of care, when care is needed and methods of providing care. These presuppositions provide the impetus to explore the sources of information, assistance, and support that low-income women use to cope with midlife transitions.

Two sets of propositions are presented by Orem (1995), set one includes the following: (a) materials provided through self-care are essential for life; (b) conditions that are provided or maintained through self-care are concerned with protection from environmental and self-imposed hazards, and what is needed for unhampered physical, cognitional, emotional, interpersonal, and social developments and functioning of individuals in their life situations; (c) the quality and quantity of materials and the conditions provided or sustained through self-care must be within a range that is known 
to be compatible with what is biologically required for human life, for integrity of human development, as well as integrity of human structure and functioning; (d) self-care performed by persons with the intention of doing good for self may fall short of the focal conditions and goals sought because of their lack of knowledge and skills or other action limitations.

The second set of propositions include the following: (a) engagement in self-care involves performance of operations to estimate or establish what can and should be done, to decide what will be done and the operations to produce care; (b) self-care is work or labor that requires time, expenditure of energy, financial resources, and continued willingness of persons to engage in the operations of self-care; (c) self-care performed over time can be understood (intellectualized) as an action system (self-care system) whenever there is valid and reliable information about care measures performed and the connecting links among them; and (d) care measures selected and performed are specified by the technologies or methods selected for use to meet known or estimated requirements for regulation of functioning or development.

These propositions relate to the deliberateness of self-care practices. In relation to this study, the researcher attempted to explore how low-income women in midlife came to decide which self-care practices should be utilized, and which ones they actually engaged in. It is this area of inquiry that demonstrated the limitations of Orem's Model of Self-Care with a low-income community sample of women in midlife.

Bronfenbrenner's Ecology of Human Development Framework emphasizes the connections between the processes of human development, the environment, and the interdependent links between the multiple environments within which development occurs (Glossop, 1988). The framework provided for observations of the interconnections 
with the larger contexts in which low-income women's lives are embedded. Transitions are viewed as occurring throughout the lifespan, Transitions are considered to be both a function of biological changes and altered environmental circumstances and therefore representing examples of the process of mutual accommodation between the individual and her environment. This view of transition provided for more of a holistic approach to understanding midlife that has been identified as lacking when this stage of life is only viewed from a single perspective such as the biomedical or the social perspectives.

\section{Ecology of human development framework.}

Bronfenbrenner's (1979) conception of the environment draws heavily on the work of Kurt Lewin, particularly his concept of interaction of forces in life space. The ecological environment is envisioned as "a set of nested structures, each inside the next, like a set of Russian dolls" (p.3).

The innermost structure, is the immediate setting containing the individual. Examples of immediate settings include the family, home, workplace, or classroom among others. Bronfenbrenner (1979) refers to interconnections within the immediate setting as the microsystem. The microsystem is defined as "a pattern of activities, roles, and interpersonal relations experienced by the developing person in a given setting with particular physical and material characteristics" (p. 22).

The next ecological environmental level involves looking beyond the single settings to the interconnections between them. Bronfenbrenner (1979) refers to interrelations among two or more settings in which the developing person actively participates (such as among family, work, and social life) as a mesosystem. He argues that the interconnections between the settings can be as decisive for development as events taking place within a given setting. 
In the third level, Bronfenbrenner (1979) asserts that the person's development is profoundly affected by settings in which the person is not even present. The interconnections that occur with settings in which the person never enters but in which events occur that affect the person's immediate environment are referred to as the exosystems.

Macrosystems, the fourth level, refers to the complex nested interconnected systems that are a "manifestation of overarching patterns of ideology and organization of the social institutions common to a particular culture or subculture" (Bronfenbrenner, 1979 , p. 8). Bronfenbrenner asserts that the environment as conceptualized in the ecological framework differs from previous conceptions in scope, content and structure. In terms of scope, what matters with regard to behaviour and development is the environment as it is perceived, rather than the "objective" reality. It is this principle that he states illustrates the weakness of the laboratory as a context in which to observe behaviour. Bronfenbrenner identifies that various settings have different types of meanings to participants in a study, partly as a function of their social and experiential background. It was this conceptualization of the environment that supported the need for a qualitative methodology, with interviews taking place in the participant's homes. The home was considered to be ideal as it is this setting that is most likely to reflect day-today living and be least affected what Hammersley and Atkinson, (1995) describe as social constructions. It is in the home that the participants were considered to feel most comfortable in discussing their self-care activities to maintain functioning and development associated with midlife.

Bronfenbrenner (1979) proposes that development never takes place in a vacuum, it is expressed through behaviour in an environmental context. Human development is 
defined as "the process through which the growing person acquires a more extended, differentiated, and valid conception of the ecological environment, and becomes motivated and able to engage in activities that reveal the properties of, sustain, or restructure that environment at levels of similar or greater complexity in form and content" (p. 27). There are three features of this definition that are relevant to this study. First, development involves a change in the characteristics of the person, and it implies a reorganization that has some continuity over time and space. Secondly, developmental changes take place in both perception and action. Thirdly, perception and action have a structure that is similar with that of the four levels of the ecological environment. Bronfenbrenner proposes that the properties of the individual and of the environment, the structure of the environmental settings and the processes taking place within them must be analyzed in terms of systems rather than distinguished by reference to linear variables.

Bronfenbrenner (1979) differentiates between molecular and molar activities. Molar activities are defined as "ongoing behaviour possessing a momentum of its own and perceived as having meaning or intent by the participants in the setting" (p. 45). Molecular activities are defined as those that lack meaning or intent to the individual and are short-lived. Examples of molecular activities are a smile, a knock on the door, a single question, examples of molar activities are reading a book, or carrying on a telephone conversation.

Molar activities are considered to constitute both the internal and external evidence of psychological development. The momentum that characterizes molar activities makes for persistence through time and resistance to interruption. Bronfenbrenner (1979) identifies that this momentum is maintained by the intent. The intent of activities vary in degree and complexity. This variation is reflected along two 
dimensions that are defined according to how they are perceived by the participant. The first is time perspective, determined by whether the activity is considered as occurring only in the immediate present or as part of a longer temporal trajectory, "transcending the bounds of ongoing action, reaching back into the past or forward into the future (Bronfenbrenner, p. 46). The second dimension is that of explicit goal structure, whether the road to the goal is considered as direct, involving one action, or whether it involves a series of planned steps. Bronfenbrenner identifies that the question of the substantive nature of molar activities is an empirical one and can only be answered after relevant data have been obtained. The intent of activities, the time and goal dimensions will be explored with participants by asking women to identify the conditions they seeking to create or maintain. The researcher was attentive to the process of mutual accommodation between the participant and her environment across the mico- meso-, exo- and macrosystems.

The capacity of a setting to support development is considered to depend on the type of social interconnections between settings including participation, communication, and the existence of information in each setting about the other. Questions related to facilitating and limiting factors regarding self-care were explored with the participants in an attempt to uncover the effect of others, and interconnections between settings.

Bronfenbrenner (1979) hypothesizes that the settings with the least potential for development are those in which the links are either nonsupportive or absent, in other words when the mesosystem is weakly linked. This hypothesis is also applicable at the exosystem level. Bronfenbrenner predicts a higher correlation between developmental outcomes for individuals and families with extensive social networks than for those with few links outside the home. The participants were asked what links to settings at the 
mesosystem level would support them through this developmental transition and what characteristics must those settings have in order to be most helpful. It is this area of inquiry that provided information on how links with mesosystem level settings, such as health care settings might be facilitated for low-income women.

Bronfenbrenner's framework facilitated the representation of the idea that that the self-care activities of low-income women at midlife were embedded in a complex system of social networks and of societal, cultural, and historical influences.

Summary

This chapter outlined the problem statement, the purpose and significance of the study. Orem's Model of Self-Care and Bronfenbrenner's ecological framework served to identify the following areas of inquiry in this study: the perceived self-care needs of lowincome women in midlife; identification of sources of information on midlife and selfcare activities; the identification of who they go to for assistance and support in coping with this transition; how women decide which self-care activities should be utilized and how they select which ones they will engage in; which factors affect the selection; what self-care activities are engaged in; and what are the facilitating and limiting factors or conditions regarding self-care; and suggestions low-income women in midlife have for health professionals regarding the facilitation of interconnections with settings including the health care system that are required for development during this time of life. These areas of inquiry guided the uncovering of self-care activities of low-income women within their particular environmental contexts. 


\section{Chapter 2}

\section{Literature Review}

A review of the literature from the early 1960 s to the present demonstrates that the experiences and self-care activities of women in midlife, and in particular low-income women has not been adequately been researched.

Researchers have used a wide variety of definitions for midlife in studies illustrating the inability of any one definition to capture the essence of midlife. Researchers have used age boundaries, reproductive capacity, and role patterns to define midlife (Woods \& Mitchell, 1997). There is little agreement on age boundaries. Jacobson (1995) defined midlife as beginning between the ages of 35 and 40 up to age 65 . Hartweg (1993) defined midlife as 40 to 59 years of age. Mitchell (1997) found that women enrolled in the Seattle Midlife Women's Health Study, most frequently defined midlife as an age range, such as 35 to 55 years, or 40 to 60 years. Common language for the discussion of menopause or reproductive capacity is also lacking. There is confusion in the literature in the use of terms such as premenopause, climacteric, perimenopause, and postmenopause (World Health Organization, 1981). Complicating the definition is that it is determined only in retrospect, one year without menstrual bleeding (Mansfield, Jogensen, \& Yu, 1989; Voda \& George, 1986). Neugarten (1968), using role patterns identified the following as midlife parameters: the launching of children; reaching a peak in one's occupation; menopause; grandparenthood; retirement; onset of chronic illness, and widowhood. In addition, most of the research regarding midlife women has been conducted in the context of menopause, consequently little is known about the meaning midlife holds for contemporary women and how they are experiencing it (Woods \& Mitchell, 1997). 
A literature review was conducted using the CD-ROM databases of MEDLINE, and CINAHL, as well as a manual literature search from key articles. The following review is organized and critically reviewed according to the following major categories: (1) midlife; (2) in search of a common understanding of menopause; (3) the multiple and conflicting perspectives of menopause; (4) the estrogen dilemma; (5) alternative approaches; (6) self-care; (7) self-care activities of women in midlife: a review of the research; (8) definitions of low-income; (9) poverty, a determinant of health; (10) women and poverty; and (11) socioeconomic status and menopause.

Midlife has largely been studied from the perspectives of the various disciplines that have conducted research resulting in fragmented knowledge. Few studies have looked at midlife from the whole of the experience of women. The first three sections: "midlife"; "in search of a common understanding of menopause" and "the multiple and conflicting perspectives of menopause" review the various conceptualizations of midlife and menopause as identified in the literature. The developmental theories that address midlife are discussed. The biomedical, sociocultural, ageist, sexist, and feminist perspectives of menopause are also reviewed.

The sections on estrogen and alternative approaches describe current therapies for the management of menopausal manifestations. The current debate on the effects of estrogen occurring in the scientific literature is presented. The section on self-care describes how individuals and families have always engaged in self-care and the impact of various historical developments on self-care. Self-care is also discussed from the various theoretical perspectives identified in the literature. The use of Orem's Model of Self-Care in nursing research is discussed and critiqued. Self-care activities that women carry out in midlife and menopause as identified in the empirical literature are presented. 
The final sections in the literature review explores the various definitions of lowincome and provides rationale for the definition of poverty used in this study. Poverty is discussed as a determinant of health. The over representation of women among Canada's poor is highlighted with discussion of factors that influence poverty among women. Finally the literature examining socioeconomic status and menopause is reviewed. Midlife

In this section, the differences between earlier and more recent cohorts of midlife women are highlighted, followed by descriptions of midlife as perceived by women themselves. Developmental theories that address midlife are also discussed.

Midlife is a relatively new phenomenon. During the early part of the twentieth century few women lived past 45 years of age, now Canadian women born today are expected to live an average of 81 years (Statistics Canada, 1995). This means that women can expect to live approximately 30 years postmenopause. These 30 years will make up a third of most women's lives. Jacobson (1995) identifies that the middle years may be classified differently, renamed and even lengthened in the future as the baby-boom generation ages. The baby-boom generation as defined in Canada, those born between 1947 and 1966 (Foot, 1996), has changed societal norms and is expected to experience increasing productive longevity.

As Jacobson (1995) states "much has been said, but little written" about midlife, as a result it is difficult to separate fact from myth. This is particularly true of the cohort of women born after World War $\Pi$, known as the baby boomers. Women from different cohorts, have lived in different worlds. The initial baby boomers are now entering their fifth decade. As Jacobson identifies, these women were raised differently from women now in later midlife. 
Most older midlife women, born during the 1920 s and 1930 s made the transition to midlife with ease, but for those who had difficulty dealing with the new roles once their families were grown, many experienced anxiety, stress, and depression (Jacobson, 1995). Others have been rendered incapable of supporting themselves financially, without major changes in lifestyle following increasingly common midlife divorce. There is little in the form of societal support for midlife women in light of no-fault divorce, inequitable marital property settlements, and decreasing alimony payments.

The baby boom women bom in 1947 have only recently entered midlife. Jacobson (1995) identifies that

"they have been portrayed as more liberal and less conforming than women born a generation earlier. Baby-boom women had more career and educational opportunities, later marriage, and more sexual freedom than those who preceded them. Some in the baby-boom cohort were among the first to experience the benefits of equal opportunity for women that came about as a result of the feminist and civil rights movements. For the most part, the baby boomers came of age during an era of affluence, television, sexual revolution, proliferation of illegal drug use, and Vietnam protests against government." (p. 4).

The oldest cohort of midlife baby boom women were the first generation to have access to the birth control pill (Jacobson, 1995; Jones, 1980). This cohort has experienced a doubling of the divorce rate by the 1970 s and by the 1980 s a tripling of the rate, but are remarrying and are involved in blended families. Many were somewhat active in nontraditional careers (Naisbitt, 1984). Household income is equal to that of their older counterparts, however largely because they live in two-income households (Jacobson). This cohort was also reared in front of the television set and with Dr. Spock's values in 
child-centered households. Children were at the centre of the world, their needs important and they could shape events to their liking. (Jones, 1980).

Woods and Mitchell (1997) conducted a telephone survey on a random sample of 131 women enrolled in the Seattle Midlife Women's Health Study, born between 1935 and 1955 with a median age of 41 . The purpose of their study was to determine how the women defined midlife, what midlife events were viewed as important, distressing, and satisfying. Eighty percent of their sample was of European American descent with eight percent African American, and eight percent Asian American. Data on income status were not reported, women had a median educational level of 15 years. Woods and Mitchell identified the following themes in women's descriptions of midlife: age; changes or transitions in many aspects of life; life half lived with half left to live; goal attainment and reappraisal; vulnerability; and mortality. Women most frequently defined midlife as an age range, such as 35 to 55 years or 40 to 60 years.

Woods and Mitchell (1997) identified important events of midlife as including personal goal attainment, work, family events, health-related events, and losses. Goals were often linked to both family and work roles. Family events included launching children, dealing with health problems of parents, celebrating the births of grandchildren, adapting to family relationship changes, changing family roles, and including a parent in the household. Health related events included experiences of health problems or good health for herself or others in her life. Many described the poor health of parents or death of a parent as stressful. The most frequently identified distressing events were health problems, work-related problems, frustrated goal attainment, relocation, and financial problems. The most satisfying events included goal attainment, household related, work related, family related and travel/leisure events. 
Woods and Mitchell (1997) note that the centrality of work and personal achievements in their lives is in contrast to data from older birth cohorts of midlife women. The baby boomers were not trying to figure out what to do with the rest of their lives, they were still juggling the multiple roles of integrating work and family. As can be deduced, menopause is not the primary issue for every woman in midlife. It is the juggling of multiple roles that is the challenge facing women in midlife. It is not known whether the themes identified by Woods and Mitchell (1997) apply to low-income women.

Most of the research related to midlife and menopause has been conducted on nonrepresentative samples of white, educated, middle to upper income women, limiting the generalizability of findings to those populations. A few studies have been conducted on women of various cultural and racial backgrounds (Buck \& Gottlieb, 1991; Hautman, 1996; Jackson, Taylor, \& Pyngolil, 1991; Lee, 1997; Padonu et al., 1996), but even fewer have been conducted on low-income women (Standing \& Glazer 1992).

Faludi (1991) states that despite the gains women have made, equality for women is still elusive. Women represent the majority of adults living in poverty. Women continue to be underrepresented in the nontraditional professions. Most women work in traditional service jobs as clerks and sales personnel. Divorce has also contributed to the feminization of poverty, with increasing numbers of women and children living at or below the poverty line following divorce. Teen pregnancy and subsequent single parenting also contribute to the feminization of poverty. Caregiving also contributes to poverty for women. As Oakley (1989) identifies caregiving has implications for women's mental, emotional and physical health The costs involved to women caregivers include direct financial ones as when caregiving necessitates withdrawal from paid employment. 
Caring work promotes health for others by can be health denying for the carers. In addition very little has changed in how midlife women are perceived, despite the fact that there is a dramatic explosion in the numbers of women between the ages of 35 and 65 . In Canada women born during the baby boom years from the late 1940 s to the mid 1960 s make up the largest group of women (Statistics Canada, 1995). In 1991, 19\% of the women were aged $45-64$ and $34 \%$ were aged $25-44$. It is this latter group that will be now entering midlife.

The literature indicates that the baby boomer women are different than older birth cohorts of midlife women. However as Faludi (1991) and Oakley (1989) indicate, many live in poverty and remain in traditional service jobs. Divorce, teen pregnancy and caregiving were identified as factors contributing to the poverty of women. The researcher selected a cohort of women born between 1947 and 1958 for this study, as this is a large cohort of women just entering midlife and little is known about this cohort of low-income women.

\section{Developmental theories.}

In this section the developmental theories that address midlife are reviewed. There are few developmental theories that address midlife. Most of the early studies on midlife reflected the work of Freud, who studied emotionally disturbed women and attributed their characteristics to all women (Jacobson, 1995). Another major criticism of the empirical studies upon which much of the theory of midlife is based is that most of the subjects were male and most of the research conducted by males (Gilligan, 1982).

Erikson is one of the few theorists who extended developmental stage beyond childhood into adulthood. According to Erikson (1963), midlife is characterized in terms 
of the struggle between generativity versus self-absorption or ego stagnation. He defines generativity as expansion of ego interests and a sense of having contributed to the future (establishing and guiding the next generation) (Neugarten, 1968). The concept of generativity is also meant, according to Erikson, to include synonyms as productivity and creativity. If these tasks are not achieved, he believes that the individual will become selfabsorbed and stagnant. Jacobson (1995) questions whether Erikson's developmental tasks are relevant to the baby boomer generation as many are having their children at age 40 .

As has been noted above choice has been a persistent theme in the lives of baby boom women. They have had more choices in terms of career, motherhood and in selecting the types of relationships they engage in. Gerber, Wolff, Klores, and Brown (1989) propose that as the baby boomer women reach middle age they are likely to have more leeway in defining the "self" rather than having the defining done for them by the precepts of outdated psychology. They suggest that there is a strong possibility that adult developmental theories will undergo major change over the next few decades as the baby-boomer generation of women move through midlife. Many of the age-defined stages have already been found to be inappropriate when applied to the development of women.

Gerber et al. (1989) suggest that the encounter with generativity could come early or later, even in their sixties for baby boom women. Their mothers were raised as nurturers and identified with the need to meet the needs of others. Baby boom women are pressured by the forces of tradition to feel guilty if they give too little time to their children or have no children at all. These women are also expected to achieve in the world of outside work. The line between themselves and others close to them was supposed to be thin, women however have matured into a world of autonomy and 
independence. Gerber et al. suggest that generativity could pose more of a challenge for these women since the poles of "self" and "other" may seem farther apart than those confronted by their mothers. Few scholarly works have been written by gerontologists that covered midlife to old age until the early 1980 s. As a result there is no proven body of knowledge to explain how individuals make the transition through midlife (Gerber et al.).

The large cohort of aging baby-boom women are likely to greatly influence this stage in the life-cycle as they themselves continue to seek answers about their own place within it. Often the belief is that menopause is the major cause of physiological and psychological distress for midlife women (Jacobson, 1995). A panacea of medical treatments are often considered to be the remedy of choice. It is important to recognize that menopause is not the primary issue for every woman in midlife. Nevertheless menopause is an important issue for many women that must be discussed.

\section{In Search of a Common Understanding of Menopause}

Prior to proceeding into the examination of the literature on self-care activities in midlife, it is important to discuss the definition of menopause and the various perspectives from which menopause is conceptualized as women tend to associate midlife issues and aging with their experience of menopause (Dickson, 1994). The natural menopause is a developmental marker and a universal event for all women. A common language for the discussion of menopause, however is lacking. There is confusion in the scientific literature regarding the use of terms such as premenopause, climacteric, perimenopause, menopause, and post menopause (World Health Organization, 1981). 
The natural menopause is difficult to define because it involves two physiological events, namely the cessation of ovulation and the cessation of menstruation (Treloar, 1982). Technically menopause has been defined as that point when a woman has experienced her last menstrual period. Complicating the definition is that, it is determined only in retrospect, one year without menstrual bleeding (Mansfield et al, 1989; Voda \& George, 1986). Unlike menarche, there is no clear marker. The definition ignores the transition period during which most women notice gradual changes in physical, emotional, sexual, and menstrual characteristics that occur before menstruation eventually ceases (Mansfield \& Voda, 1997). Anecdotal and research evidence suggests that menstrual cycle changes occur up to a decade before menstruation ends (Chiazze, Brayer, Macisco, Parker, \& Duffy, 1968; Cutler \& Garcia, 1992; Meldrum, 1983). Fertility also ends, but also not suddenly, it declines gradually as the frequency of anovulatory cycles increase, therefore, a woman may become pregnant during the months after her final menstrual period (Kaufert, 1985). The precise number of years women spend in this transition period is unknown (Voda \& George). It has been suggested that the term perimenopause may more accurately reflect this period of transition (Mansfield \& Voda).

According to definition, women with ovaries are classified as naturally menopausal if they have not had a period for one year. The term menopause is also used to describe women who have undergone a hysterectomy. Menopause in the latter situation is described as an induced, or as a surgical menopause (Voda \& George, 1986). The transition, marked by the end of menstrual bleeding in natural menopause, occurs gradually. Whereas, the end of menstrual bleeding occurs precipitously when menopause 
is induced either surgically or medically. Women who have had a simple hysterectomy (removal of the uterus while retaining the ovaries) also experience the end of menstrual bleeding. By definition these women are menopausal, yet their ovaries continue to synthesize ovarian estradiol for variable periods after surgery. How these women differ from women with natural or induced menopause as they enter the perimenopause is not known.

Many other terms are frequently used to refer to menopause such as "climacteric" and "change of life". These terms are equally ambiguous. None of the terms define or identify specific biological or endocrine indicators that may be used to characterize entry into or passage through perimenopause.

In 1981, a scientific group of the World Health Organization, conducting menopause research recommended the following definitions: (a) menopause, the permanent cessation of menses resulting from loss of ovarian, follicular activity; (b) perimenopause or climacteric, includes the period immediately prior to the menopause when the endocrinological, biological, and clinical features of approaching menopause commence, continuing for at least the first year after the menopause; and (c) postmenopause, a period dating from the menopause, although it cannot be determined until after 12 months of spontaneous ammenorrhea has been observed.

Many changes have been associated with menopause, there is however, little scientific evidence to support the multiple manifestations that women experience as they progress through this developmental phase of their lives. The majority of changes are subjective and complicated by the fact that their incidence, character, and severity vary both among women in the same society, and between women in different societies (Kaufert \& Syrotuik, 1981). 
There appears to be some agreement about the average age at which menopause (cessation of menstrual periods for one year) occurs. McKinlay, Bifano, \& McKinlay (1985) reported a median age of 51.4 (plus or minus 0.19 ) years from a cross sectional survey of randomly sampled 7,828 women aged 45-55 years. McKinlay et al. included women from towns with per capita incomes below the state median. Treloar (1982) in his longitudinal study of 393 menopausal women between the ages of 41 and 59 years, reported the most commonly occurring age (mode) of menopause to be at 51 years. Frommer (1964) in examining 443 hospital records of women between the years of 1951 and 1961 , reported a modal age of 50.1 years. Women with carcinoma of the breast, treated with hormones or irradiation, and those with systemic, endocrine, and those with conditions thought to be influenced by menstrual bleeding or menopause and vice versa were excluded. Other than marital status and number of children, no other demographic data were reported. Investigations into the age of menopause have been known to be affected by recall problems. Frommer noted that women appear to round off their age of menopause to the nearest multiple of five.

Estrogen use and smoking have been found to influence the age of menopause (Emster \& Petrakis, 1981; Flint, 1976; Goodman, Grove, \& Gilbert, 1978; Treloar, 1982). Treloar noted that women who had used estrogen in the preceding five years, tended to experience menopause at one or two years later than women who had not used estrogen. Smoking on the other hand, has been associated with an early menopause (Hill, 1982; Jick, Porter, \& Morrison, 1977; McKinlay, Bifano, \& McKinlay, 1985).

Most of the research conducted to describe the developmental changes associated with menopause have employed cross-sectional designs, leading to the inference of menopausal changes from differences in menstrual patterns at different ages. The 
problem with such an approach is that averages may in fact, obscure findings about variability in patterns, resulting in potential erroneous conclusions that pathologize patterns that differ from the average (Mansfield et al., 1989). One exception is Treloar's (1982) longitudinal study of the menstrual patterns of University of Minnesota graduates and the Midlife Women's Health Survey, a longitudinal study of menopause involving several hundred normal midlife women across the United States. Despite the methodological limitations, there appears to be general consensus on a number of menstrual changes that are considered to occur during the transition to menopause. Cycles become farther apart and more variable in length from month to month (Presser, 1974) cycles become increasingly irregular over a span of seven years (Cutler et al. 1983). Two other manifestations, hot flashes and vaginal dryness also appear to be associated with the change in estrogen levels during the menopausal transition (Chang, Plouffe, \& Schaffer, 1994; Gath, Osborn, Bungay, Iles, , Day, Bond and Passingham, 1987; McElmurray \& Huddleston, 1991; Voda \& George, 1986). Hot flashes often begin while women are still menstruating and gradually subside postmenopausally as the body adapts to lower estrogen levels (Severne, 1982). The falling estrogen levels also cause the vaginal walls to become thinner and drier (Mansfield \& Voda, 1997).

The association of psychological symptoms such as depression and anxiety, with changes in estrogen levels has been the subject of considerable debate (Schmidt \& Rubinow, 1991). Many of the early studies suffer from sample bias (McKinlay, McKinlay \& Brambilla, 1987) as they tended to be conducted on clinical populations (midlife women presenting with complaints). These studies typically asked women to describe themselves according to a checklist of negative symptoms, further creating potentially biased responses (Kaufert \& Syrotuik, 1981; Mansfield et al., 1989). These 
biases according to Mansfield et al. resulted in the characterization of the menopausal transition as negative events caused by hormonal changes. Abplanalp, Rose, Donnelly, and Livingston-Vaughan (1979) demonstrated no relationship between mood states or enjoyment of activities, and phase of menstrual cycle, psychological states, and absolute levels of estradiol and progesterone in a sample of 14 well women between the ages of 23 and 39. The women in this study were not on oral contraceptive medication, were screened as psychologically healthy, and did not report strained spousal or partner relationships. No other demographic data were reported. Estrogen therapy has been found to not relieve psychological symptoms, further supporting the assertion that these symptoms may not be related to declining hormone levels at menopause (Golub, 1992). Gath et al. (1987) found in a survey of 521 randomized women aged 35-59 recruited from two medical group practices with computerized age and sex registers, an association of psychiatric morbidity and neuroticism with gynecological symptoms, but not with menopause. Among menstrual symptoms, dysmenorrhea and menstrual tension were found to be strongly related to psychiatric status. Mental state, however was found to be related to vasomotor symptoms in women aged $45-49$ years. It has been hypothesize that the vasomotor symptoms may be distressing enough to induce emotional symptoms (Gath et al., 1987). The current psychiatric state was also found to be significantly associated with recent adverse life events and with indices of psychiatric vulnerability (neuroticism and previous psychiatric history). No other demographic data were reported on the sample.

Popay, Bartley and Owen (1993) explored three prominent explanations for female excess of minor physical morbidity and affective disorders as compared to men using data from a national cross sectional survey of 6,232 British women and men aged 
18-59 carried out between 1984 and 1985. No other demographic information was reported. Among those explanations is that the female excess is due to problems associated with menstruation and menopause, or that it is caused by the social positions which women occupy in contemporary western societies. Their analysis suggested that problems associated with menstruation and the menopause cannot explain gender inequalities in minor illness. Generally the relationship between minor illness and four dimensions of social position, marital status, employment status, social class and income, were broadly the same for women and men, but that in each of these categories, women reported higher rates of both types of ill health than men. Popay et al argue that the current measures do not capture the differing experiences of women and men in particular social positions. They indicate that even when the relationship between social position and ill health is the same for women and men, their different distributions within the categories can be expected to account for women's higher rates of both minor illness and affective disorders. Both low-income men and women were found to have higher than expected rates of both types of ill health, however a greater proportion of women, particularly women between the ages of 40 and $59(24 \%)$ are exposed to low-income as a risk compared to men. Severne (1982) found that both employment and socioeconomic status affected menopausal symptoms. She identified in a representative sample of 922 married Belgian women 46 to 55 years of age, that the more privileged women, with greater material and educational resources, and more life choices were less prone to symptoms. The effect of working outside the home was favorable for the privileged, however, this was not the case for women of lower socioeconomic status. A job for the less privileged was hypothesized by Severne as creating additional stress and tension during the perimenopause in particular. In the post menopause, however a job was found 
to have a stabilizing effect for both groups. Below all the other groups stood the housewives of the less privileged socioeconomic group, among whom a definite lower level of "subjective" adjustment was noted.

Ballinger (1975) in a survey of 539 women between the ages of 40 and 55, recruited from the lists of general practitioners general population found that ailing or demanding parents seemed to be a source of anxiety and that changing patterns in relationships with children was associated with psychiatric morbidity. No other demographic data on the sample were reported. Two thirds $(n=346)$ of the women in the Seattle Midlife Women's Health Survey, a longitudinal study of overwhelmingly white, highly educated, married and economically secure women between the ages of 45 and 49 (at the start of the study in 1990), reported irritability or anger (Mansfield \& Voda, 1997). Of the women who reported depression or sadness (41\%), $54 \%$ indicated that these symptoms fluctuated with their menstrual cycles. Mansfield and Voda conclude that their findings suggest that hormones likely play a role in midlife women's emotional status and that they are perhaps related to the same mechanisms responsible for changes experienced premenstrually. They hypothesize that perimenopausal women may actually be experiencing an "extended, perhaps worsened midlife version of premenstrual symptomology" (p. 60). Information on income for the participants was not reported.

Despite the fact that only three major menopausal manifestations are recognized (menstrual irregularities, hot flashes and vaginal dryness), half of the women in the Midlife Women's Health Survey reported the following four conditions most frequently: weight gain (58\%), fatigue (56\%), joint pain (52\%), and food cravings (51\%). At least one third of the respondents reported feeling calm (45\%), feeling unattractive (41\%), 
memory loss (38\%), anxiety (35\%), and insomnia (34\%) (Mansfield \& Voda, 1997). Mansfield and Voda suggest that the conditions may have existed prior to menopause or may be more related to aging than to menopause.

It is also important to recognize that not all women suffer during the menopausal transition. Many of the women in the Midlife Women's Health Survey reported feeling calm and focused (45\%) and having high energy (29\%). In fact, overall mean ratings on a five-point Likert scale (very poor to excellent) were 4.3 for physical health and 4.2 for emotional health (Mansfield \& Voda, 1997).

The lack of documentation of the normal menstrual pattern changes that women experience in the menopausal transition tend to create unnecessary fear in women, and the use of unnecessary interventions by physicians (Mansfield \& Voda, 1997). Women who are unaware of the norms regarding menopause have been shown to likely misinterpret normal, healthy, changes as signs of disease, and to expend considerable energy wondering whether their changing patterns are signs of menopause. It is not surprising then, to find that the lack of understanding about perimenopausal changes has been reported as the worst aspect of many women's menopausal transition (Mansfield \& Jorgensen, 1992; Perlmutter \& Bart, 1982).

There is also thought that women have been subjected to inappropriate diagnoses as a result of the lack of normative data on menopause. Meldrum (1983) identifies that variable bleeding patterns in perimenopausal women have been viewed as a disturbance and treated by some clinicians (Meldrum, 1983).

The lack of a consistent and objective definition of menopause along with the ambiguity of words used to describe menopause have led to methodological problems, 
affected subject selection and data analysis in the research. These limitations have affected the generalizability and comparability of findings on menopause (Voda \& George, 1986). The lack of documentation regarding the normalcy of menopause have prevented women and health professionals from understanding this complex phenomenon. This lack of understanding affects women's ability to cope successfully with a wide variety of experiences and has potentially led to unnecessary medical interventions.

This study will focus on midlife, including the perimenopause, the period according to the literature, during which women experience many of the changes related to the transition to menopause. Understanding women's self-care activities during midlife is important, particularly considering the fact that many of the changes are not clearly understood by either the scientific community or the women themselves. By understanding the self-care activities that women engage in during this transition, nurses and other health professionals may assist women through this developmental stage in meaningful and relevant ways. The age range of 40 to 51 years will be used as inclusion criteria, as perimenopausal changes have been identified as occurring up to a decade before menopause.

The Multiple and Conflicting Perspectives

Menopause is a complex biosocial and biopsychological phenomenon. Most of the research to date has focused on selected aspects of menopause fragmenting the experience of menopause. Few studies have examined menopause as a whole (Voda \& George, 1986). Furthermore, much of the research has been conducted using models that have tended to bias the perspective. The use of biomedical models, sociocultural models, 
ageist and sexist perspectives have served to limit the view of women's whole experience of menopause (McKinlay \& McKinlay 1973). These various perspectives will be explored including the feminist perspective to develop a fuller understanding of how these multiple and conflicting views have influenced and continue to influence our understanding of this complex phenomenon.

Within the biomedical model, menopause is viewed as a deficiency disease with particular symptoms. Physiological manifestations are correlated with decreasing estrogen levels (Dickson, 1990) and psychological manifestations experienced at menopause, such as depression are related indirectly to an estrogen deficit (Gath et al., 1987). This view of menopause supports the belief that menopause is unhealthy and that women require medical treatment for it (Bernhard \& Sheppard, 1993). The definition of menopause as a disease is associated with the current research linking menopause and hormone therapy with two high-profile areas of research, cancer, and heart disease (Kaufert, 1985).

The biomedical model is in fact a biological reductionistic model which views menopause as a medical syndrome. Over the years this model has come to be questioned. The model tends to ignore the environmental events and social aspects that may affect the relationship between hormonal levels and menopausal changes (Voda \& George, 1986). This reductionist approach is congruent, however, with the objective/positivist ontological position, that complex entities should be reduced to smaller and measurable, and quantifiable parts (Struebert \& Carpenter, 1995).

In addition to the limitations of the reductionist and disease orientation of the biomedical model, biomedical research, has been largely been done using clinical 
populations to study the normal, natural biological phenomenon of menopause (Koeske, 1982; McKinlay, \& McKinlay, 1973). The conclusions and inferences related to menopause are therefore drawn from a minority of ill women who have sought medical and psychiatric help rather than from healthy women (Wilbur, Miller, \& Montgomery, 1995). Using populations of women seeking medical help prevents the development of knowledge regarding the normalcy of menopause (Voda \& George, 1986).

The social or behavioural science model, considered to have been spearheaded by the Freudians, particularly Deutsch (1945), tends to reduce women to a set of roles and functions. Deutsch derives the interpretation of the significance of menopause from a theory that the meaning of a woman's life is based on her ability to bear children. The behavioural model discounts women's experiences of menopause, such as hot flashes and interprets menopausal changes as either social events or as cultural-symbolic events.

Koeske (1982) identifies that this model also points to the woman's personality and previous adjustment as characteristics which determine whether a woman will be symptomatic or not at menopause. Others point to the many stresses or adjustments that women encounter around the time of menopause as predisposing to psychological difficulties (Koeske).

The cultural relativists, according to Koeske (1982) examine the cross-cultural, societal or historical features. Kaufert (1985) identifies that the anthropological literature challenges the assumption that menopause coincides with the loss of the mother role as it does not fit with situations of Bengali women. In this culture the mother at mid-life presides over a household that is expanding with the addition of daughters-in-law and grandchildren. Likewise Flint (1975) argued that the reason Indian women did not 
present any menopausal manifestations was due to the heightened social prestige accorded to menopausal women in the Rajput society. She points out that in our culture there is no reward for attaining menopause and no elevation in status. McCrae (1983) states that the aging woman has a particularly vulnerable status in our society. She is "no longer the object of adoration and romanticism that youthful women frequently are" (p. 119).

The view of menopause as simply a sociocultural construction has been identified as problematic for women. Some women claim to experience no manifestations, but for others who have serious manifestations that affect various aspects of their lives, their experience is discounted and disbelieved (Bernhard \& Sheppard, 1993).

Kaufert (1985) found in a cross-sectional mail survey of 2294 mid-life Manitoba women that the majority of women had their last child by age 35 . In general women did not want another child, nor did they regret this decision. Kaufert recognized the limitation with the methodology used in accessing data on the implications of menopause as the symbolic closure of a woman's life. The empty nest, however was not found to be a universal characteristic of women in her study. Just over half $(52 \%)$ of the households included children below the age of 18 . It was not until women were five to ten years beyond their final menstrual period that women were found to live in childless households, and even then no more than half were doing so. Kaufert concludes that there is no strict coincidence between menopause and loss of the mother role, neither is it evident that any such synchronization of events would necessarily result in depression. No demographic data on the income levels of the participants were reported, however $40 \%$ of the sample had less than a secondary level of education. The sample was simply 
stratified on the basis of urban and non-urban place of residence. Likewise, Datan, Antonovsky, and $\mathrm{Maoz}$ (1985) concluded that midlife women of five Israeli cultures (N= 1148) unanimously welcomed the cessation of fertility despite the large variation in conception control and fertility history of the sample. Psychological symptomatology was found to be more frequent among Europeans. Somatic symptoms were found among all other groups supporting their conclusion that, in general the response to mid-life and menopause is shaped by ethnic origin. Clinical depression was found to be rare, but occurred in equal rates across cultures. Social characteristics of the sample were reported such as literacy, number of children, religion and employment status. No other demographic data were presented.

Matthews, Wing, Kuller, Meilahn, and Kelsey (1990) followed 541 healthy women aged 42 to 50 , from premenopausal to postmenopausal stages for five years. No demographic data on income were reported, the sample was educated, $73.7 \%$ of the women had education levels beyond secondary school. Comparison with 101 agedmatched premenopausal control women indicated that natural menopause led to few changes in psychological characteristics with only a decline in introspectiveness and an increase in reports of hot flashes. Matthews et al. concluded that menopause was a benign event for most women. They hypothesize that it is perhaps the exclusion of women with hypertension, diabetes, and women on a variety of medications including psychotropics, that have led to the null effects on the diverse indices of psychological functioning. Likewise, Severne (1982) found, also that effects of menopause were felt by most women, but that menopause as a physical event, was considered of little importance by approximately two-thirds of the women. Women considered menopause not so much as a 
phase to be feared, but a period of "frequent, bothersome but passing troubles which were not expected to affect their health fundamentally: more or less a hazard like a toothache." (p. 242).

The separation of menopausal changes into biologically and hormonally caused events - versus socioculturally and environmentally caused ones, confounds the understanding of the total experience of menopausal women. The sole recognition of sociocultural determinants of menopausal changes is as reductionist and deficient as the biological model (Kaufert, 1985; Voda \& George, 1986). Kaufert asserts that anthropological accounts, of midlife tend to ignore the experiences of childless, divorced or widowed women, just as the biomedical model tends to ignore the experiences of active, independent, socially, politically, or economically productive women through the use of clinical populations. Biological reductionism, therefore, is not the only criticism in menopausal research. Almost all research in menopause has been conducted from the discipline's perspective perpetuating reductionist philosophical thinking (Dickson, 1990; Koeske 1982).

Ageism further confounds the understanding of the total experience of menopausal women. Koch and Webb (1996) identify that the biomedical construction of aging is also reductionist in nature. Similar to the biomedical view of menopause, it is a mechanistic view of the person, where the body is composed of parts that can be inspected individually to determine the nature of its function. This view, as mentioned above, fits conceptually with the scientific method and in particular biomedical science. The biomedical construction of aging has implications for not only the way health professionals view aging women but for the way aging is viewed by the larger society 
(Koch \& Webb). Central to this view is the idea that the human machine comes to a halt when parts wear out and there is an increasing need for maintenance. This view has been significant in determining ageist attitudes and attitudes toward menopause. Evidence of the impact of this view on menopausal women is seen with the current powerful and pervasive emphasis on the need for estrogen replacement therapy in the maintenance of body function postmenopausally.

The biomedical model is concerned with degenerative effects rather than adaptive and developmental progress (Koch \& Webb). As Benner \& Wrubel (1989) state, this model also tends to create paternalistic relationships between health care providers and those they help. Koch and Webb conducted a phenomenological study on the experiences of 14 elderly patients on a geriatric ward. Their findings suggested that the biomedical perspective reinforces the low self-esteem in which older people are held and that it discourages understanding of older patients as human beings who want to be in control of their own lives. Koch and Webb identify the need for research focusing on the way aging people can exert more control over the quality of their lives. A major limitation to this study was the limited generalizability of findings to independent aging persons living in the community.

Within a sexist perspective, it is the male experience that is viewed as the norm contributing to the stereotype of menopausal women experiencing a catastrophic crises that renders women incapable of rational functioning. This view persists despite the lack of empirical support for it (Voda \& George, 1986). Bleier (1984) and McCrae (1983) argue that cultural prejudices founded in the belief that women are handicapped by the menstrual cycle and therefore inferior to men, have often been disguised as scientific 
facts. McCrae states the health care system legitimates sexism, by depicting women's capacities as dependent on their reproductive functions. The feminist perspective, conceptualizes menopause, as a tabooed subject in which women are suppressed in the name of biology (Dickson, 1990). Feminists have advocated that menopause is a natural developmental process of aging and that most women experience minimal difficulty (MacPherson, 1981; McCrea, 1983). Menopause is not viewed as a process that includes both positive and negative biologic, sociopsychologic, as well as spiritual, cultural, and cognitive aspects (Bernhard \& Sheppard, 1993; Guttman, 1985;). The disease label according to $\mathrm{McCrea}$, decreases the status and the autonomy of the woman, while increasing the status of the physician. Feminists reject the disease model as another example of menstrual and menopausal myths that have been used to control and exploit women (Estok \& O'Toole, 1991; MacPherson, 1981; McCrea, 1983). MacPherson asserts that the idea of menopause as a disease, perpetuates the political, economic and sexual control of menopausal women. Ideologically feminists have opposed the routine use of estrogen. Health related associations and consumer groups have taken a similar stance with respect to estrogen replacement therapy.

There are few feminist studies of menopause, most of the work has been conducted with the study of the menstrual cycle (Dickson, 1990). Most recently, however, a revitalization of the women's health movement is being witnessed, largely due to the increasing recognition that women's health issues generally have not been part of the public policy agenda, and the observance of the success of the recent aggressive activist stance of the AIDS movement (Jones, 1994; Sheehy, 1993). Women's health activists are becoming increasingly more vocal in demanding that more attention and particularly more money be directed to both research and social programs that address 
women's health needs. Jones identifies that it is the predominantly grassroots and consumer driven political activism that is beginning to raise public consciousness of the health needs of women. Table 2.1 summarizes the various perspectives discussed.

Table 2.1 The Multiple and Conflicting Perspectives of Menopause

\begin{tabular}{ll}
\hline Perspective & Description \\
\hline Biomedical model & $\begin{array}{l}\text { Menopause is viewed as a deficiency disease with particular } \\
\text { symptoms. Physiologic and psychologic manifestations are } \\
\text { correlated with decreasing estrogen levels. }\end{array}$
\end{tabular}

Social or behavioural The meaning of a woman's life is based on her ability to bear science models children. This model discounts women's experiences of menopause, such as hot flashes and interprets menopausal changes as social events. Women's personalities, previous adjustment, and stress are considered to determine whether a woman will be symptomatic at menopause or not.

Cultural relativist perspective

This perspective challenges the assumption that menopause coincides with the loss of the mother role as it does not fit with the situations of women in other cultures. The experience of Midlife and menopause is considered to be shaped by ethnic origin and culture.

Ageist perspective Central to this perspective is the idea that the human machine comes to a halt when parts wear out and there is an increasing need for maintenance.

Sexist perspective The male perspective is viewed as the norm contributing to the stereotype of menopausal women experiencing a catastrophic crises that renders women incapable of rational functioning.

Feminist perspective Menopause is viewed as a natural developmental process of aging and that most women experience minimal difficulty. The disease model is rejected as another example of menstrual and menopausal myths that have been used to control and exploit women. Ideologically feminists have opposed the routine use of estrogen.

It is evident from the literature on menopause that there is a great deal of disagreement among the disciplines regarding this significant life transition. The disagreement has permitted stereotypes about menopause to persist (Mansfield et al. 
1989). An interdisciplinary approach to menopause research is beginning to emerge, moving away from the biomedical versus social analyses, toward more of an interactional approach that recognizes the mutual influences of biology, culture, and symptomatology on well-being.

It was hoped that by conducting this study using a qualitative ethnographic design, that the mutual influences of biology, symptomatology, culture, and environment on the self-care activities that low-income women use would emerge.

\section{The Estrogen Dilemma}

A literature review that does not address estrogen replacement therapy would be seriously flawed in terms of understanding women's self-care activities. Despite the various perspectives discussed above, the biomedical perspective continues to dominate the view of menopause. Menopause continues to be viewed as an estrogen deficient medical condition that requires treatment in both the medical and popular literature. More recently pharmaceutical companies have been active in promoting estrogen replacement therapy by producing and sponsoring educational pamphlets, videos and public forums.

Estrogen replacement therapy was popularized during the 1960 s. However, during the 1970 s concerns regarding the association between estrogen replacement therapy and endometrial cancer began to surface (Smith, Prentice, Thompson, \& Herrmann, 1975; Ziel \& Finkle, 1975) This was followed by a dramatic decrease in the use of estrogen replacement therapy (Kennedy, Baum \& Forbes, 1985). In the 1980s medical attention shifted to the long term effects of decreased estrogen on the cardiovascular system and the skeletal system, as the body of evidence indicating that the short term effects of decreased estrogen symptoms were not troublesome for the majority of women (Wilbur et al., 1995). 
The Framingham study demonstrated in a cohort of 2873 women between the ages of 29 and 62 years who were followed for 24 years, that menopause more than doubled the risk of coronary heart disease (Gordon, Kannel, Hjortland, \& McNamara, 1978), the leading cause of mortality and morbidity in postmenopausal women (Grady et al., 1992). The Post Menopausal Estrogen/Progestin Interventions (PEPI) Trial (1995) demonstrated that estrogen reduced coronary heart disease by $50 \%$ among postmenopausal women. Acceleration of the rate of bone loss beginning around the time of menopause has also been associated with a decrease in serum estrogen (Nilas, 1987; Nordin, Need, Chatterton, Horowitz, \& Morris 1990). Estrogen has been found to decrease the risk of hip fracture due to osteoporosis by $25 \%$ (Grady et al., 1992). There is, however, strong evidence that long term estrogen therapy increases endometrial cancer risk, and weak evidence that long term estrogen therapy is associated with a small increase in breast cancer risk (Grady et al.). The addition of progestin to estrogen has been shown to prevent the endometrial cancer risk associated with estrogen therapy (Grady et al.). The risk-benefit equation, however remains incomplete. Most of the studies, have been observational studies and therefore subject to bias. Data from long term randomized trials, are required to definitively establish the risks and benefits of hormone replacement therapy (Butler, 1995).

The emphasis in medical practice is on a return to estrogen replacement therapy or hormone (estrogen and progestin) replacement therapy for use by most menopausal women to prevent osteoporosis and cardiovascular disease. Both the American College of Physicians (1992) and the Society of Obstetricians and Gynecologists of Canada, have recommended that every postmenopausal women consider hormone replacement therapy, 
with knowledge of the associated benefits and risks (Canadian Menopause Consensus Conference 1994).

Women, however, as Grady and Rubin (1993) illustrate, are often reluctant to comply with estrogen replacement therapy on a long term basis. They identify that the median duration of estrogen replacement therapy is about 2 years on average. Ryan, Harrison, Blake and Fogelman (1992) conducted a study to assess compliance with recommendations for hormone replacement therapy in 400 postmenopausal women aged 40-69 years. The mean age of the women was 52 years, no other demographic data were reported. Their results indicated that $74 \%$ of respondents followed advice, Those who rejected advice did so on the basis of concem regarding side effects or the efficacy, or safety of treatment. Of the women who started hormone replacement therapy, $28 \%$ discontinued its use principally on the bases of withdrawal bleeding and weight gain. By eight months after advice, $39 \%$ of the women recommended to take hormone replacement therapy, were not taking treatment either because they ignored advice (22\%) or because of side effects (17\%). Women also decline estrogen replacement therapy because of the need to take daily medication; the need for regular medical follow-up, the complexity of the regimen, and the fear of cancer, in addition to not wanting to experience the many side effects of estrogen and progestin. For many women the risks and disadvantages may outweigh the perceived benefits (Canadian Menopause Consensus Conference, 1994; Grady et al., 1992). Stampfer et al. (1985) in a survey of 121,964 married nurses between the ages of 30 and 55 years found that non-use was associated with misinformation regarding the long term benefits.

Several factors have been correlated with Hormone Replacement therapy use. A woman on hormone replacement therapy is more likely to be younger, thinner, to be 
educated, to have had a hysterectomy, to drink alcohol, to be a nonsmoker, and to be more physically active (Cauley, Cummings, Black, Mascioli, \& Seeley, 1990; Derby et al., 1993; Egeland, Mathews, Kuller, \& Kelsey, 1988; Harris, Laws, Reddy, King, \& Haskell, 1990; Hemminki, Malin, \& Topo, 1993; Standeven, Criqui, Klauber, Gabriel, \& Barrett-Connor, 1986). Ferguson, Hoegh, and Johnson (1989) examined 274 women's attitudes toward estrogen replacement therapy using a questionnaire. The women ranged in age from 19 to 90 years with an average age of 60 years. Seventy three percent of the women had an educational background beyond high school and over half were married. Findings indicated that women taking estrogen replacement therapy were more likely to know that decreased estrogen levels lead to osteoporosis, to perceive that menopause is a medical condition, to believe that natural approaches are less favorable, to be receiving care from a gynecologist, and to believe that women should take estrogen replacement therapy for hot flashes. The diagnosis of osteoporosis was found to be a major determinant of continued estrogen replacement therapy. Researchers are concluding, on the basis of the determinants for use of postmenopausal estrogen, that women who are selected for or self-select hormone therapy have healthier profiles than nonusers (Derby et al.; Hemminki et al.)

The estrogen dilemma illustrates the limitations of the biomedical model. Women are questioning both the need for a medical intervention in a normal transitional process, and the assumption that menopausal women are naturally disadvantaged (MacPherson, 1987). As noted above, few studies have included low-income women in their samples. The decision regarding hormone replacement therapy is clearly a complex one, in that it involves the weighing of gains and losses related to physiological risks that may challenge personal values (Grady et al., 1992; Rothert et al., 1990). 


\section{Alternative Approaches}

Several other approaches to the management of menopause appeared in the literature. The Canadian Menopause Consensus (1994) have summarized them and have made recommendations regarding healthy lifestyles and health promotion approaches. The approaches include eating a diet according to the Canada's Food Guide. A diet low in fat and high in fiber is recommended for its cardio-protective and anticarcinogenic effects. Moderation in terms of salts, sugars, and caffeine is suggested along with avoidance of alcohol. Calcium and vitamin D supplements are recommended for their osteo-protective effects. Antioxidants such as vitamins C, E, betacarotene, and gamma linoleic acid (evening primrose oil) preparations have been used by women during the menopause, however, as the Canadian Menopause Consensus points out, there is insufficient scientific evidence on their effectiveness as this time.

Exercise such as walking, swimming, cycling, or cross-country skiing is recommended for their osteo- and cardio-protective effects. The development of relaxation, coping, problem solving and time management skills are also suggested as behavioural approaches to mental health. Psychotherapy and/or pharmacotherapy in addition to hormone replacement therapy, along with the above identified approaches are suggested for continued fatigue, irritability, anxiety, depression, sleep disturbances, or memory and attention problems. Clonidine and belladonna alkaloids are suggested for controlling hot flashes, and anxiolytics and antidepressants particularly when hormone replacement therapy is declined, contraindicated, or ineffective (Canadian Menopause Consensus Conference, 1994).

Alternative therapies such as acupressure, acupuncture, and herbs including teas are frequently used by women to manage menopausal symptoms, however, these 
approaches have not been subject to scientific scrutiny through randomized clinical trials (Canadian Menopause Consensus Conference, 1994).

\section{Self-Care}

Self-care is not a new concept. Self-care has existed as long as human beings and families have struggled with the uncertainties of their existence, and therefore predates modern medicine (Barofsky, 1978; Hill \& Smith, 1990; Lipson \& Steiger, 1996; Woods, 1989). Lipson and Steiger identify that specific self-care activities, particularly in the area of health promotion have not often been described in ethnographic or historical accounts, nevertheless, they suggest that we must assume that the majority of health care, over the ages, occurred in the family, and that self-care activities have been passed down from generation to generation. Clark (1996) states that self-care is deeply rooted in culture. There is, however little data available on what people did to achieve and maintain health.

As mentioned self-care existed long before the emergence of modern medicine. Self-care, however has been affected by various historical developments. Ancient Chinese medicine emphasized balance and harmony with nature and the rhythms of the universe (Lipson \& Steiger, 1996). Later ancient Greek medicine, associated with the goddess Hygeia, advocated living wisely and maintaining health through hygienic living habits and appropriate nutrition. Even Hippocrates, born in $406 \mathrm{BC}$ stressed the importance diet, exercise, rest and baths. He emphasized the healing power of nature. Lipson and Steiger, identify that physicians later denied the healing power of nature and began to treat illness quickly and aggressively.

According to Lipson and Steiger (1996), several centuries after Hippocrates, illness became regarded as punishment for sin, with prayer being the only appropriate treatment. As the knowledge of the human body grew, the body came to be seen more 
and more as a machine. Despite the successes in medicine, most of the population had no access to a doctor, those who sought care beyond prayer and home remedies, were treated by lay practitioners. Ehrenreich and English (1973) identify that these lay practitioners were usually women, they were the abortionists, nurses, and counselors, and the pharmacists cultivating herbs and exchanging information about their uses. They were the midwives, and, as Ehrenreich and English state they were the doctors without degrees, barred from books and education. Women learned from each other, passing on information and experience from neighbor to neighbor and mother to daughter. Women have been autonomous healers, and often the only healers for women and the poor.

Florence Nightingale (1860) in her Notes on Nursing: What It Is and What It Is Not, wrote guidelines for women's care of their families that included adequate ventilation and warming; hygiene of homes; household management; noise control; variety of stimulation; nutrition; care of bed and bedding; control of light; cleanliness of rooms and walls; and personal hygiene among others. These writings illustrate the early reference to self-care in families in the discipline of nursing.

Later as the advancements in medical technology led to the control of communicable diseases and decreased mortality rates, many became convinced that the formally educated physician was qualified to determine health status and interventions (Lipson \& Steiger, 1996). As medical interventions came to be held in high regard, selfcare was devalued, people were discouraged from evaluating their own health status or to care for themselves. This brief review of history demonstrates that self-care is not a phenomena of the middle-class, but rather that self-care and care by indigenous healers has been the norm, with the elite receiving the services of professional medicine. 
Williamson and Danaher (1978) propose that, $75 \%$ or more of health care is in fact self-care. They suggest that when physicians discuss self-treatment, they are generally referring to self-medication. Williamson and Danaher state that this perspective is narrow in scope, and assert that it is important to view self-care in its wider context. They conceptualize self-care as comprising health maintenance, including disease prevention and care of self in illness. Williamson and Danaher also suggest that self-care is truly the first level of care.

The growing strength of the self-care movement is illustrated by the popularity of self-care classes, wellness centres, and the preoccupation with exercise and nutrition. Levin, Katz, and Holst (1979) trace this to the women's health movement and the consumer movements of the 1960s. It has been suggested that the following forces underlie the current interest in self-care: de-medicalization and demystification of primary medical care; consumerism and demand for increased control and participation related to anti-technology and anti-authority perspectives; changes in lifestyles and increased education; concern about perceived abuses in medical care; and lack of availability of professional services (Levin et al. 1979; Lipson \& Steiger, 1996; Williamson \& Danaher, 1978). The self-care movement as identified above has been criticized as being largely irrelevant to the poor. Others perceive self-care as a way to decrease costs (Lipson \& Steiger).

\section{Orem's Model of Self-Care.}

Orem's Model of Self-Care (1995) is the most well known and widely referred to in the nursing literature. In this section the use of the model in research will be discussed followed by a brief description and critique of the model. Orem's Model of Self-Care has been used extensively by nurse researchers (Daschiff, 1992; Jirovec \& Kasno, 1993; 
Kubricht, 1984; Riesch, 1988; Sandman, Norberg, Adolfsson, Axelsson, \& Hedly, 1986; Storm \& Baumgartner, 1987). Most of these studies were focused on self-care activities related to particular physical problems. Only one study focused on a low-income population. Daschiff used the model to study the self-care capabilities in black girls of an economically depressed area related to the anticipation of menarche. She found the model useful in terms of a framework for describing the variables that influence self-care abilities. As noted there are a few studies related to women's health issues.

Woods (1985) explored the universal and illness related self-care activities of young adult women between the ages of 20 and 38 years. The majority of the responses related to illness oriented self-care, such as the prevention of symptoms. Allan (1988) examined the use and interpretation of health information in the practice of self-care activities of women as related to their weight. She identified that Orem's Model of SelfCare linked with an explanatory model provided a set of concepts that enabled exploration of the environments that women must negotiate in dealing with weight. Hartley (1988) tested the relationship between nursing system and self-care behaviour by examining the congruence between teaching strategies and learning styles of women and their effect on accuracy and frequency of performance of breast self-examination. She noted that the findings of her study supported Orem's conceptualization of the relationship of nursing system to self-care behaviours. It is important to note that Hartley was actually testing the educative nursing system on self-care behaviour, versus the theory of self-care.

Hartweg (1993) used the model in her study of the self-care actions of healthy middle-aged women in the promotion of well-being. Over $35 \%$ of the sample were below the federally determined median incomes for Americans at the time. Hartweg was able to 
classify all but $4 \%$ of the self-care actions according to the three types of self-care requisites. Hartweg found that self-care requisites was adequate as a framework for classifying the self-care actions. This particular study will be discussed in more detail in the next section.

The three interrelated theories proposed by Orem (1995) are: the theory of selfcare, the theory of self-care deficit, and the theory of nursing system. The theory of selfcare describes self-care behaviours that regulate human structural integrity, functioning, and human development. The theory of self-care deficit articulates and identifies the reasons why persons require nursing, and the theory of nursing system establishes the structure and content of nursing practice.

The focus of the three theories is on self-care. Health is referred to by Orem (1995) as a sense, or a state of a person, that is structurally and functionally whole. The physical, psychological, interpersonal, and social aspects of health are viewed as inseparable, and becoming more highly integrated with progressive development. Well being, is referred to in the sense of a person's perceived existing condition. Orem describes it as a state distinguished by "experiences of contentment, pleasure, and kinds of happiness; by spiritual experiences; by movement toward fulfillment of one's selfideal; and by continuing personalization" (p101). Well being is considered to be associated with health, success in personal endeavors, and with adequacy of resources (Orem).

This discussion will be limited to the theory of self-care (Orem, 1995), as it is this theory that is most consistent with the concepts of development and health promotion, therefore most relevant to this study. The theories of self-care deficit and nursing system are more consistent with an illness or disease orientation than a health orientation. The 
theory of self-care includes the concepts of therapeutic self-care demand and self-care agency. This theory explains why individuals initiate self-care activities to meet self-care requisites. Self-care, according to Orem is a human regulatory function that individuals carry out for themselves to maintain life, physical and psychosocial functioning, and development compatible with conditions necessary for life, and for integrity of functioning and development. Refer to Chapter 1 of this thesis for further description of the theory.

Orem's (1995) Model of Self-Care has been criticized for its focus on illness (Melnyk, 1983) and on the individual despite the family's and community's influence on self-care (Woods, 1989). Smith (1981) identifies that research based on a clinical model of health, focuses on compliance, adherence, therapeutic alliance, and self diagnosis. The model has been further criticized for it's confusing terminology and complex organization (Lipson \& Steiger, 1996). On the other hand, Hagen, O'Neill, and Dallaire (1995) describe Orem's definition of health as being congruent with health promotion. Hartweg (1990) in her analysis of selected statements by Pender about health promotion and Orem about self-care activity, suggests that there is congruency between the concepts. She states that Pender's description of health promotion behaviours as: ongoing, action oriented activities, purposeful, and an integral part of a person's lifestyle, with individuals striving towards expression of human potential, is consistent with Orem's ideas of self-care activity: that individuals initiate and perform activities on their own behalf, self-care is a contribution to one's own continued existence, health and well being. Orem's theory of self-care also presupposes self-care as deliberate action consistent with Pender's ideas regarding goal direction. It is the conceptualization of health promotion behaviour and self-care as self initiated, deliberate, continuous activity, 
and goal directed that is particularly congruent between the two frameworks. Orem's Model of Self-Care has been underutilized in health promotion and requires further development (Denyes, 1988; Hartweg, 1990; Lipson \& Steiger, 1996).

\section{Qther relevant models.}

Other nursing models are also considered to be relevant to self-care. Clark (1996) proposed a wellness model which the health practitioner is involved in self-care activities, but the decisions about goals, actions, and evaluations are made by the client. Rogers (1980), although not necessarily known as a self-care theorist, defines the role of the nurse as aiding people to achieve their maximum health potential. Rogers proposes that humankind and the environment are coextensive energy fields. The interaction between human and environmental fields is continuous, mutual, and simultaneous. Pender's (1996) conceptual framework for health promotion and disease prevention depicts the multidimensional nature of individuals interacting with their environment as they pursue health. The framework integrates expectancy-value theory with social cognitive theory in the explanation and prediction of the factors which motivate individuals or health promotion or protective activities.

In addition to the discipline of nursing, the behavioural and social science disciplines have also proposed models, but few have used the term self-care. Mechanic (1978) largely concerned with illness behaviour referred to processes exercised by individuals when they experience symptoms, the perception, evaluation, and response that reflect the sociocultural patterns and the circumstances of their lives. The variety of possible responses to illness include: discretionary inaction; the use of medications; seeking professional care; and use of the lay network. 
A second model is the Health Belief Model (HBM). The HBM originated in the 1950s by Hochbaum, Kegeles, Leventhal, and Rosenstock, it explains preventive healthrelated behaviour at the level of individual decision making (Rosenstock, 1974). The HBM includes four concepts: perceived susceptibility, perceived seriousness, perceived benefits, and barriers. The model proposes that both the perceived threat of the disease, and the ratio of perceived benefits to perceived barriers to taking action influence the likelihood that an individual will take preventive action.

Orem's self-care model is limited however, in that it does not consider the interactions with the environment. Bronfenbrenner's Ecology of Human Development framework was useful to combine with Orem's model as it emphasized the interactions between the multiple environments within which development occurs (Glossop, 1988). Bronfenbrenner's framework provided for observations of the interconnections with the larger contexts in which low-income women's lives are embedded.

The framework views transitions occurring throughout the lifespan such as midlife, to be both a function of biological changes and altered environmental circumstances. Bronfenbrenner (1979) defines the ecology of human development as "the scientific study of the progressive, mutual accommodation between an active, growing human being and the changing properties of the immediate settings in which the developing person lives, as this process is affected by relations between these settings, and by the larger contexts in which the settings are embedded" (p. 21). His conception of the environment draws heavily on the work of Kurt Lewin, Lewin's concept of interaction of forces in life space, and his interest in perception and motivation.

The ecological environment is considered to extend beyond the immediate situation directly affecting the developing person, the objects to which the person 
responds, or the people with whom the person interacts on a one-on-one basis. Equally important are the relations between others, the nature of these connections, and their influence on the developing person through their effect on those who interact with the person directly.

The ecological environment is envisioned as "a set of nested structures, each inside the next, like a set of Russian dolls" (Bronfenbrenner, 1979, p.3). The innermost structure, is the immediate setting containing the individual. Examples of immediate settings include the family, home, workplace, or classroom among others. Bronfenbrenner refers to interconnections within the immediate setting as the microsystem. The interrelations among two or more settings in which the developing person actively participates (such as among family, work, and social life) are referred to as a mesosystem. The interconnections that occur with settings in which the person never enters but in which events occur that affect the person's immediate environment are referred to as the exosystems. Macrosystems, the fourth level, refers to the complex nested interconnected systems that are a "manifestation of overarching patterns of ideology and organization of the social institutions common to a particular culture or subculture" (Bronfenbrenner, p. 8).

Bronfenbrenner (1979) hypothesizes that "the developmental potential of settings in a mesosystem is enhanced if the role demands in the different settings are compatible and if the roles, activities, and dyads in which the developing person engages encourage the development of mutual trust, a positive orientation, goal consensus between settings, and an evolving balance of power in favor of the developing person" (p. 212). The literature indicates that women in fact experience a variety of role demands that are not necessarily compatible. Women's roles in our society continue to include the juggling of 
work, household and caregiving responsibilities. In addition social policy has not been adequately modified to deal with the reality of women's lives and to permit the evolving balance of power that Bronfenbrenner refers to (Malveaux, 1993).

Bronfenbrenner (1979) hypothesizes that the settings with the least potential for development are those in which the links are either nonsupportive or absent, in other words when the mesosystem is weakly linked. This hypothesis is also applicable at the exosystem level. Bronfenbrenner predicts a higher correlation between developmental outcomes for individuals and families with extensive social networks than for those with few links outside the home.

Bronfenbrenner's framework extended Orem's Model of Self-Care to go beyond the health professional-client model to view the multiple environmental influences that shape low-income women's self-care activities at midlife.

\section{Self-Care Activities of Women in Midlife: A Review of the Research}

In this section the self-care activities during midlife and the menopausal transition identified in the literature will be reviewed. The studies that relate directly to self-care activities in midlife and menopause will be reviewed, followed by other studies that although not specifically related to self-care, identify self-care activities of women at midlife or during menopause.

Research in the area of midlife as a whole, has been largely neglected by nursing. It wasn't until the 1980s that nurse researchers began to conduct studies on menopause. Much of the research has been conducted from a biomedical perspective, focusing on the signs and symptoms of menopause that could be relieved by hormone replacement therapy (Voda \& George, 1986). More recently, nursing with its strong foundation in the biomedical, behavioural and developmental sciences is one of the disciplines that is 
bringing together the multiple perspectives in an effort to begin to understand the whole of the experience of women in midlife (Dickson, 1994). Research with regard to self-care in midlife or menopause is scant.

Only two studies in the nursing literature were found specifically addressing selfcare at midlife. One was related to self-care actions in midlife (Hartweg, 1993) and the other addressed self-care during the menopausal transition (Bernhard \& Sheppard, 1993).

Hartweg (1993) described the self-care actions healthy middle-aged women performed to promote well-being, and the relationship of these actions to age, sociocultural orientation, family systems factors, and work patterns with a heterogeneous sample of 153 black and white women ranging in age from 40 to 59 . The median age was 49 , the majority had some college education, with a median household income of $\$ 35,000$. Over $35 \%$ of the sample were below the federally determined median incomes for Americans at the time. The majority of the participants were married or in a sustaining relationship with a mean number of 2.9 children. Over $55 \%$ of the women worked full-time for wages. Participants responded to a structured interview guide based on Orem's theory of self-care and a developmental change list.

Women in Hartweg's (1993) study identified 8,693 diverse deliberate self-care actions to promote well being. Hartweg (1993) found women took deliberate action to engage in social connectedness through contacts with friends and family members and performed many "helping" behaviours. She noted that self-care actions to meet developmentally specific needs were performed in response to specific changes that the participants experienced since tuming 40. Many were positive actions, such as those performed to enhance self-reflection. Hartweg identifies that this finding suggests women's knowledge of self and ways to enhance well-being are deliberately performed 
as self-care. Multiple individual examples of self-care actions associated with personal hygiene were identified, such as wearing panty liners and special bathing due to increased odors with middle age. Hartweg concluded that the magnitude of the relationship observed between social interaction and the developmental change requisites supported the complexity of women's lives, with deliberate actions to maintain contact with parents, children, and friends. Many women in the study were also found to perform actions related to annual examinations and diagnostic testing such as obtaining mammograms to improve their well-being. Hartweg concluded that women have knowledge of self and of many creative and diverse self-care activities that promote their individual well-being. She suggests that nurses can assist women to develop and enhance those actions that comprise their identified self-care system. However, Hartweg asserts that the personal and complex nature of the individual's self-care system must be acknowledged.

Bernhard and Sheppard (1993) conducted a descriptive, cross-sectional study to determine the relationships among perceived health, menopause, and self-care responses in a convenience sample of 101 well-educated, employed, affluent, and healthy perimenopausal and postmenopausal women aged 43 to 58 years. Self-care responses were measured using the Self-Care Responses Questionnaire, anchored with menopause as the particular health experience. The women generally perceived themselves to be in good health. The most frequently reported symptoms associated with menopause on the Menopause Symptoms Checklist were tired feelings (91\%), hot flashes (87\%), and being irritable and nervous (76\%). The symptom that was identified as most worrisome was weight gain ( $28 \%$ ), followed by hot flashes, tired feelings, and trouble sleeping ( $22 \%$ each). The most frequent self-care responses were: accepting bodily changes (97\%), having faith (94\%), and throwing themselves into their work (93\%). Despite reporting a 
wide range of menopausal symptoms, women did not worry about them. Bernhard and Sheppard suggest that health care providers not automatically suggest or provide treatment for symptoms, but rather assess symptoms and self-care practices and affirm women who describe themselves as healthy for their appropriate self-care practices. Bernhard and Sheppard recommend further study with women of diverse socioeconomic backgrounds.

Other studies on midlife and menopause that have identified self-care practices in their results will also be reviewed for the purposes of determining the kinds of self-care activities women have reported. Voda (1982) undertook a study using 20 randomly selected daily records of hot flash experiences of 67 menopausal (natural and induced) women. The women were between the ages of 33 and 67 years. Fifty five percent of the women did not work outside of the home. No other demographic information were reported. Women were asked to record their basal body temperature, the time of day a hot flash occurred, duration, intensity, trigger, origin, spread and coping strategies used, for a period of two weeks. Voda found extreme variability in the ways in which women coped with the hot flash. Women reported the following coping strategies: ingesting cool liquids; using external coping strategies including fanning self, standing in front of an air conditioner, an evaporative cooler, or a fan, swimming, showering, and/or opening a window, choosing to ignore the hot flash and/or coping with it by recording it, trying to forget it, or actively trying to tell it to go away, and doing nothing. No drug or vitamin use, other than estrogen were reported as coping strategies for hot flashes. These women reported making changes in their daily activities. Without exception all of the 20 women decreased out-door activity during hot summer months. A common complaint was that they were always having to lower the thermostat at home to achieve thermal comfort, this 
was however, not possible in the workplace. Women were also found to make wardrobe adjustments, switching from nonbreathable fabrics to clothing made of cotton. Voda identifies that the data in this study suggest, that of all of the coping mechanisms used by women, nothing was as effective as estrogen replacement therapy. Voda concludes that due to the fact that there was no discernible intersubject pattern regarding hot flash origin, spread, time of occurrence, duration, coping activity, or common trigger that the hot flash is a unique experience for each woman.

Dosey and Dosey (1980) conducted a survey using a convenience sample of 143 women between the ages of 39 and 60 to assess the frequency of occurrence of various physiological and sociopsychological menopausal symptoms, to compare the incidence of the climacteric reaction with a number of possible sociopsychological determinants, and to ascertain how women handle their menopausal reactions. The median age of the women was 49 years, $46 \%$ were not employed outside of the home, and $82 \%$ were married. The sample was somewhat over represented by women of higher education, occupational status and family income than the middle aged women in the American population at that time. Dosey and Dosey found that unpleasant reactions were more common than pleasant ones. The most frequently identified physiological symptoms were headaches, hot flashes, feeling depressed and some irritability. Of eight life situation variables, three were found to be associated with the reaction to menopause, namely, family income, marital status, and children in the home. High income women had fewer symptoms than either middle and low-income women, married women had fewer symptoms than women living alone, and having many children was associated with a pleasant reaction, no children with an unpleasant reaction. 
In terms of the primary source of information on menopause, Dosey and Dosey (1980) found that $50 \%$ of the women identified their physician, $15 \%$ identified their mother, $15 \%$ identified a friend, $13 \%$ identified books and magazines, and $5 \%$ identified school. Findings also indicated that $31 \%$ of women discussed their menopause with their husbands, $25 \%$ with a friend, $10 \%$ with their children, $4 \%$ with their mother, and $27 \%$ identified that they did not discuss their menopause with anyone. Among professionals, physicians were sought most frequently for information and treatment, psychologists, counsellors, and nurses were rarely consulted. Two thirds of the women in the study who had gone to a physician indicated they were given estrogen, and more than half indicated they were given tranquilizers. This study demonstrates that the biomedical perspective dominates in terms of where women obtain information, with whom they seek help, and the kinds of self-care practices they are engaging in, namely medication. This study is however limited by the use of a convenience sample and an over-representation by women of higher education, occupational status and family income.

Jones (1994) used a qualitative methodology to analyze the meaning women made of their experience of menopause. Her sample was a homogeneous group of 17 white, middle-aged, middle class, relatively highly educated women. All but one worked outside of the home, sixteen had at least one child at home, nine were married, with eight having been married. Similar to the findings of the Dosey and Dosey (1980) women's major sources of information were their physicians, Jones attributes this finding to the fact that $76 \%$ of the women were taking hormone replacement therapy. Women were also found to look to other resources, in addition to relying primarily on their physicians, among these resources were literature on women's health, according to Jones, much of it coming out of the women's health movement. Seven of the women reported tuming to 
other women for information and for support, particularly other women who had completed the menopause process.

The midlife issues which were most often associated with menopause by the women in this study (Jones, 1994) were: appearance, sexuality, aging and health. All of the women reported recent changes in their physical appearance and most associated those changes with the onset of menopause. They reported: graying hair; skin changes, including an increase in wrinkles, dryness, and liver spots; muscle tone changes, or a general sagging, such as sagging breasts, sagging cheeks, and sagging arms. In addition, women reported a recent weight gain and overall change in body shape. Some of the women indicated that they had to change their style of dress to consciously cover up their bodies. Others reported coloring their hair, dieting and exercising as strategies for looking more youthful. Many of the women also indicated that they were taking better care of their bodies than ever before and were experiencing the rewards of increased vigor and resilience. Women were noted to be attempting to develop a new aesthetic based on the character and substance which comes with experience rather than on the ideal of youthful beauty and appearance.

In terms of sexuality, women identified a decrease in libido, a general drying and shrinking of the genitals, particularly the vagina, increased vaginal infections, positive changes included an increase in sexual interest due to the absence of fear of pregnancy and/or not having to use birth control (Jones, 1994). It should be noted, however, that 11 of the 17 women did not report any change in their sexuality related to menopause. Many of the women used hormone replacement therapy as a strategy to manage these changes. Many of the women were also found to be initiating change, rather than ending sexuality 
in the years ahead. According to Jones, they talked of both a new capacity for intimacy as well as the importance of learning to pleasure themselves.

All of the women associated aging, like midlife issues with their experience of menopause. Jones (1994) indicated that it was difficult to know where one ended and the other began. The negative meanings associated with aging included the inevitability of the decline of the body and eventually death. Seven of the women reported being worried about the possibility of increasing social isolation and economic security. On the other hand, eight women identified a new sense of vigor and well-being and a stronger sense of self. Several women indicated that they were more self-accepting and confiderit than at any other time in their lives. The strategies used to deal with their anxiety of aging included: denial, trying to hold on to youthfulness by whatever means were available such as dying one's hair, exercising, and dieting. Another response identified, was to remind themselves that although one was aging, they were early on in the process. In relation to health, menopause was perceived by most of the women as a marker, rather than the cause of changes in health. Only three women associated changes in their health directly to menopause. The physical symptoms included general aches and pains, low energy, back pain, and headaches. Most of the women identified that they believed that their health would never be as good as it had been in the past and that they were coming into a phase of their life of inevitable decline. They reported taking better care of their bodies and attending more to their health. As Jones concludes, it is clear that menopause represented important changes in their bodies and lives. Women had obviously internalized the biomedical perspective and were struggling to create new perspectives. The experience and meaning of menopause to women in this study underscores the limitations of the biomedical perspective. The women in this particular study, although 
mostly users of hormone replacement therapy, went beyond the pharmaceutical approaches to include, social reconstruction of the experience and healthy lifestyle approaches as self-care practices.

Dickson (1994) also studied the experience of menopause using a qualitative design. She interviewed ten middle income women ranging in age from 42 to 53 . Two of the women were of African American descent, the remainder were Euro-American. Most were middle class with incomes more than $\$ 40,000$, however two women were in the lower strata between $\$ 25,000$ and $\$ 35,000$. Dickson found that most of the women were in fact knowledgeable about hormone replacement therapy, but spoke of hormone therapy in terms of relief for current discomforts of the menopausal transition, rather than for the possible long term benefits. The women in this study did not reveal a real movement to taking hormones. Women were not found to be interested in hormone therapy until they had a problem that hormones may help. Dickson identified that the women made lifestyle changes such as increasing exercise, giving up alcohol, reducing stress and taking vitamins or minerals to feel better. She found that many of the women were concerned about their bones and were aware of the risk factors for osteoporosis, however remain skeptical about the long term effects of estrogen use. Dickson, like Jones (1994) also found that some women clearly identified the menopausal transition as a marker of aging and a time of coming to terms with getting older. Other women in Dickson's study also identified it as an opportunity for time for themselves, and an opportunity for enjoyment of a new and different kind of life. Returning to school, starting new careers, enhancing old ones, and starting a business, were some of the ways in which women were found to be renewing their lives. Like Dosey and Dosey (1980), Dickson found that the women in her study found it difficult to talk about their experiences with people close to them. 
These studies indicate that women do not necessarily share the idea that menopause is a period of loss, deteriorating health and declining sexuality, but rather are thinking of it as another stage of life. It is apparent from these studies that midlife represents a time of change and transition for these women. A time when women are attempting to come to terms with midlife and aging in general, and that the menopause is simply a marker.

Based on the findings of the studies, it is apparent that women continue to rely heavily on physicians, as a source of information, and as a professional from which to seek assistance for the management of physical symptoms in particular. Although the women in these samples tended to be users of hormone replacement therapy, many were also actively engaging in other self-care practices including coming to terms with getting older, accepting changes, and taking better care of themselves through lifestyle changes. Hormone replacement therapy was used for relief of specific physical symptoms such as hot flashes and vaginal dryness. Women seemed to recognize the limited benefits of medications in terms of dealing with the symptoms related to a decrease in estrogen levels and the need to engage in other self-care practices for coping with the developmental and social changes they were experiencing in this stage of life. A major weakness in all of the studies is the predominantly white, educated, employed, and affluent samples, limiting the generalizability of findings. Little is known about the experience of low-income women and their self-care practices.

\section{Definitions of Low-Income}

A trend of increasing poverty is currently being observed in Canada with women being disproportionately represented among Canada's poor (National Council of Welfare [NCW], 1998a). It is well known that a relationship between socioeconomic status and 
health exists. This section of the literature review will discuss the various methods used to define poverty.

Ross, Shillington, and Lockhead (1994) identify two approaches to defining and measuring poverty. The first approach is based on determination of an absolute measure of poverty by estimating certain basic goods and services as necessary for physical survival. The poverty line using this approach is very low. Absolute poverty lines imply an absence of choice or flexibility in how one lives. The second approach, on the other hand, is a relative approach. In addition to physical survival, this approach takes into consideration the social and psychological aspects of life. It is based on the concept of equity (Ross et al.). Equity is considered to be the extent to which society should tolerate inequality in the distribution of wealth. This approach according to Ross et al., takes into consideration that Canadians live in communities in which they are surrounded by wealth.

Poverty is defined differently by various agencies in Canada. The most commonly used measure of poverty in Canada is the Statistics Canada measure. Statistics Canada does not measure poverty per se, but rather identifies a set of income cut-offs below which people are considered to live in restricted circumstances. Most social policy analysts, politicians and editorial writers consider the cut-offs as poverty lines (Ross et al., 1994). In calculating its low-income standard, Statistics Canada begins by estimating the percentage of gross income spent by the average Canadian family on food, clothing, and shelter. It then marks up this percentage by 20 percentage points to arrive at the lowincome cut-off (LICO) for a particular year (NCW, 1998a; Ross et al.). The LICOs are considered to represent levels of gross income where people spend disproportionate amounts of money for food, shelter and clothing (NCW, 1998a). According to the 1986 
data on spending patterns, the average Canadian family spent $36.2 \%$ of gross income on food, shelter and clothing, it was therefore assumed that low-income people spent $56.2 \%$ or more on the essentials of life (NCW, 1998a). These cut-off levels are adjusted for number of family members, and community size (NCW, 1998a; Ross et al.). There are seven categories of family size, ranging from one person to seven or more people and five community sizes ranging from rural areas to cities with 500,000 or more residents. The result is a set of 35 cut-offs (NCW, 1998a; Ross et al.). These cut-offs are updated annually using the Consumer Price Index (NCW, 1998a). Refer to Appendix A for the NCW (1998a) estimates of Statistics Canada's LICO (base 1986) for 1998.

Ross et al. (1994) argue that, the debate on poverty definitions, is to a large extent, theoretical. Poverty standards have not been used to set the level of the income safety net. They identify that the income of poor households falls well below the recommended incomes of the most commonly used definitions of poverty. The average income of the average poor Canadian family in 1992 was $\$ 7,376$, well below the lowincome cutoff of $\$ 8,274$ (lone-parent mother) established by Statistics Canada, demonstrating that poverty in Canada is largely guided by the absolute approach (Ross et al.). In reality, it is the provincial social assistance rates that identify poverty lines.

Welfare is the social safety net of last resort. Most recipients have no other income apart from child and sales tax credit benefits (NCW, 1998b; Ross, 1994). Social assistance therefore, defines minimum income sanctioned by provincial governments. The rates are not based on explicit budgets to ensure adequacy, therefore one cannot assume that recipients of social assistance have incomes sufficient to cover essentials (Ross et al.). One problem with using the social assistance rate, is that these rates do not include the working poor. As Ross et al. identify, half of the people considered to live in 
poverty are the working poor. Although a job has been traditionally considered to be the best insurance against poverty, the NCW (1998a) indicate that even 52 weeks of work a year does not always protect a person from poverty. In $1996,20 \%$ of all poor unattached people were found to have worked between 49 and 52 weeks that year, and seven percent of all poor families with heads under the age of 65 were found to be poor even when both spouses together worked for a combined 93 or more weeks during the year $\mathrm{NCW}$, 1998a). Workers in the service sector have been found to have the highest rates of poverty (NCW, 1998a).

The LICOs as identified by Statistics Canada were used to define "low-income" in this study. Even though the cut-offs are not intended to define poverty, they do define low-income. The advantage of using this definition rather than the provincial social assistance rates is that, the low-income cut-offs encompass some of the working poor.

The majority of the data that follows were gathered by Statistics Canada and analyzed by NCW (1998a; 1998b). A family is defined according to NCW (1998a), as a group of individuals occupying the same dwelling unit and related by blood, marriage or adoption. Common-law relationships are included in this definition. Unattached individuals are considered to be people living alone or in households where they are not related to other members (NCW, 1998b).

The depth of poverty becomes apparent when the average incomes of poor Canadians are considered as a percentage of the poverty line, or considered according to the difference in actual dollars between the poverty line and the average income of the poor (NCW, 1998a). The national lines may also be compared with the leading absolute definition of poverty, the provincial social assistance rates. Taking each of the above identified approaches, it can be seen that measuring the depth of poverty permits the 
calculation of the poverty gap, in other words, how much additional income would be required to go over the poverty line. The NCW arranged the eight family types according to average income as a percentage of the poverty line. The three family types with the greatest disparity were, beginning with the poorest, unattached men under the age of 65 , with incomes that were only $53 \%$ of the poverty line on average, followed by unattached women under the age of 65 with $57.1 \%$, and then single-parent mothers with incomes $59.9 \%$ of the poverty line (NCW). In terms of actual dollars these percentages translate to $\$ 6,768$ for unattached men under the age of $65, \$ 6,368$ for unattached women under 65 , and $\$ 9,604$ for single-parent mothers. The inconsistency noted between the percentages and the dollar arnounts for unattached persons is related to the fact that poverty lines are higher for families. In looking at people in different income categories NCW found that the poorest of the poor were the unattached women under the age of 65 and the poor unattached men under the age of 65 with incomes of less than $50 \%$ of the poverty line.

\section{Poverty: A Determinant of Health}

Income and social status are known determinants of health (Hamilton \& Bhatti, 1996). In this section poverty as a determinant of health will be explored. The various hypotheses that have been suggested to explain the morbidity and mortality gradients observed in lower socioeconomic groups will be identified followed by empirical literature

The association between position on the social hierarchy and health is well documented (Marmot et al., 1991; Marmot, Rose, Shipley, \& Hamilton, 1978; Marmot, Shipley, \& Rose, 1984; Wilkinson, 1989; 1992a; 1992b) Rachlis and Kushner (1995) identify that poor health is associated with lower positions on the social hierarchy regardless of whether hierarchy is defined by education, income, or job classification. 
There are several hypotheses that have been suggested to explain the morbidity and mortality gradients observed in lower socioeconomic groups. These hypotheses include: limited access to medical care; non-use of available medical services; and living in more toxic, hazardous and non-hygienic environments (Syme \& Berkman, 1990). There is little doubt that the high rates of morbidity and mortality observed in the lower socioeconomic groups are in part due to these issues, however, it is well known that inadequate medical care, and physical environments do not completely explain the discrepancies observed. Syme and Berkman (1990) identify that, while huge improvements have been made in the environment and in medical care, the mortality gap has not changed between the socioeconomic groups.

Wilkinson (1989) identifies that in fact, statistics show a widening of class differences in health during the post war period (1951-1981). He notes that trends in mortality differences have not been related to trends in class differences in average incomes, but have been related to trends in relative poverty. Wilkinson (1992a) investigated the cross sectional relationship between income distribution and mortality and its possible associations with gross national product per person to determine whether changes in income distribution over time are related to changes in mortality in developed countries. Overall he found clear evidence of a strong relationship between a society's income distribution and the average life expectancy of its population. He concludes that mortality is affected by income distribution and uses the contrasting experiences of Britain and Japan to illustrate his point. In 1970 the income distribution was similar in the two countries. In 1992 Japan had the highest life expectancy in the world. It was observed that Japan achieved the most egalitarian income distribution of any country on record. Britain, on the other hand experienced a widening of the income distribution since 
the mid 1980s and mortality increased among men and women aged 15 to 44 years of age. He hypothesizes that the social consequences of people's differing circumstances in terms of stress, self esteem, and social support may be one of the most important influences on health. Wilkinson states that if health differences within the developed countries are principally a function of income inequality itself, this explains why social class differences in health have not narrowed despite growing affluence and fall of absolute poverty.

While it is known that certain stressful events have physiologic consequences (Selye, 1976), very little is known about the nature of these events. Less is known about what constitutes stress (Syme \& Berkman, 1990). It may not only be the impact of these factors, but rather, how people cope with such stress that affects generalized susceptibility to disease. Syme and Berkman define coping as the way in which people deal with problems in their everyday life. Cigarette smoking and obesity, are examples of coping responses that have a wide range of disease outcomes. Graham (1987) suggests that health behaviour should not be thought of as indicative of free choice, easily amenable to change, but rather as no-choice options for people struggling to make ends meet.

In Canada, the poverty rate has been inching up every year in the five years since the 1990-1991 recession. One of the major reasons for poverty according to the NCW (1998b), is the lack of good jobs. As the literature indicates poverty in Canada is different than poverty in many Third World countries. The poor in Canada suffer not because the necessities of life are lacking, but rather as a result of deprivation and need (Ross et al. 1994). As Wilkinson (1989) suggests, with increasing Gross National Product per capita, it would be expected that mortality rates of those at the lower end of the income 
distribution would fall faster than others. The fact that this has not happened implies that it is the effects of relative rather than absolute poverty. It is the unequal distribution of income that blocks access to Canada's wealth (Hamilton \& Bhatti, 1996; Ross et al, 1994).

\section{Women and Poverty}

Although women make up $51 \%$ of the population, $57 \%$ of the low-income people in Canada are women (Health and Welfare Canada, 1990). During the 1980s, many developments occurred in an effort to change the situation of women in Canada. Among the developments were the changes to the Charter of Rights and Freedoms, asserting women's right to equality, and the enactment or amendment of numerous other provincial and federal laws to include anti-discrimination provisions, reform of the divorce property legislation and to mandate affirmative action and pay equity (NCW, 1990). In addition, important changes to social programs were made, child benefits were increased for lowincome families and the Guaranteed Income Supplement for seniors was improved. Most importantly the participation by women aged 25 to 65 years in the labour force increased from $53 \%$ to $68 \%$ (NCW).

The issue of gender equity has been identified as being pivotal in the lives of baby boomers. Malveaux (1993) identifies that gender equity issues have dominated and will continue to dominate public discourse as the population ages and the baby boomers enter retirement in the first decades of the next century. While women have made some progress entering management and the professions, it is important to recognize that many others have not had the benefit of higher education, descent paying jobs, and many have had to take time away from work to care for family (Malveaux; Taeuber \& Allen, 1993). The majority of women are still in traditional, low paying occupations where more than 
half of the workers are women (NCW, 1990; Nelson, 1997; Taeuber \& Allen). The proportion of women among Canada's poor has not changed as a result of the developments that have taken place during the 1980s (NCW, 1990). Women continue to be at higher risk of poverty than men.

The economic status of aging women, according to Malveaux (1993) is largely a mirror of their past, reflecting their education, employment history, and marital status. Those women who were underemployed in their earlier years, tend to experience continued underemployment and low retirement incomes in their older years. Poverty is reflective of the low pay and occupational segregation during women's working lives, as well as the assumption that women will bear the responsibility for caregiving in families, without social support for child care, or the care of elderly relatives (NCW, 1990; Malveaux). However, Malveaux notes that even with the best prepared women, "poverty is an accident waiting to happen" (p. 169). The NCW (1998b) identify that losing a job, losing a spouse, and losing good health are some of the reasons that people go on welfare.

Family type has been identified by NCW (1998a) as the most important determinant of poverty. As Malveaux (1990) states the slogan, "a woman is only a husband away from poverty" continues to be true. Unattached individuals were found to be about two and a half times more likely to be poor than families were (NCW, 1998a). An obvious reason for this is that families tend to have a second family member gaining some form of income. Poverty rates for married couples were found to be low, regardless of the age of the spouses, or the presence of children, whereas, the poverty rates for families led by single-parent mothers were all high. Single-parent families led by women with children under 18 had a poverty rate of $61.4 \%$ in 1996, a rate many times higher than the rates for couples (NCW, 1998a). 
Based on the current trends in marriage, divorce and life expectancy, the NCW (1990) concludes that $84 \%$ of all women can expect to live alone in situations where they will have to support themselves and often their children as well. Included in this $84 \%$ are the $13 \%$ of women who never marry, $30 \%$ who separate or divorce, and $41 \%$ who become widows (NCW). Women are much more likely to find themselves in vulnerable family situations now than in 1979 . In $1979,74 \%$ of women could expect to find themselves in these vulnerable positions as compared to $84 \%$ in 1990 (NCW). The NCW identifies the increases in marriage breakdowns as being largely responsible for this increased vulnerability. In addition to marriage breakdown, the increasing rate of births to single mothers and the aging of the population have also contributed to the vulnerability of women. The NCW states that, if families had not changed as dramatically, the relative poverty of women would have dropped. This according to the NCW (1990) clearly demonstrates that as women work to improve their financial situation, the changes in the structure of households are pulling in the opposite direction.

The risk of poverty normally decreases with education. The data reflect that the poor as a group, tend to have lower levels of education than the non-poor. According to the NCW (1998a), the poverty rate for families led by single-parent mothers with less than a high school education was found to be $87.2 \%$, by far the highest rate among all those who did not complete high school. The poverty rates for single-parent mothers decrease to $51.8 \%$ with completion of high school (NCW). The poverty rates of singleparent mothers continue to be the highest of any family type. Young women who drop out of school due to pregnancy are considered to be poor because of their circumstances, as opposed other causes of poverty. Education is also an important determinant of health in addition to income (Hamilton \& Bhatti, 1996). It is important first of all because it 
provides access of employment and secondly, education increases access to health information and the capacity to make informed decisions regarding health. Health and Welfare Canada (1990) found in their Health Promotion Survey, that among high income women with high levels of education, only $4 \%$ reported their health as fair or poor. This percentage rises to $23 \%$ among very poor women and $34 \%$ among very poor women with low levels of education. A very poor woman with less than secondary education is 8.5 times more likely to describe her health as fair or poor than is a high-income woman with post-secondary education (Health and Welfare Canada, 1990).

Malveaux (1993) identifies that it is social policy that has not been modified adequately to deal with the reality of women's lives, which includes the juggling of workplace, household responsibilities and caregiving. She asserts that the absence of family policy only exacerbates the tendency toward older women's poverty. Educational access may protect some women, but many young women will continue to be disadvantaged by their need to take time out of the labor force for caregiving (Malveaux). The NCW (1990) states that the fact that fathers are much less vulnerable to poverty demonstrates that things could be different. Malveaux also argues that the unequal pay women receive, and the peripheral work that women are offered reduces their access to pensions contributing to high poverty rates among elderly women. The NCW (1990) identify that while men occupy the full range of occupations, $59 \%$ of employed women occupy three types of jobs, namely clerical, sales and service types. These occupations are among the least stable and lowest paying (NCW, 1990).

Women are in fact harder hit than men when it comes to poverty. The poverty associated with being a single-parent mother complicates women's lives by effectively removing any opportunity for higher education, creating a life-long condition of poverty. 
As the NCW (1990) identifies, midlife and older women who are widows, divorced and separated, who spent many years at home caring for their families are at the greatest risk for poverty.

Research suggests that health behaviour among low-income groups is unlikely to be modified simply through individually targeted information and advice (Graham, 1987). Graham sought to understand women's experiences of smoking in the context of caring-in-poverty. Her sample consisted of 37 lone mothers and 20 women living with partners living below the low-income threshold. She found that over half of the mothers in the low-income households were smokers. Smokers were found less likely to have a friend in whom they could confide in; less likely to have a good relationship with their mothers; more likely to feel that their lives were stressful, in terms of financial and relationship worries and concems about their children; more likely to be socially isolated; feel under greater emotional stress, be lower on energy; and report more sleeping difficulties. Smoking appeared to be part of a daily routine, marking, along with a cup of tea or coffee, short spaces of time from a busy schedule during which they rested and refueled. Graham indicates that the women's accounts suggest that smoking is not only a way of taking a break, it is an important way in which women cope. In particular smoking was described as a major coping strategy when the demands of child care became too much to handle in a controlled manner. Graham found that smoking emerged as their only luxury and only leisure activity. She describes it as a moment of self-caring which, unlike a cup of tea or coffee doesn't require preparation. Graham points to the paradoxes of smoking working on the one hand, to promote women's sense of wellbeing, while on the other, threatening physical health. While helping women to cope with caring and promoting family welfare it increases the risks of ill-health and developmental 
delay in children. Graham concludes that smoking is the only purchase women make and the only activity they do for themselves.

Similarly Nelson (1997) identifies that the combination of poverty and multiple role responsibilities may inhibit healthy behaviours and contribute to the poorer health outcomes experienced by low-income women. Nelson found in her exploratory, descriptive study of 34 multiethnic low-income working women between 19 and 63 years of age, that although women were fairly knowledgeable about general health practices, they encountered time, energy, and financial restraints to engaging in them. The lowincome women were found to give priority to those practices that "kept them going" (Nelson, p. 204), that enabled them to continue to carry out their home and work responsibilities. She found that health practices that were not considered to be directly relevant to carrying out the activities of daily living, were not likely to be practiced. Nelson concludes that strategies that are effective in motivating higher income women to devote more of their time to engage in health promotion activities will not likely be effective with low-income women.

Popay et al. (1993) used data from a national cross sectional survey of British women and men aged 18-59 to explore three explanations for the excess of minor physical morbidity and affective disorders compared to men. One of the explanations was that this observation of the excess was due to the social positions that women occupy in contemporary western society. They suggest that even when the relationship between social position and ill health is the same for men and women, their different distributions within the various categories of social position can be expected to contribute to the excess of both minor physical morbidity and affective disorders. Both men and women experiencing low-income were found to have a higher than expected rate of both types of 
ill health, however a greater proportion of women aged $40-59$ years (24\%) are exposed to those increased risks as compared to men.

Graham (1987) so aptly describes the coping strategies that low-income women engage in to deal with everyday problems as no choice options. Nelson (1997) further exemplified the plight of low-income women in describing their self-care activities as being prioritized according to what women believed would keep them going. These descriptions of self-care practices are in sharp contrast to the practices of the educated middle-class perimenopausal and menopausal women described by Jones (1994) and Dickson (1994).

Nelson (1997) further asserts that educational interventions that discount women's knowledge and life situations are likely to be considered as irrelevant. Individually targeted information and advice tends to ignore the interactions between the processes of human development, the environment, and the interdependent links between the multiple environments within which development occurs. It is hoped that in this study Bronfenbrenner's (1979) framework will permit observations of the interconnections with the larger contexts in which low-income women's lives are embedded. As Bronfenbrenner states it is the properties of the immediate settings in which a person lives and the interconnections and relations between various settings and larger contexts that affects the progressive, mutual accommodation between a developing human being and the changing properties of the immediate settings. What matters with regard to behaviour and development is the environment as it is perceived, rather than the "objective" reality. It is critical therefore, that attempts be made to understand the selfcare activities of women in midlife in the context of the constraints and inequities of poverty in order to develop appropriate health promotion strategies. 


\section{Socioeconomic Status and Midlife: A Review of Research Findings}

Several studies have examined socioeconomic factors as possible determinants of the experience of menopause and/or affecting attitudes toward menopause. These studies are reviewed here. Dege and Gretzinger (1982) examined the attitudes of families toward menopause. Nine families with at least one high school aged child were divided into two groups according to the woman's level of education. Four families in the more educated group were compared to five families in the less educated group in terms of attitudes and beliefs toward menopause. Family members were interviewed using the Menopause Attitudes and Beliefs Interview schedule in conjunction with a revised version of the Attitudes toward Menopause checklist. The two groups also fell into separate socioeconomic groups, with the more educated group being white, professional families and the less educated group being white lower-class families. The less educated women and their husbands held more negative attitudes toward menopause than the better educated group. Both groups viewed knowledge, talk about, and help concerning menopause as coming primarily from other women and physicians. The more educated women, however, identified family as an additional source. All families were aware of changes occurring at the time of menopause, including changes caused by children leaving. For the more educated women and their families, this change and menopause were seen as part of a time when things were getting better. Families in the less educated group viewed changes as negative, and menopause as time to prepare for the loss of children as they leave home. Menopause was viewed as a negative time from which to recover. In addition the less educated and lower class women were found to believe that they had less power to direct their lives than the more educated group. Dege and Gretzinger postulated that this was due to an inverse relationship between menopausal 
attitudes and amount of control over life stress. This study was limited by the small number of families participating.

On the other hand Standing \& Glazer (1992) in examining the attitudes of 66 lowincome clinic women between the ages of 18 and 55 years, toward menopause, found that women in their low-income ( $93 \%$ Black) sample had a somewhat positive overall attitude to menopause. Attitudes were measured using the Menopause Attitude Scale. The typical participant was a single, 34 year old, Black woman with an annual income of less than $\$ 10,000$. Standing and Glazer provided three possible interpretations of the more positive attitudes observed in their low-income sample. The first was the linking of the concept of relational integration to the racial characteristics of the sample. Relational integration was defined as having friends and frequent contact with them, providing the much needed emotional support. The second interpretation was that the more positive attitudes may have been due to one of three other more salient problems such as food security, shelter, and safety. A final interpretation was that the sample was potentially biased by excluding women with menopausal problems. The more favorable attitude toward menopause was also hypothesized to be associated with the relief of stress from further unwanted pregnancies. A greater proportion of women in their sample also expressed feelings of uncertainty when compared with other samples of middle income women.

Wilbur, Miller, and Montgomery (1995) investigated the influence of demographic characteristics, including ethnicity, socioeconomic status, marital status, number of children, menopausal status, physical and psychological manifestations on midlife women's attitudes toward menopause with a random sample of 149 employed women aged 35 to 65 stratified by occupation, age, and race. Menopausal status was determined by both self-report and serum estradiol and follicle stimulating hormone. 
Physical and psychological symptoms were determined with the use of the Kaufert and Syratuik Symptom Index. Attitudes toward menopause were measured also using the Menopause Attitude Scale. No differences in menopausal attitude were demonstrated based on ethnicity, occupation, and education. A generally neutral attitude toward menopause was found across ethnic and socioeconomic lines.

The evidence based on the limited number of studies regarding socioeconomic status is contradictory and inconclusive. Social support did seem to mediate the negative attitudes towards menopause, particularly in the more educated and black women. Women of lower socioeconomic status in the Dege and Gretzinger study did appear to have a more biomedical, deficiency disease orientation as evidenced by their identifying a need to recover.

\section{Summary}

The relevant literature has been reviewed largely to determine what research has already been conducted and to more clearly identify the gaps in the knowledge base. As was noted in the review of the literature little is known about midlife. The lack of a consistent and objective definition of menopause and the multiple and conflicting perspectives have limited the knowledge development in this area as well. As Voda and George (1986) identify, the lack of documentation regarding development at midlife, particularly with low-income women has prevented both women and health professionals alike from understanding this complex transition. Women have been noted to engage in a variety of self-care activities ranging from doing nothing, to psychologically reframing the transition to taking hormone replacement therapy for menopausal manifestation and/or the prevention of chronic illness. What is lacking, is the information on how lowincome women experience midlife and what kinds of self-care activities they engage in to 
cope with midlife. As noted from the statistics presented on poverty and women, poverty is a way of life for many women in Canada. It is critical to understand the self-care activities of low-income women in midlife in the context of their everyday lives. The work of Graham (1987) and Nelson (1997), demonstrates the importance of understanding their life situations, as it is unlikely that health promotion strategies that are considered to be effective with higher income women will be effective with lowincome women. This study provided a unique perspective on self-care in midlife through the examination of the practices of low-income women. 


\section{Chapter 3}

\section{Methodology}

\section{Introduction}

In this chapter the methodology and method are presented. A focused ethnographic approach with a feminist perspective was used to uncover the self-care activities of low-income women in midlife. A feminist perspective views the experiences of women from their particular vantage point emphasizing the importance of the development of more parallel, nonhierarchical relationships between the researcher and the participants. Consciousness raising as a general orientation is central to feminist methodology as is the empowerment of women and transformation of patriarchal social institutions through research.

The sample was selected from a job re-entry program and a women's resource centre. Snowball sampling was used to access additional low-income women in midlife and to ensure variation within the sample. The data were collected in the women's homes using a semi-structured interview guide. Ethical standards were maintained throughout the study and in the reporting of the findings.

\section{Approaches to Studying Women in Midlife}

Most of the research on midlife and menopause has been carried out using research designs that have yielded fairly narrow and reductionist perspectives, oversimplifying women's experiences. As Seibold, Richards, and Simon (1994) identify, menopause was essentially viewed as a deficiency disease requiring estrogen replacement therapy. They identify that the shift now, is to one of pathology portraying midlife women's futures as one of osteoporotic bones and heart disease. There is a need for a more contextual mode of interpretation of women's experiences (Gilligan, 1982). 
During the 1970s and 1980s research on women and women's health issues proliferated (Duffy, 1984). Duffy, however cautions the acceptance of this knowledge regarding women. She asserts that the knowledge gained be considered in terms of the sociopolitical and theoretical contexts in which the research is conceived and conducted. Duffy identifies that it is the dominance of men in the scientific community that has created a standard for scientific methodology that incorporates objectivism, neutralism, reductionism, and control, characteristics she identifies as attributable to, and valued by men. It is this paradigm that has guided the majority of the research on women (Bleier, 1984). Feminist scholars have unveiled academic literature that historically served to reinforce the oppression of women by imposing ideology on facts. DuBois, Kelly, Kennedy, Korsmeyer, and Robinson, (1985) state "sexist ideology gives rise to cultural conventions, habitual reactions, and general practices that belittle women, overlook them, or shunt them into places of secondary importance" (p.101).

With the exception of research on reproductive issues, men have been the subjects of research. Gilligan (1982) notes that women have generally not been subjects in research studies on normal human development. Women's experiences have been viewed outside of the norm. Since the 1970 s feminist scholars have begun to offer alternative perspectives (Duffy, 1984). Feminist inquiry has challenged traditional epistemology in the biological sciences, economics and social sciences (Seibold, et al., 1994). Worell (1990) describes research in the psychology of women as proceeding into uncharted areas that would not have been explored in the absence of a feminist psychology movement. She identifies that as women's lives have become the focus of exploration, researchers have begun to study women of color, poverty, and women with nontraditional sexual orientations. As in this study, these populations are studied in order to gain a greater 
understanding of their lives and the meanings that are transmitted to them as a function of their minority status. The dissemination of research findings facilitates the integration of information into current attitudes, beliefs, practice, and policy development.

There tends to be agreement that qualitative methods using a feminist perspective are appropriate for studying women, as women's frame of reference tends to be contextual and relational (Burnell, 1990; Duffy, 1984, Gilligan, 1982; Ladner, 1987; Smith, 1987; Streuernagel, 1990; Thronton Dill, 1987; Wood Sheriff, 1987; Worell, 1990). DuBois (1983), however argues that it is important that the method selected must be the one most likely to yield relevant answers. A qualitative approach was used in this study as little is known about the self-care activities of women in midlife, particularly, those of low income women. A qualitative approach, according to Morse and Field (1995) is particularly useful in studying a phenomenon where there is suspicion that the current knowledge is biased. As noted in the literature review, current knowledge in midlife and menopause is thought to be biased from the perspectives of the various disciplines.

According to Harding (1987), it is not the method used to collect data, but rather it is the purpose of the study and the altered relationships established between the researcher and participant that makes feminist research distinctive, suggesting that feminist research should not prescribe one method. Feminist research is distinguished by certain features, even though it may use a variety of different methods (Duffy, 1985; Seibold et al., 1994). Cook and Fornow (1986) identified five basic epistemological principles. They include: (1) The necessity of continuously and reflexively attending to the significance of gender as a basic feature of all social life, (2) the centrality of consciousness-raising as a specific methodological tool and as a general orientation or 
"way of seeing", (3) the need to challenge the norm of objectivity that assumes that the subject and object of research can be separated from one another and that personal experiences are unscientific, (4) concern for the ethical implications of feminist research and recognition of the exploitation of women as objects of knowledge, and (5) emphasis on the empowerment of women and transformation of patriarchal social institutions through research. Several of these principles were used to inform the strategies used in this study.

Women and their experiences were the focus of this study, acknowledging gender as basic feature of all social life. The study sought to understand the personal experiences of women at midlife, within the contexts of their daily lives. In addition the researcher, being female, brought her own experience of being a woman at midlife to the research process. The researcher, acknowledges her own personal experience as one of privilege. The researcher's position of privilege and her personal experiences could not be simply set aside, they were integrated into the research process.

The idea of consciousness-raising as identified by Cook and Fornow (1986) was incorporated into this study in several ways. The focus on understanding the self-care practices of women at midlife within the context of their daily lives uncovered life circumstances that typically produce changes in consciousness, such as divorce, unemployment, and physical and emotional abuse. Women talked about changes in consciousness and demystification of the "naturalness" (Cook \& Fornow) of patriarchal relations that accompanied these crises, or in the words of Cook and Fornow "the rupture of normalcy". In addition by examining their personal self-care practices, the women developed a new awareness of themselves and how they care for themselves within the 
context of their lives. Their experiences were validated and affirmed as the researcher clarified data, tested analytic categories, interpretations and conclusions with the women.

The researcher sought to minimize the objectification of the women by using a conversational approach to interviewing. Consistent with Oakley's (1981) feminist paradigm for interviewing, the researcher answered questions posed to her by the women, sometimes the questions were personal, such as about the researcher's extended family, her marital status, age of her children, educational history, whereas other questions were more related to the domain of nursing, such as health related concerns. The researcher and the women shared moments where their lives connected, similar experiences, feelings or influences, which helped to humanize the experience and place both the researcher and the women on a more equal footing.

A concern with ethical issues is another characteristic of feminist methodology. In this study, the researcher anticipated potential consequences of the research on the women who participated. It was anticipated that the women might talk about sensitive life experiences. The researcher informed women of the possibility of experiencing emotional responses to the research activities in the consent process. The researcher developed a plan for managing them a priori. If women had developed any signs of distress requiring intervention, the researcher would have worked with the participants to locate appropriate counseling services in the community ensuring accessibility by low-income women. The researcher had prepared a list of counselling services that were deemed to be accessible to the women for these purposes. The researcher also considered how she would deal with emotional responses during the interview. The women did talk about sensitive life experiences, such as childhood abuse, among others. The interview uncovered some intensely personal experiences. The researcher turned off the tape recorder and stopped 
the data collection temporarily, during tearful moments. Once the tears were wiped away, and the women regained their composure, the researcher requested permission to continue with the interview. None of the participants required any other intervention. The researcher was prepared to intervene with some brief counseling if necessary, however, turning off the tape recorder while women wiped away their tears, proved to be adequate.

Central to feminist methodology is the notion that the purpose of knowledge is to change or transform patriarchy (Cook \& Fornow, 1986). In this study knowledge of oppressive and exploitive conditions in our society were elicited, namely those related to the feminization of poverty. The women recognized that this type of information was surfacing as the interviews progressed. They began to recognize more and more the importance of their participation. Near the end of the interviews women urged me to publish the findings and thanked me for seeking the voices of low income women. Policy implications were also identified in the analysis of the data and are described in Chapter five.

In addition, women were provided with the opportunity to think about their life circumstances and how they care for themselves in the context of their lives. The interviews provided them with the opportunity to think about the transitions they had made and how successful they were at making those transitions in the face of adversity.

\section{$\underline{\text { Research Design }}$}

A qualitative methodology was used to addiress the research questions in this study. Qualitative methodology seeks to find answers to questions that centre on how social experience is created, and how it gives meaning to human life (Denzin \& Lincoln, 1994). As Streubert and Carpenter (1995) identify, knowledge of "how social experiences construct individuals' reality is important" (p. 2). They also assert there is little available 
objectively derived measurement that is meaningful in studying human phenomena within a social context. As noted in the review of the literature, the biomedical model has limited the view of menopause to that of a medical syndrome requiring treatment, ignoring the environmental events and social aspects that may affect the relationship between hormonal levels and menopausal changes (Voda \& George, 1986). This objective/positivist ontological position defies the authentic fiber of women and their social interactions (Streubert \& Carpenter, 1995).

Within a human science framework, Streubert and Carpenter (1995) describe the researcher as striving to provide understanding and interpretation of phenomena within context. Selected issues can be studied in depth and detail through the use of qualitative methods (Patton, 1990). Qualitative methods reveal meanings for the purposes of enriching and informing human life. The whole is viewed as greater than the sum of its parts and is context dependent (Streubert \& Carpenter, 1995).

A qualitative approach was particularly appropriate to this study as it attempted to uncover the self-care activities of low-income women at midlife within the context of their lives. Qualitative methodology was also consistent with Bronfenbrenner's focus on the environment as perceived by the participant. This approach facilitated the observation of interactions between the processes of development, the environment, and the interdependent links between the multiple environments within which low-income women care for themselves. A qualitative approach was therefore most appropriate for this study and important in gaining an understanding of the whole of the experience of self-care activities of low-income women at midlife.

The term 'ethnography' according to Hammersley and Atkinson (1995) refers to a particular method or set of methods. Most characteristically it involves the researcher 
participating, overtly or covertly in people's daily lives observing what happens, listening to what is said and asking questions, collecting whatever data are available. Originating in the field of anthropology, ethnography has become a fundamental tool for understanding ourselves and our multicultural society (Spradley, 1980).

The researcher in ethnography, is according to Hammersley and Atkinson "the research instrument par excellence" (p. 19). The researcher relies on all senses, thoughts, and feelings. The human instrument according to Fetterman (1989), is a most sensitive and perceptive data gathering tool. Ethnographic methods help to guide the researcher through the maze of personal observation and to identify and classify accurately the array of observations. Consistent with feminist principles, there is recognition that the investigator influences the context and is central to the analysis. Differences in interpretation between the researcher and the participants were clarified as they occurred.

Ethnography bears a close resemblance to the ways in which people tend to make sense of the world in everyday life (Hammersley \& Atkinson, 1995). The researcher actively makes sense of the world without undermining the purpose of the research, that of a commitment to realism and knowledge. The primary aim of ethnography is to describe what happens in the setting, how people see their own actions, and the contexts in which the action takes place. Hammersley and Atkinson (1995) further assert that human actions are based on, or are as a result of social meanings, intentions, motives, beliefs, rules and values. They argue that viewing people as interpreting stimuli and the unfolding of the interpretations as shaping their actions, is a rejection of the stimulusresponse model of human behaviour which is the essence of the methodological arguments of positivism. The same stimulus can be interpreted differently by different people and to the same person under differing circumstances. In order to understand 
behaviour, Hammersley and Atkinson state that an approach that provides access to the meanings that guide behaviour is essential. Morse and Field (1995) describe ethnography as a generalized approach to the development of concepts and understanding of human behaviour from the emic point of view, in other words, the insider's view. They further describe ethnography as a method of accessing the health beliefs and practices of a culture. In the words of Morse and Field (1995) "rather than studying people, ethnographers learn from people" (p. 26). This idea of learning from people was particularly relevant for this study, as some women purposely taught the researcher about their culture, so that she could more fully understand the context of their lives. As the researcher took the stance of learner, and the women as teacher, more parallel relationships developed, a position essential to ethnography and a feminist perspective.

Ethnographic analysis according to Morse and Field, moves beyond description to uncover or explain aspects of social patterns. It was through thick description and the searching for meaning within the culturally patterned behaviour and the context that the culturally embedded norms that guide women's actions were revealed. Spradley (1980) asserts that culture is fundamentally important as it is continually used in the generation of behaviour and in the way in which experiences are interpreted. Ethnography was particularly appropriate to this study, as self-care was found to be rooted in culture and embedded within the context of their lives.

A focused ethnographic method, a subtype of the ethnographic approach guided this study. A focused ethnography is a more delineated, yet still context bound ethnography (Morse \& Field, 1995). It involves a smaller number of respondents and a shorter time span (Dobson, 1986). It was appropriate to the limited nature of this study, yet it permitted the development of an understanding of self-care from the perspective of 
low income women in midlife, As noted in the literature review, it is the women's perspective that remains unknown. Ethnographic methods facilitate the exploration of the nature of particular phenomenon, rather than testing out hypotheses. The method permitted the researcher to go beyond the identification of self-care activities to uncover the meaning of these activities in the context of women's lives. The analysis of primarily unstructured data involved interpretation of the meanings and functions of their actions through description and explanation (Atkinson \& Hammersley, 1994).

Ethnography also lends well to meeting many of the criteria for a feminist perspective. It facilitated the development of understanding regarding women's experiences and the development of more parallel, non-hierarchical relationships between the researcher and the participants, consciousness raising, and empowerment.

\section{Sampling.}

In qualitative research, the selection of an adequate and appropriate sample is important, as the quality of the research is dependent on appropriateness and adequacy (Morse, 1991). Appropriateness requires purposive sampling, selection of participants most able to meet the informational needs of the study. Purposive sampling is based on the researcher's knowledge of a population, it is this knowledge that is used to select participants who will make up the sample (Polit \& Hungler, 1995). Adequacy refers to sample size. Sandelowski (1995) cautions that inadequate sample sizes in qualitative research studies may not support claims of informational redundancy; on the other hand, she suggests that too large a sample size may not allow for the in-depth analysis required to understand phenomena. The following three factors were identified by Sandelowski, to assist researchers in making decisions regarding whether enough data has been collected: 
the aim of the sampling, the type of purposeful sampling, and the research method employed.

The aim of the sampling is generally about achieving deep understanding through the analysis of "information rich cases" (Sandelowski, 1995, p. 180); it is case-oriented rather than variable oriented. Any sample size which compromises the case-oriented nature of qualitative research thereby compromising in-depth study, is considered too large.

People enter qualitative studies largely by virtue of having direct and personal knowledge of an illness, pregnancy, or as in this case a life transition (Sandelowski, 1995). Maximum variation is one type of purposive sampling. Researchers using this type of sampling must make decisions a priori about the kinds of variation that is to be maximized. Maximum variation requires larger sample sizes. According to Sandelowski, the more the variability, the greater the number of sampling units required to reach informational redundancy. In this particular study variation was sought only on age, marital status, employment, and ethnicity. This was in an effort to capture some variation, but not to loose the case-oriented and focused nature of a micro-ethnography.

In addition to purposive sampling, a snowball sampling method was utilized. Snowball sampling refers to an approach whereby early participants are asked to identify and refer other women who meet the eligibility criteria (Polit \& Hungler, 1995). It was anticipated that there may be some difficulty identifying low-income women at midlife. This method is particulariy appropriate in such a situation.

The final factor, to consider in deciding upon a sample size is the particular qualitative method utilized. Ethnographies tend to require approximately 30 to 50 interviews or observations. The focus in this particular study is on depth, rather than 
breadth. As such, information from a small sample can be particularly valuable (Patton, 1990).

\section{Recruitment and access.}

As discussed, appropriateness is derived from a sample of women who will best provide information according to the theoretical requirements of this study (Morse \& Field, 1995). It was therefore important to make some decisions a priori. The inclusion criteria for the sample were:

1) Ability to speak English

2) Not a client of Youville Centre. The researcher was a nurse at Youville Centre. Avoiding women who were clients of the centre prevented the potential for the researcher to be in a position of power vis-à-vis the participant.

3) Income levels at or below the National Council of Welfare estimates of Statistics Canada's Low Income Cut-offs (1986 base) for 1998 for cities of 500,000+ (according to family size) (Appendix A).

4) Live within the perimeter of Winnipeg. Statistics Canada Low Income Cut-offs are adjusted according to size of community. The City of Winnipeg was used as the community. It has a population of 667,209 (Statistics Canada, 1997). The Low Income Cut-offs according to family size for cities of 500,000 and over were used (Appendix A).

5) Female, between the ages of 40 and 51 years of age. The aim of obtaining a sample of women between the ages of 40 and 51 was to focus on the baby-boom generation, defined in Canada as those born between 1947 and 1966 (Foot, 1996). Women born in 1947 were 51 years of age at the time of data collection. Women born in 1966, however were only 32 years of age. Jacobson (1995) indicates that even 35 years of 
age, the age at which midlife is considered to begin, may be too young for this cohort of women, particularly considering that this cohort tended to delay marriage and childbearing. For the purposes of this study, midlife was defined as women born between the years of 1947 and 1958. Women were therefore between the ages of 40 and 51 during the time of data collection. This age range also encompasses the average age at which women experience perimenopause and the menopausal transition.

Women of varying age (some at the younger, middle, and older age range), marital status (living with a partner and not living with a partner), employment status, (employed, unemployed, and homemakers), and ethnicity (immigrant and Canadian born) were included to ensure some variation in the sample. Marital status was interpreted simply as living with a partner or not living with a partner. The goal of varying the sample on the basis of employment status, was to ensure that both the unemployed and the "working poor" were part of the sample.

The main source for recruitment was through a job re-entry program. The job reentry program is a government funded program aimed at assisting people on social assistance to become gainfully employed. The program focuses on identifying interests and strengths, and skill building; participants are placed in either training programs or paid work settings. This program provided access to both employed and unemployed women.

After receiving access to the job re-entry program (Appendix B) the researcher met with a teacher in the program to explain the study. Thirteen former female participants between the ages of 40 and 51 were initially contacted by phone, by a third party. Past participation was defined as prior to March 1998 (the time at which the researcher became involved professionally with the program). The women were asked if 
they would be interested in hearing more about the study (Appendix C). Ten women agreed to their name being provided to the researcher. The researcher then telephoned the potential participants to explain the project (Appendix D), and answered any questions they had. The women were then asked if they were interested in participating in the study; if they agreed, an interview was arranged in a location of their choice. Seven women agreed to participate. Three women declined, one due to time limitations, another did not meet the inclusion criteria, and a third had changed her mind.

In addition to recruiting through the job re-entry program, a snowball sampling approach was used. Participants were asked if they knew of any other women who would meet the eligibility criteria, and if they would be willing to approach them to participate in the study (Appendix E). Participants were asked to contact potential participants and provide them with an information sheet (Appendix F) asking them to contact the researcher if they were interested in participating. The information sheet was designed similarly to a poster to keep the information simple and clear. This process was attempted in the study, however many of the women were immigrants who knew of few other women who met the eligibility criteria. Only one participant was recruited through the snowball technique. The researcher explained the project to the potential participant obtained through the snowball sampling method, in the same manner as it was explained to the potential participants from the job re-entry program (Appendix D).

After conducting seven interviews with women, all of whom had been recruited from the job re-entry program, the researcher noted that the women were focused on work. All of the women were found to have gone through a process of self-exploration, and had developed a clear direction for the future. The researcher began to ask herself if this was a function of the source of recruitment, or if in fact, this was a theme emerging 
for women at midlife. As the number of participants was inadequate, a second agency was contacted, a women's resource centre. The resource centre provides information, access to community resources, a resource library, a clothing exchange, support and selfhelp groups. A request was made to the Ethical Review Committee of the Faculty of Nursing to add the second agency using the same recruitment processes as was used with the job re-entry program. Permission was granted, and two participants were recruited from the agency. An additional participant was recruited through the snowball technique. The researcher collected data until no new information was obtained (Morse, 1991). Informational redundancy was reached at 8 women. The ninth and tenth interviews did not yield any new or additional information. The researcher then made the decision to end the recruitment process at 10 participants.

\section{Setting.}

Ethnographers conduct research in naturalistic environments (Hammersley \& Atkinson, 1995). The home was selected as the ideal naturalistic setting in which to observe women and their behaviour. Hammersley and Atkinson also suggest that people distinguish between different contexts that require different kinds of behaviour. They suggest that settings are social constructions rather than physical locations. The researcher considered the home to be the natural setting, and the one in which women would be most comfortable discussing their personal experience within the context of their lives. Bronfenbrenner (1979) identifies that strange situations tend to evoke an individual's characteristic response to the unfamiliar. He suggests that this phenomenon is particularly relevant for low-income populations among others. It was thought that the home would be the least likely place for what Goffman (1963) describes as social acting, 
or the creation of illusions and impressions. The women were offered a choice of location within which to be interviewed, all of the women chose their homes.

\section{Data collection.}

Ethnographic methods and techniques help to guide the investigator through the array of observations (Fetterman, 1989). It is only through watching, listening, asking questions, and formulating hypotheses that the researcher can begin to understand the culture of the participants (Hammersley \& Atkinson, 1995). Data were collected through the use of interviews, and the recording of field notes after the interviews. In addition a reflective journal was kept by the researcher for the analysis of the researcher-participant experience. The data collection methods are further described below.

The interview is considered the ethnographer's most important data gathering technique (Fetterman, 1989). Demographic questions were formulated to collect information regarding age, education, income, employment status, marital status, household composition, ethnicity, and number of children (Appendix G). Following the demographic questions the researcher proceeded with a semi-structured interview that was conducted as informally as possible. Morse and Field (1995) state that the semistructured interview is used when the researcher knows what the questions are, but does not know the answers. The researcher used an interview guide (Appendix $\mathrm{H}$ ) outlining a series of questions to be asked, however the investigator waited for the most appropriate time to ask them. The interviews resembled a conversation and eventually became transparent to the women. Fetterman differentiates interviews from conversation by stating that interviews are a mixture of conversation and embedded questions. This approach was particularly important in maintaining a more parallel, non-hierarchical relationship between the researcher and the women. 
Both the demographic and interview guides were pre-tested with a colleague and revised based on the feedback. The guides were also pre-tested with two women in the study to ensure that the information being obtained was providing useful and interesting answers to the research questions and to ensure that the questions were logically arranged. The guides were revised after the pretest. Women were found to be having difficulty with the first broad open-ended question: "Tell me about your personal experience at this time of life"; this question was simply omitted and the interviews were started with "What does midlife or middle age mean to you?" (Appendix H).

On the scheduled date, time, and in the preselected setting, the researcher and participant met. The researcher explained the study to the participants, read and explained the consent process and obtained consent (Appendix I) for participation in the study. The researcher read the consent to the women to ensure that they were fully informed regarding the study. Reading the consent to the women prevented participants with low levels of literacy from feigning that they were able to read and therefore avoid the potential for uninformed consent. Reading the consent was particularly valuable in obtaining consent with the immigrant women because of the language barriers. All but one of the immigrant women had a family member who was more fluent in English present during the consent process. Women who were having some difficulty with English were asked to repeat back to the researcher salient points in the consent process to ensure informed consent. Once the consent process was completed, the tape recorder was turned on. The interviews were audio tape-recorded, with the permission of the participant, to avoid note-taking during the actual interviews, and so as not to interfere with the informality and conversational nature of the interview. The researcher began the interview by asking the demographic questions. Fetterman suggests that these types of 
questions serve as a nonthreatening icebreaker. The researcher then asked what Spradley (1980) terms a "grand tour question", a broad question that asked women to describe what "midlife" or "middle age" meant to them. This question was intended to gain a broad view of the participant's perspective to assist in focusing and directing the investigation (Fetterman, 1989). Grand tour questions also tend to stimulate a barrage of specific, detailed questions followed by more survey questions. As mentioned, since the original "grand tour" question was not effective in getting the interviews started, the interview guide was modified slightly. As the interviews progressed, the researcher began to ask more focused questions to clarify the meaning of responses and to ensure that the research questions were addressed.

The interviews were ended by asking participants if they wanted to contribute any further information and by asking them if they had any questions. The participants were also asked if they would agree to be contacted at a later date for clarification of the content of the interview. One in-person interview was conducted with each participant. The interviews ranged in length anywhere from fifty minutes to two and one half hours.

Five of the ten women recruited immigrated to Canada at some point over the last fifteen years. Some of the women had more difficulty speaking English than others. The researcher repeated and at times re-phrased what the women had said to ensure understanding of what the women were saying. The frequent repetition made for long interview transcripts, but proved useful in both understanding what the women were saying, and for the transcriptionist. Women responded with comments like "yea, this is the same idea" and "you understand me" which were indicators to the researcher that a common understanding of the conversation was being achieved. The researcher identified a personal characteristic that facilitated working with these women. The researcher's 
knowledge of French was particularly helpful. Some Spanish words are very similar to French words, at times the researcher asked the participant to "say it in Spanish" to facilitate understanding. This worked very well, one woman said "you speak Spanish!" Field notes were privately taped immediately following the interview to prevent problems with recall and loss of detail (Hammersley \& Atkinson, 1995). The researcher ensured adequate time for recording after each interview.

A reflective journal was also kept by the researcher to record experiences, thoughts, and impressions in the course of the interviews and ideas about relationships, propositions, and hypotheses that were emerging from the data. This journal was primarily for the purposes of keeping separate objective and subjective records and the analysis of the researcher-participant experience (Aamodt, 1991; Morse \& Field, 1995).

Schatzman and Strauss (1973) suggest that the researcher organize notes according to distinct "packages" according to whether they are "observational", "theoretical" or "methodological". Observational notes are statements about events experienced mainly through watching and listening. The typed transcripts of the interviews and the field notes were considered observational notes in this study.

Theoretical notes are defined by Schatzman and Strauss (1973), as representing the self-conscious attempts to derive meaning from the transcripts and field notes. The researcher interprets, infers, and hypothesizes through relating observations.

Methodological notes, are defined as instructions to the researcher, a reminder and critique of the researcher's own procedures. The plans for recording of data in this study were consistent with Schatzman and Strauss's identification of "packages" of material. 


\section{Data analysis.}

Analysis of the data proceeded concurrently with data collection. Fetterman (1989) states that analysis in ethnography begins the moment the problem is selected for study and ends with the last word in the report. He describes analysis as iterative, building on ideas throughout the study. Data in this study was in the form of textual narrative derived from the transcribed interviews; field notes; and recordings in the researcher's reflective journal.

Morse and Field (1995) identify the first major task in analyzing interview data as becoming familiar with the data. Immediately after the interviews, the researcher replayed the tapes in order to become more familiar with the data. The tapes were then transcribed verbatim by a transcriptionist directly into a Microsoftß Word files with a three inch right margin to facilitate coding. The transcription was then checked against the tapes for accuracy by the researcher.

The data were analyzed using a process referred to as content analysis. Content analysis involves the development of categories and themes from the data (Burnard, 1991). Morse and Field (1995) suggest that by the time the researcher has conducted the interview, listened to the tape, and checked the transcript for accuracy, the researcher will recognize common words, phrases, or themes within the data. They identify qualitative analysis as a cognitive process involving comprehending, synthesizing, theorizing and recontextualizing.

The first step in the process of analysis was a careful reading of the interview transcripts for the purposes of increasing the researcher's familiarization with the data. Hammersley and Atkinson (1995) identify that the aim at this stage is to begin thinking about the data. The interview transcripts were then coded line by line. Categories were 
developed inductively from the codes. Hammersley and Atkinson describe the identification of these categories as important starting points and as the germ of the analysis. The process of coding the data according to general categories was a concurrent one, as new ones emerged, previously coded data were re-coded to determine if it contained any examples of the new categories. Categories were continuously revised, broken down, and added as appropriate. This process was carried out for each transcript. The researcher then looked across all of the transcripts to determine if saturation has been reached. Computer files were created for each category using tables in Microsoftß Word. Coded sections of the transcript that relate to each of the categories were copied and pasted into the appropriate file. Morse and Field (1995) identify that interparticipant analysis and the analysis of categories, sorted by commonalties, consisting of segments of transcripts, facilitates the processes that enable the researcher to synthesize and as the research process continues, to interpret, link, see relationships, conjecture and verify findings. Copies of the first three uncoded transcripts were read independently by the thesis chair. In addition segments were coded independently. This process assisted in determining intercoder reliability and ensured the fit and clarity of categories.

Once each category was reasonably full and saturation was reached, categories were revised and combined as appropriate. The researcher then engaged in the process of looking for patterns, linkages, and relationships between the categories. Categories were aggregated into themes. Morse and Field (1995) state that this is the sorting phase of the analysis, or the theorizing process. They describe this process as one of constructing alternative explanations and holding these against the data until the best fit that explains the data most simply is obtained. This process was that of recontextualizing. 


\section{Measures to enhance methodological rigor.}

Lincoln and Guba (1985) identify the four criterion areas for trustworthiness in qualitative inquiry. The four criterion areas are: credibility; transferability; dependability; and confirmability. These four terms are considered the qualitative equivalents of "internal validity", "external validity", "reliability", and "objectivity". These terms however have been deemed inappropriate when applied to qualitative or naturalistic inquiry. The four criterion areas for trustworthiness as identified by Lincoln and Guba are considered to be more logical and related to naturalistic axioms. It is these four criterion areas that guided the procedures to enhance methodological rigor in this study.

According to Sandelowski (1986) the credibility of a qualitative study generally rests with the discovery of human experiences as they are lived or perceived by the participants rather than in the verification of previously defined conceptions of those experiences. Lincoln and Guba (1985) suggest that it is credibility rather than internal reliability that should be the criterion in qualitative research. The implementation of the credibility criterion according to Lincoln and Guba involves two tasks, that of carrying out the study in such a way that the probability that the findings will be found to be credible is enhanced, and secondly to demonstrate the credibility of findings by having them verified by the constructors of the multiple realities being studied. It is faithful descriptions or interpretations of the experience that people recognize as their own. Credibility in this study was enhanced through informal member checks; verification of the coding and coding process; validation of emerging concepts in subsequent interviews; negative case analysis; progressive subjectivity; ongoing debriefing; and through the verification of the findings. 
Informal member checks occurred continuously throughout the study. Member checks are a process whereby data are clarified, analytic categories, interpretations and conclusions are tested with participants. Negative case analysis was conducted to revise and refine hypotheses until a "fit" was achieved between the findings and the data. Progressive subjectivity is the process of monitoring the researcher's own emerging impressions. These impressions were monitored throughout the research process. Prior to conducting an interview, the researcher reviewed the data gathered to date for the purposes of analyzing the progression of the developing constructs. In a more formal manner than the informal member checks described above, the findings were verified with participants. The purpose of this check was to test for factual and interpretive accuracy and to provide evidence of credibility. Verification is important not only to the researcher but also to the participants and consumers of the research report. It is important that the research report be recognized by the participants as reflecting their culture or experience (Streubert \& Carpenter, 1995).

In order to verify findings with the participants the researcher verified the initial findings with the last woman interviewed, at the conclusion of the interview, and contacted two other participants to verify the findings. The researcher asked the participant if she would meet with her for approximately 20-30 minutes to discuss the findings (Appendix J). As the participants agreed, the researcher arranged a meeting. The researcher met with the selected participants to verify the findings, the findings were presented verbally and the participants were asked if they could relate to the findings. The verbal presentation facilitated verification with those who did not read English. The researcher also asked if there was anything else they wanted to contribute to the study. 
Verification with related literature is also important as a verification procedure (Morse \& Field, 1995). The researcher was able to determine that similar concepts as those that emerged from this study were identified in the literature.

The researcher engaged in debriefing with the thesis chair. Lincoln and Guba (1985) describe peer debriefing as a process of exposing oneself to a peer for the purposes of exploring aspects of the inquiry that might otherwise remain only implicit in the researcher's mind. Debriefing also provided an opportunity for testing working hypotheses that were emerging from the data analysis.

The establishment of transferability of the study findings to other contexts in the strict sense was and is not possible (Lincoln \& Guba, 1985). Sandelowski (1986) states that there are fewer threats to external validity in qualitative research than in quantitative research because qualitative methodology emphasizes the study of phenomena in their natural settings with few controls. Lincoln and Guba identify that in order to be sure of one's inference, one needs to know about both the sending and receiving contexts. They assert that transferability inferences cannot be made by a researcher who knows only the sending context. Lincoln and Guba suggest that the "burden of proof" lies less with the original researcher than with the research consumer. The responsibility of the original researcher ends with providing detailed descriptive data to facilitate comparability judgments regarding the context. Transferability was however, increased through thick description and direct quotes in the research report (Germain, 1993). In addition, detailed descriptions of the setting, sample and data collection procedures are presented to provide data required to the research consumer to judge the transferability.

Dependability or consistency refers to the whether the findings would be consistent if the study were replicated with the same subjects or in a similar context 
(Morse \& Field, 1995). The researcher enhanced dependability by keeping detailed accounts of the research process and the decisions related to method.

Confirmability or neutrality refers to whether or not the study findings are grounded in the data themselves (Sandelowski, 1986). In order to determine whether this was in fact the case, the researcher ensured the establishment of audit trail linkages. Findings are traceable back to the interview transcripts or field notes and entries upon which the findings are based. The reflective journal also provides information about methodological decisions made and the reasons for making them. Subjective interpretations were recorded to maintain awareness of potential bias. Finally, confirmability was achieved through careful attention to the above identified criterion areas for rigor, namely, credibility, transferability, and dependability.

\section{Ethical Considerations}

There are ethical considerations in qualitative methods, just as there are in quantitative methods. In qualitative research, ethical questions arise within the shifting focus of the study, the unpredictable nature of the research, and the trust between the researcher and the participant (Robley, 1995). The focus here was primarily on considerations having to do with the behaviour of the researcher and its consequences for the women participating in the study. Informed consent, privacy, harm, and exploitation were considered. In addition, the research proposal was approved by the Ethical Review Committee of the Faculty of Nursing, University of Manitoba further ensuring the protection of the participants.

It was critical that the participants be informed about the study in a comprehensive and accurate way, and that participants gave their voluntary consent (Hammersley \& Atkinson, 1995). Munhall (1988) suggests that because qualitative 
research is conducted in an ever-changing field, informed consent must be an ongoing process. Process consent needs to be re-negotiated as unexpected events or consequences occur. Voluntary informed consent was obtained by the researcher prior to beginning the interview. Each of the participants signed two consent forms, one for the researcher, and one for their personal records (Appendix I). As mentioned above the researcher read the consent to the women to ensure that they were fully informed regarding the study, particularly for those women who had low levels of literacy and fluency in English. The researcher explained the nature of the research study, the responsibilities of the researcher, the right of the participant to decline participation in the study, and the potential risks and benefits. After which the researcher provided the participants with an opportunity to ask questions and inform them that they could continue to ask questions at any time during the research process. In addition to the initial consent, consent continued to be obtained verbally on an ongoing basis throughout the interview, particularly after women regained composure after emotional reactions to the content of the interview. To ensure voluntary consent, participants were informed that participation was entirely voluntary and that they were free to withdraw at any time.

Closely linked with informed consent are the issues of privacy, confidentiality, achieving accurate portrayal, and inclusion and exclusion of information (Munhall, 1988; Robley, 1995). Several measures were taken to maintain confidentiality. Measures included the storing of participant names, addresses, phone numbers, consent forms, and identifying codes separately from the audiotapes and transcripts. The data transcripts were labeled using an identifying code rather than names. Audiotapes and corresponding transcripts were coded with a unique code. Only the researcher has access to the codes and participant names, addresses and phone numbers. The job re-entry program and the 
resource centre did not have access to information on who actually agreed to participate in the study. The importance of confidentiality was discussed with the transcriptionist. Only the researcher, the transcriptionist and the thesis committee chair had access to the tapes and the transcripts. The thesis committee only had access to the transcripts. All research materials are locked in filing cabinet drawers and will be kept for seven years. The researcher also recognized the potential to receive information or observe situations that may have legally required disclosure to appropriate authorities. An example is the report of, or observation of child abuse. The participants were informed that the researcher would be obliged to contact the appropriate authority upon disclosure.

An understanding of anonymity is also part of the consent process (Munhall, 1988). Participants were assured that information from the study would be grouped in such a way that it would not be possible to identify the participants. The participants were also informed of the possibility for publication of the findings.

It was important to recognize that ethnographic research can have important consequences for both the participants and others. These consequences may occur as a result of actually doing research or through the publication of findings (Hammersley \& Atkinson, 1995). Hammersley and Atkinson identify that at the very minimum, participating in research may create anxiety or worsen it. Careful consideration of the likely effects on the participants is necessary. The researcher also had an ethical responsibility to provide subjects with information indicating the possibility of experiencing emotional responses to the research activities (Cowles 1988). The women in this study were informed of this possibility during the consent process.

Hammersley and Atkinson (1995) state it has been suggested that research exploits those studied. Some critics have suggested that researchers investigate those who 
are less powerful than themselves to establish a research bargain that advantages the researcher and disadvantages the participants. The issue of exploitation was particularly relevant to this study of low-income women. As Hammersley and Atkinson suggest the costs as well as the benefits are difficult to assess for those involved in research. The concept of exploitation implies a comparison between what is given and what is received and yet most of the benefits, costs, and contributions cannot be measured. Many of the women identified how important it was for their voices to be heard.

\section{Limitations of the Study}

Several limitations to this study have been identified. Limitations were related to the demographic characteristics of the women who participated in the study. None of the women in the study relied on Income Assistance as their sole source of income. The sample can really be described as "working poor". Secondly the lower age limit set for the eligibility criteria might have been too low for some women to consider the concept of midlife. In addition the small number of participants, the limited sources from which the women were recruited and the short time frame during which the study was completed limited the study. Additionally women may not have fully disclosed to the researcher self-care activities such as alcohol or drug use.

\section{Summary}

This chapter outlined the methodology and procedures for carrying out the study on the self-care activities of low-income women in midlife. The study was conducted using a qualitative, focused ethnography from a feminist perspective with a sample of 10 women. Specific information regarding the sampling procedures, the recruitment, setting, and data collection methods were presented. A detailed description of the procedures 
used for data analysis were also provided. Measures to enhance rigor and ethical considerations were discussed. 


\section{Chapter 4}

\section{Findings}

In this chapter the findings that emerged from the analysis of the data are presented. The findings are organized into the five major themes identified in the analysis of the data. Each theme is composed of several categories. The themes and the accompanying categories uncovered are presented using the voices of the women living with a low-income in midlife. Each woman's individual story contributed to the development of the larger view with common categories and themes. Each woman was unique in her situation and circumstances. It is in the exerpts from the women's stories that the individual attributes and experiences are documented.

The past and present circumstances that make up the context of the women's lives are described. The understanding of the context of low-income women's lives at midlife is a critical first step toward developing an understanding of their self-care activities and for the development of approaches to support women in caring for themselves through midlife. Self-care activities were found to be embedded in the context of their lives.

\section{Who Were the Women?}

Ten women talked about the circumstances of their lives, the struggles they encountered in trying to create a better future for themselves and their families, and the self-care activities that they carried out in the context of their lives. In order to protect the identity of the participants, personal circumstances including their occupations, and the gender of their children, were modified to ensure anonymity. Seven of the women were recruited from a job re-entry program, two from a resource centre and one through the snowball sampling method. 
In this section the women are described in terms of their demographic characteristics. The women ranged in age from 40 to 51 with a mean age of 45.6 (Table 4.1).

Table 4.1 Age of Participants

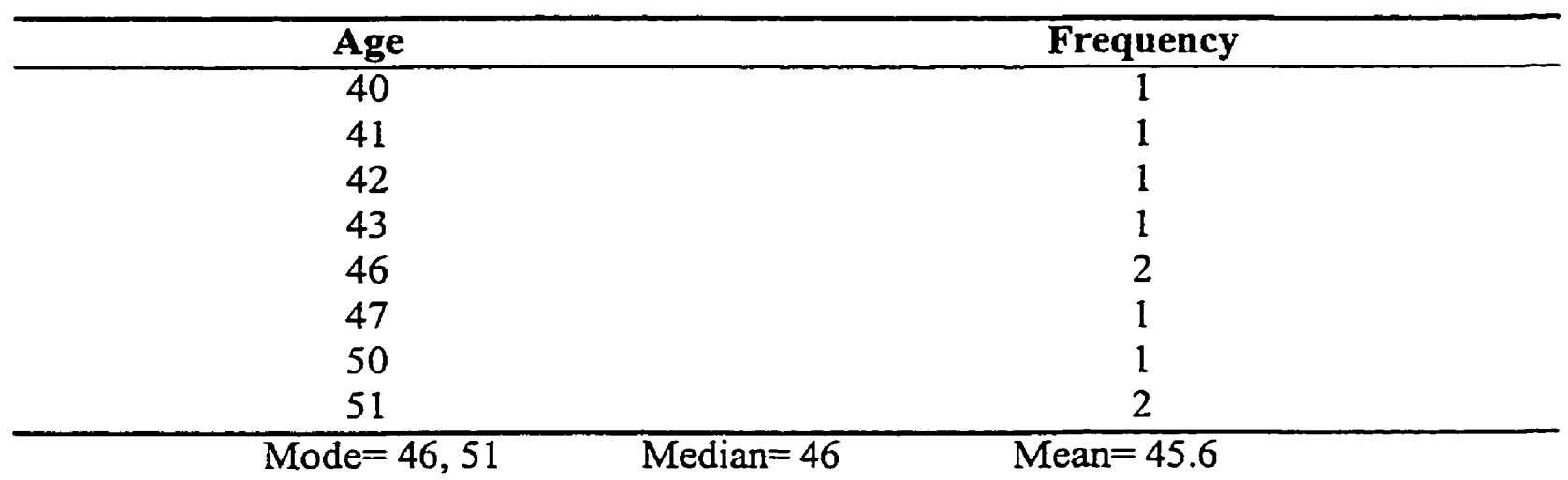

The women had an average of 2.3 children each, ranging from no children to four children. Most of the women had all of their children living with them. Four women had one child of adult age living away from home (Table 4.2).

Table 4.2 Number of Children, Number of Children Living in Home

\begin{tabular}{|c|c|c|}
\hline Number of Children & Number of Children Living in Home & Frequency \\
\hline none & none & 1 \\
\hline 1 & none & 1 \\
\hline 2 & 2 & 1 \\
\hline 2 & I & 1 \\
\hline 3 & 3 & 4 \\
\hline 3 & 2 & 1 \\
\hline 4 & 3 & 1 \\
\hline
\end{tabular}

The mean age of children living in the home with the women was 14.6 years (Table 4.3). One women was a grandmother with her daughter and granddaughter living in a separate dwelling. 
Table 4.3 Age of Children Living in Home

\begin{tabular}{cc}
\hline Age of Child (years.) & Frequency \\
\hline 6 & 1 \\
8 & 1 \\
10 & 3 \\
12 & 2 \\
13 & 2 \\
14 & 2 \\
15 & 2 \\
18 & 1 \\
19 & 1 \\
20 & 1 \\
22 & 1 \\
23 & 1 \\
25 & Median=13.5 \\
Mode $=10 \quad$ Mean=14.6
\end{tabular}

With regard to marital status, three women in the sample were married and living with their husbands. Three women never married, one was childless, and the others single parents. Four women were divorced and lone-parenting one to three children (Table 4.4).

Table 4.4 Marital Status

\begin{tabular}{cc}
\hline Marital Status & Frequency \\
\hline Single never married & 3 \\
Married & 3 \\
Divorced & 4 \\
\hline
\end{tabular}

The levels of education of the women who participated in the study varied. Many of the women had immigrated to Canada and completed educational levels that are not recognized as equivalent in Canada. Table 4.5 illustrates the varying levels ranging from grade nine in Canada, to University level education from another country. 
Table 4.5 Educational Level

\begin{tabular}{cc}
\hline Highest Grade Completed & Frequency \\
\hline Grade 9 (Canada) & 1 \\
Grade 11 (Canada)+ GED & 1 \\
Grade 12 (Canada) & 1 \\
Grade 12 (Canada) + trade & 1 \\
Grade 12 (Canada) = 1 year University \& 1 year college & 1 \\
Grade 9 (Middle East) + trade & 1 \\
Grade 10 (Central America) & 1 \\
Grade 12 (Central America) & 1 \\
Grade 12 (Central America) + trade & 1 \\
University degree (India) & 1 \\
\hline
\end{tabular}

The participants were diverse in terms of their ethnicity. Five $(50 \%)$ of the participants had immigrated to Canada within the last 15 years. Three of the participants were from Central America, one from the Middle East, and another woman was from India. Five (50\%) women were born in Canada and identified themselves as Canadian, French Canadian, English and Swedish (Table 4.6). All of the women spoke English. Two of the women identified their religion as Muslim, and one as Catholic.

\section{Table 4.6 Ethnic Origin}

\begin{tabular}{cc}
\hline Ethnic Origin & Frequency \\
\hline English & 1 \\
Canadian & 2 \\
French Canadian & 1 \\
Swedish & 1 \\
Central American & 3 \\
East Indian & 1 \\
Middle Eastern & 1 \\
\hline
\end{tabular}

Household income levels were difficult to discern. Several of the participants identified that they did not know what their household incomes were, however were able to identify with certainty that their household incomes were below the Statistics Canada Low Income Cut-offs (LICOs), (Appendix A). Three women were unemployed, one of these women lived with her husband who was employed, one was receiving employment 
insurance benefits, and the other insurance benefits. None of the women had full time employment. Five women had part-time employment and two were employed on a casual basis (Table 4.7). Many of the women worked over and above their part-time hours, on occasion bringing the total number of hours to the equivalent of full-time hours.

Table 4.7 Employment Status

\begin{tabular}{cc}
\hline Employment Status & Number of Participants \\
\hline Unemployed & 3 \\
Employed (casual) & 2 \\
Employed (part-time) & 5 \\
\hline
\end{tabular}

The fluctuation in total number of hours worked created uncertainty regarding their incomes. In addition, women received income from a variety of sources such as inheritances, child support, informal community supports, Income Assistance, and insurance benefits. To further confuse the estimation of household income, two of the women had children living with them who were working either part-time with unpredictable incomes, or full time. None of the women relied solely on Income Assistance. Table 4.8 illustrates the multiple sources of income.

Table 4.8 Source of Household Income

\begin{tabular}{lc}
\hline \multicolumn{1}{c}{ Source of Household Income } & Frequency \\
\hline employment only & 1 \\
employment (self + children) and child support & 1 \\
employment (self)+ child support & 1 \\
employment (partner only) + Income Assistance & 1 \\
employment (self and partner) & 1 \\
employment (self and children), Income Assistance \& community support & 1 \\
employment and Income Assistance & 1 \\
Employment Insurance benefits and government pensions & 1 \\
insurance benefits and child support & 1 \\
Employment and inheritance & 1 \\
\hline
\end{tabular}

The LICOs are based on the number of people in the household (Appendix A).

The limitation of using household income with regard to women, however, is the 
assumption that household income is shared. Women in this study did however, identify that household income was shared. Employed children were found to be contributing to household income. In one situation, the children "topped off" the woman's income in order to pay the rent, in another, the children paid room and board to their mother.

The mean number of persons living in the households was 3.6 (table 4.9). Household composition was largely made up of women and their children, women, in some situations husbands and children, and in one, a mother in law.

Table 4.9 Number of People Living in Household

\begin{tabular}{cc}
\hline Number of People Living in Household & Frequency \\
\hline 1 & 2 \\
2 & 1 \\
3 & 2 \\
4 & 2 \\
5 & 2 \\
6 & 1 \\
\hline Mode $=1,3,4,5 \quad$ Median $=4 \quad$ Mean $=3.4$
\end{tabular}

Most of the women who were employed worked in low-paying service sectors, such as restaurants, health care, and in commercial cleaning (Table 4.10). One woman recently completed her general equivalency diploma (GED), three completed certificate programs that prepared them to work in health care such as a health care aide, as a unit clerk and in restaurants as a cook. All of these women were employed largely in the fields in which they took their training, except for one who did not feel confident in her level of skill to work in the occupation for which she was trained. Despite employment, all of the participants were still living with incomes less than the LICOs.

\section{Table 4.10 Occupation}

\begin{tabular}{cc}
\hline Occupation & Frequency \\
\hline Health Care attendant & 2 \\
Cook & 3 \\
Commercial Cleaner & 2 \\
\hline
\end{tabular}


All of the women lived in the south to south central areas a city of approximately 600,000 people. Five of the women lived in public housing complexes, one lived in her own home, and four others lived in rental housing. The public housing complexes in the south parts of the city are located within suburban types of neighbourhoods. Most of the women who were employed, were employed close to where they lived, with the exception of three. They used public transportation to get to work.

Most lived in two story "town house" types of homes. The two women who lived alone, lived in apartments. They had all of the basics, such as furnishings, televisions, many had entertainment systems, and several had older computers that their children used. A few women had obtained either new furniture or more aesthetically pleasing furniture, and were very proud of these acquisitions as they pointed them out to the researcher. All of the immigrant women except one, displayed wall hangings and calendars from their homeland. Most of the homes were organized and orderly.

\section{A Closer Look}

Another way to get a picture of the characteristics of the participants is to look at a composite picture of the circumstances of the lives of these women. One woman, a 46 year old woman immigrated to Canada eight years ago, with her three children as a refugee. After leaving school in grade nine she took a technical training program. She worked until she got married.

The family lived on Income Assistance. Three years ago, she left her husband who was physically abusive. Not being able to speak English, she took English language courses. She can now understand English, but continues to find it difficult to speak and express herself. She lives with her three children, however her two oldest children no longer qualify as dependents for Income Assistance benefits. 
Full of self-doubt, and fear of not being able to manage without fluency in English, she enrolled in a job re-entry program. She had to choose an occupation that did not require too much verbal communication. She trained as a health care aide and passed with $80 \%$. She is currently employed on a casual basis in a nursing home. She feels good about completing the course, and becoming employed but, is disappointed that she is not able to continue to attend classes to learn more English. Her income continues to be supplemented by Income Assistance. Her oldest daughter and son, both studying, and working in fast food outlets on the weekends are helping her out, by buying her clothing and giving her any extra money she needs to cover the rent. She has also had to rely on her church for financial assistance when money has run out. This woman thought things would be different once she became employed, but states that nothing has really changed. She works hard and still does not have enough money to pay to send her children to university so that they can have a better life. ${ }^{1}$

\section{Themes}

Both the data on the sample's characteristics, and the closer look at one woman's circumstances convey the essence of who the women were. Data analyses focused on the uncovering of themes and categories reflective of the situations, and activities of the ten women. Typed transcripts of the interviews were analyzed for recurring codes. Similar codes were grouped into categories, the categories were then grouped into broader themes. The women's voices shaped and illustrate the development of the categories. There were few substantive differences in the categories or themes that emerged between the immigrant, and non-immigrant women, therefore, for the most part, the voices of all

\footnotetext{
'The specific circumstances of this woman's situation were altered to protect her anonymity. The circumstances were altered using actual circumstances from three women in order to depict a situation most closely resembling the actual circumstances of the women in this study.
} 
the women are blended into the category illustrations. Where differences occurred, they are identified. The themes and the accompanying categories uncovered through analysis of the data are presented in Figure 4.1.

\section{Figure 4.1-Presentation of Themes and Categories}

I. Poverty: A Consequence of Circumstance Rather Than a Way of Life

A breach of faith

No education, no skills, and no language

Surviving the early years

II. Working Towards a Better Future

The transition: a struggle in itself

The struggle continues

This is only one place on the journey

III. Self-care: Survival Strategies

I'm it, there is no one else, so I gotta keep going

Escaping it all

Social support, important, but only if I can trust

Focusing on the positive

IV. Midlife, a Stage? Not Really, Just the Continuity of Life

Taking it in stride

Opening doors for my children

Maintaining the family as the foundation

V. It's Connections I Need

Who can I talk to, where do I go?

A sense of community

\section{Poverty: A Consequence of Circumstance Rather Than a Way of Life}

It was the circumstances of the women's lives that either led them into poverty or prevented them from "climbing" out of poverty. The women described a time when they had more money, a time when they did not have to rely on Income Assistance. All of the women had worked at some point in their lives, or were supported by their husbands. 
This theme was present in all of the women's stories. It was readily apparent that poverty was not a way of life for these women. This theme is developed from the following three categories: "a breach of faith"; "no education, no skills, and no language"; and "surviving the early years".

The voices of having skills and abilities were heard in the women's stories. Two women, talked about how satisfied they were with their lives back in their countries of origin. Both women identified that they were employed, and made good money. One, who was an esthetician in her home country, identified that she owned her own shop, and that by the age of 20 she was making more money than her father. She talked a lot about how she had to leave her shop and move to another area of her country because of war. She went on, however to describe how she got other kinds of work and that she was promoted and successful in her work. She described her experience:

F Yea, and then finished esthetician course, I had my own shop. Then we have a war, and I lost those ones and I am working in produce department, it was fruits or what ever you guys call it, it produced fruits. I work myself up to office, I was doing pay stub in the end.

The other three immigrant women worked in skilled types of occupations in Central America, they did not necessarily identify that they made good money, but they did identify that they were employed and that they had particular skills:

E Oh, I worked in the factory...Yes, I worked in a factory. I was like assistant mechanic...

Canadian women also talked about a time when they worked and things were different:

I Was that the first time you were on social assistance or had you been before? 
$\mathrm{H} \quad$ No, no cause I worked, I was 16 when I started working. And ah, I knew nothing else other than working.

\section{A breach of faith.}

A common factor, although not universal that seemed to precipitate women's evolution into poverty was betrayal by their husbands, and the fathers of their children. The men did not live up to their responsibilities with regard to their children, and to the women. The women, for the most part, were left to provide for their families and raise their children on their own. Seven, of the ten women experienced some kind of breach of faith. The men varied in the nature of their breach of faith, some were abusers, some were not providing for their families, some were absent from their children's lives, and others had relationships with other women. Not only were women thrust into being the sole provider for their families, but they were also left to "pick up the pieces" related to the impact of this breach of faith on the children. One of the women who was in an abusive marriage wrote the following poem:

Marriage is just like rose, it needs nurturing and undivided attention, marriage is all about respect, trust and understanding and remember the rose, if you don't take good care of it there's a chance it may die, if you take the time to trim and water the rose you can have a beautiful looking rose, just like a marriage, you have to compromise and be understanding, be true to yourself before you are true to your partner, people think marriage is complicated but it is not, if both partners are willing to do their part, marriage can be a beautiful thing.

Two of the women were physically and emotionally abused by their husbands.

Being an immigrant and not knowing much English, one of the women did not know that help was available to her. It was a neighbor who called the police to report the abuse: 
F That was emotional. Emotional, like, it was abuse situation that is hard. Child Services came and get kids. It took me a long time feel they are not coming back anymore to get the kids. I got a scare because I didn't know, I didn't even know that there is places there they could help you. If I knew, I could go long time ago. I have no idea because like you see on the TV, but you don't actually see people that actually help the other persons...Oh, I did not understand that...Child Services person...she said I have to take the kids right now, you have to decide to go to the husband or someplace else, you're not staying here and the children...I'm not letting the kids out of my sight...Child Services find me shelter...

The women fled for both the safety of their children and for their own safety. However they were then faced with having to provide for their families with few resources. It was only after the women either got a job and were able to support their families or after they had received counselling and began to understand more about their experiences in the marriage, that leaving the abusive relationship became more positive for the women.

Two other women never married any of the fathers of their children. Both gave birth to their children on their own after having separated from their partners. Another participant immigrated to Canada as a refugee and raised her children on her own, without any extended family support, in a country where she didn't know the language, or the culture.

Two women were in arranged marriages, both women described how their unemployed husbands contributed to the circumstances that created poverty for them and their families. These husbands did not live up to their responsibilities to provide for their families or themselves, for that matter. Both women described a feeling of being trapped 
to some extent, and not being free to take the actions they believed were necessary for themselves and their families.

D ...my husband is not working is also problem. Because all the times you, um, so many times I want to change my life but at least then the bottom line that I have children. At least he is at home, he is taking them, so I don't have to, sometimes you don't have choice, you want to change but you can't. It's hard because you are not only one person, you are between the children, and I hate that one, this one that my children would be coming from the broken family, and that's why I don't want to take any steps...

I So, is the lack of work causing the problem with the relationship with your husband?

D Um, yes, sometimes this one, because you don't get the job, it's hard, so it's big problem because when the month is start, the bills is start.

Culturally, this woman indicated that there is little divorce in her country, that most of the marriages stay intact. She talked about how in her culture women are to live with their situations, whether they be good or bad, and her role in working towards solving the problem. She describes these cultural norms as follows:

D ...we strongly believe only one partner cause when you have only one partner you think that's the only my life, no, whatever is the bad and good it's my challenge I have to solve these problems myself.

The other woman's husband, on the other hand, did not want to work, and did not allow the participant to work. For her it was the marriage that thrust her into poverty. 
Leaving the marriage also meant poverty, but she would then be free to do what she felt would be necessary.

F ...my ex didn't let me to go to work...

F ...I told him you know that I am capable of going to work and I like working...

F You know he wasn't working anyway, I was getting emotionally drained because depending on Social Assistance was killing me...

Many of the women were left "holding the bag", in terms of finding a way to support their families. All of the women by necessity relied on Income Assistance, some for the entire time their children were growing up, others until they found alternate sources of income. Few of the fathers provided child support:

G ...you know the maintenance for, for support for the kids, okay, well that's something I never got, but Welfare went after him to get support so ah, for five years he didn't give a dime, nothing whatever, finally um, they took him to court whatever, and he started paying maintenance or support, not maintenance, it was for the kids...

Not only were women left having to cope with finding money to raise their families, but they were left with having to deal with the impact of the marriage on their children. For some of the families the children required counselling to deal with the impact of the marriage. One woman described her children's need for counselling: $\mathrm{H} \quad$..it was when Family Services said that he has no access, ah, no access, no correspondence whatsoever, mail, cards, what, whatever, um, he has to through counselling, she has to go through counseling, the children have to go through counselling together... 
For many of the women it was this breach of faith on behalf of the fathers of their children and their husbands that led them into poverty. The women were left to raise their children on their own, either financially, or as a lone parent, or both.

No education, no skills and no language.

Few of the women had the education or job skills necessary to secure the type of employment that would provide a high enough income to support themselves and their families. In addition many were not fluent enough in English to secure adequate employment. For many of the women the lack of education, the lack of skills and the lack of fluency prevented them from climbing out of poverty.

One of the women was laid off from her job after having worked for fourteen and a half years. With less than a high school education and limited job skills, she was not able to secure employment for six years. She ended up on Income Assistance. During this time she completed her GED and enrolled in a job re-entry program.

Three women left war tom Central America and immigrated to Canada. They left situations that were very dangerous for their families, and came to a country with very different educational standards, job qualifications, language and culture. Like the women who had to leave their marriages, these women had to take drastic steps to ensure the safety of their families and themselves. Without being able to speak the language, and having limited education and skills, these families were forced to rely on Income Assistance. One woman tried to look for work, she ended up doing very menial type work in a grocery store:

B When they helping bagging.

I Oh yes, helping bagging the groceries.

B Yes. I like it there but not too much. 
B I don't know. Maybe I like to study first after, then I find a job, you know, I need to improve my English, I don't know.

Another woman had two university degrees, however could not secure employment largely because she was not fluent in English. The combination of immigration, the lack of education, skills and fluency forced women to live on Income Assistance or survive on incomes from low paying female dominated jobs.

\section{Surviving the early years.}

Many of the women had experienced difficult times at some point earlier in their lives. For some it was experiencing abuse as a child, the death of a parent while still a child, and growing up in households with alcoholic parents. For others, it was the experience of spousal abuse, and for the immigrants it was escaping from countries experiencing armed warfare. One of the women had to cope with a mental health problem that required hospitalization in her young adult years. These early experiences did not necessarily lead women into poverty, but affected their ability to climb out of poverty or make a new life for themselves. One woman recounted her experience as a child, involving abuse, and alcoholism.

H I never had the opportunity, I never had the teenage years.

I what happened?

H ...dad was ah, dad was an alcoholic and very abusive. Ah, I can remember the, the extent, um, it took five police to get him out of the house, that the strength that he had when he, when he was drinking, so looking back at that, the overall fear...I remember dad holding a butcher knife over my brother as I came down, running down the hall going into the bedroom, and he had the butcher knife over, so I guess it's the overall fear that I'm living, um, I still the odd time, ah, ah, and I 
didn't, I didn't realize this, he tried to suffocate my sister and, and stuff so every so often when I still flash back kind of thing, and still but, but I guess it's that shutting down.

The women from Central America did not talk too much about their experiences, one woman did however say the situation was very dangerous:

C I came to Canada because my country is in the war...very difficult for my children.

When the situation is very difficult, my children is stay home for three or four days, no outside...not to the school...the situation is very dangerous.

As can be seen from the data, some of the women experienced a combination of the identified circumstances. It appears that for the women in this study that the breach of faith by a partner; the lack of education and fluency in English; and early years ridden with abuse, neglect and alcohol were elements of their circumstances of poverty. Working Towards a Better Future

Women experienced a variety of transitions, all of which involved a profound process of change both within themselves and in many other aspects of their lives. Working towards a better future was marked by transition for all of the women. Many of the women went to work after long periods of time on Income Assistance. This change involved coming to terms with having to go to work, obtaining training despite the fears of not being able to succeed, and experiencing the increased self-esteem that accompanies success in completing training, education, or securing employment. This increased self esteem led women to continuing to work towards obtaining higher paying, more interesting, and less physically demanding jobs. 
For other women the transition involved coming to terms with their early experiences of abuse so that they could prevent their children from experiencing those effects, as a result of their behaviour. The transition for them was in achieving a greater understanding of their experiences and how those experiences impacted their feelings about themselves and their behaviours toward others.

The transitions were not easy for the women, and even after women made a transition, life continued to be challenging. This theme is developed from the following three categories: "the transition: a struggle in itself"; "the struggle continues"; "this is only one place on the journey".

\section{The transition, a struggle in itself.}

It was not easy for the women to make the transitions. Transitions involved a significant amount of effort to learn English, complete training, obtain a GED, secure employment, and to deal with the impact of early experiences of abuse. In addition to the amount of work and effort required to make the transition, women made transitions in spite of their adverse circumstances. For some women, this was while living in a shelter, while going through a divorce, while trying to support themselves and their children on Income Assistance. For most of the women these transitions were not easy, they involved hard work on the part of the women. One woman described her transition from an abusive marriage, to a shelter, to training and eventually work, emerging with a sense that life had just begun:

F ...I have no experience working. And I went to the school and I prepare my GED but I didn't take the test, because I was thinking my math skills not good enough, and then I went to Job re-entry program, and I went there two months and they ask me if I know what I want and I tell them I know what I want. 
F Yea, um I finish with 96, it was surprising for me because not used to that.

I Yea, so you were surprised that you were successful at the program?

F Yea, I was insecure that I not getting a job because everybody Canadian and they know what they saying, sometime I don't understand what that means, I want somebody to explain it to me.

F I finish the course and start work.

F I told the lady, I'm ready to go out of the shelter okay, they help me to go out. Social Services help me until I finished my course. I told them I don't need them anymore. They were surprised because they said they don't hear people giving up assistance.

F $\quad$...I'm just starting to live.

For another woman who also left an abusive marriage the transition was the gaining of an understanding about her life experiences and the development of a sense of security:

$\mathrm{H} \quad$ Yea, at the time when I left, it took a long time to discover that because when I was alone then it, then it turned not, not being positive, when I had it being positive in Calgary, so when I came here and realizing, and going through the cycle of abuse, and then feeling that my space was being violated all the time, was something where I thought was positive is now negative. So I had to turn all of that around and say no that, that wasn't, that wasn't the way it was...

$\mathrm{H}$ No, before that I, I took ah two ah two years of, of counseling ah and ah I found right now that I feel the safest I have in, in ah all the years that I've been born, yea. So that some things have come out and some things that, that are still, it's an ongoing, it's an ongoing process and, and stuff. 
The women however, experienced a less tangible, but great benefit as a result of the transitions. Women indicated that they felt good about themselves in relation to how they did in their training, and in their ability to become gainfully employed:

G ...I feel like I'm capable of doing anything, and that was a good feeling, and it's through the program I learned that, you know, I didn't, I didn't think, I though, ah, I didn't know what I'm going to do, you know, and I was very, but now I know if I wanted to, I could do this, you know...

Despite the difficulties with the language, the lack of training, and for some, the lack of a permanent place to life, women experienced transitions that affected every aspect of their lives, from getting over the fears of beginning the process, to the increase in self esteem that accompanies success, to becoming self sufficient. These experiences were more than simply making the transition to employment.

\section{The struggle continues.}

Even after making the transition, life continued to be a struggle. The adverse circumstances in the women's lives had not changed all that much, but they did experience a higher degree of self esteem as a result of having successfully completed training, securing employment, or as a result of developing a greater understanding of their earlier experiences. Although women experienced a transition, life continued to be difficult. Life was still not a "bowl of cherries", despite all the effort they had put into making the transition. Incomes remained low, and often had to be supplemented with Income Assistance. Some of the women were disappointed that life did not improve after becoming employed. 
Work was physically demanding, and for some, emotionally demanding. Work involved extensive travel, long hours, repetitive actions and its accompanying injuries, as well as being on their feet all day. For some, work involved maneuvering heavy machinery. There were peak periods in the various employment sectors. For example in health care and the restaurant sectors, summer and Christmas were periods of time when the work was of high intensity, and where the availability of work hours sometimes surpassed the women's ability to work them. Women described the fatigue that accompanied these periods:

C because I am sick for my shoulder. Yea, too much work in the summer. Too much work in the summer, for cutting.

C I like it, It's too hard. Oh ya, it's too hard.

C ...before Christmas, it is crazy, too much, too much..., 9 to 6 or 9 to 5 . Yea, when I coming oh my God, only my daughter she cook, because I don't like, I come very tired, I'm very tired... now I need to relax.

These periods of high intensity of work and availability of hours, of course, was accompanied with periods of low availability of hours for women to work. These fluctuations were also reflected in their paychecks creating unpredictable incomes and sometimes the reliance on other sources of income:

C One month, the assistance, she bring $\$ 2 \ldots$ Yea, sometimes $\$ 100$ he bring me is bring the assistance $\$ 100$ to me, $\$ 200$ sometimes nothing.

C Oh, one day I needed money, for money in my job, yea, they came money is too slow ...the cheque is very down...I need money for pay the house, I need money for the hydro, asking the pastor, I go back with the money, the pastor say no, they help me. 
Most of the women expressed frustration with not having enough income to provide for their children. One woman was discouraged with her continued inability to pay for her children's education despite successfully completing a training program and obtaining employment. She described her frustration:

C I was thinking when I got the new job,...I was thinking that when I get a job, when I finish the course, the situation would be changed.

C But I'm thinking if my daughter keeps going to the university, at sometime I will need the money. My daughter was telling me that when I got the new job...she would like to go to university. To finish computer accounting in the university, so she can get a better job.

One woman described the prejudice and poor treatment she experienced when she began to work, and how that was hurtful to her. She described her experience in the following way:

F I like my boss and the people that I work with. First, take time to get used to it because um, they had some prejudiced people you know, this one, that one. I had thought, okay, either you let them get to you, or you going to be better than they are, I choose better than they are. They told me things sometimes to hurt and after I said, okay, I don't listen to them, now they are friendly to me because they know that I don't take anything serious what they say to me.

The women struggled after the transition in more ways than those related to work and income. Some women were faced with raising their children on their own now. They experienced all the struggles of trying to balance work, children, and home. Another woman, now that she left her marriage, was faced with the pressures of dealing with her 
past, while dealing with her daughter's health issues. The woman described her experience in the following way:

$\mathrm{H} \quad$...with her, like it might be something that, that's okay, that I can act instantly kind of thing but it might be something that's more traumatic to me and bringing a lot of the past. I have to realize that I have to separate those feelings um, and ah, that, that it's nothing that she did, it's just something from my past that triggered and all these different triggers, so I have to balance all this, and try to figure all this out, and separate it and, and then with the ah, I'm on overload, with the asthma and the hyperactivity, then trying to figure out what this is so I said to a girlfriend, I said, by the time I figure out which is normal behaviour, what is the hyperactivity, which is the asthma, and what is compulsive obsessive behaviour, ...and then we'll quit, you know, smack her on the bum cause I don't have time for all of this clutter here kind of thing...

In summary then, women made transitions in the midst of adversity, the transitions were a struggle in themselves, and even after the transition occurred, life continued to be difficult. Women continued to live in poverty despite employment. Employment brought its own difficulties. Women had to find ways to juggle it all.

This is only one place on the joumey.

The women identified that where they were now, particularly with regard to work, was temporary. Many were either on the way to something different, or had plans to get to somewhere different. Some of the women were already actively working towards something different, others had to wait, because of the immediate need to support themselves and their families. The women expressed their present situations in the following ways: 
A Its not bad, but my job is not something I'm going to stick with forever because I'm taking a course.

A I'm half way through my rehabilitation therapist course

A If I didn't take this course I would be in a dull job and have to work at one dull job after another.

A I want to work in long term care.

Some women were not able to actively work on getting someplace different at this time of life because of their responsibilities for their children:

F And I applied for Red River.

I Red River.

F And they told me that can be expensive and but they can give me one subject at a time, but I know myself my spelling not good, and I don't want to waste that much money, because I asked social assistance if they could help me partially, they said no.

I Oh, okay.

F But um I have to put that one aside, concentrate getting kids money, food, you know.

Two other women were also on their way, their destinations however more focused on their personal development, these two women looked toward feeling better about themselves and interacting with others in a more positive manner:

$\mathrm{H} \quad$ I guess with my past I shut down all the time so it was like, you're not going to hurt me, you can do anything you want, you're not going to hurt me, yea, so it was like I needed to get in touch with that inner child that's inside me to bring out the feelings and, and stuff so that, that's been a real biggy for me is, is not trying 
to shut down and not shutting down, recognizing, and try to recognize more and more that that's my pattern, and it's so easy to fall into it and shut down.

Most of the women talked about some self-exploration that they had done to help them decide on their destinations. The women had assessed their strengths and weaknesses and for the most part developed realistic goals for themselves. This was not only true for the women who were recruited from the job-re-entry program, but also from those who were not. The participants had a clear direction of where they wanted to go: I ...so I worked at a, the office work was not for me, I tried that, so I went back into restaurant work again, it was cooking, cleaning and serving the restaurant...

Two of the women identified that they would like to write a book, or poetry, and have it published, both women had already been recognized for their writing. One contributed to a book, through a creative writing course, the other had won an award for her poetry and was recognized by her peers as being skilled at writing poems.

Most of the women had some kind of plan. For many of the women, it was the success that they experienced in the training programs, in getting a job and doing well in a job that gave them the belief in themselves, and the self-esteem needed to dream just a little bit more, and aim for something different, a little better. Women were wanting to continue to work towards a better future.

\section{Self-care: Survival Strategies}

Women were found to be carrying out self-care activities that were directed at assisting them with the ability to carry out their responsibilities, such as going to work. Self-care activities were also directed at managing particular problems and those activities that assist them to manage their emotions within the context of their particular life situations. Women identified that voluntarily looking after themselves was important 
as there was no one else to look after them, or their families. Women saw themselves as the vital $\operatorname{cog}$ in the wheel that kept things going for their families. As a result, they viewed self-care as their responsibility.

The self-care strategies identified by the women were basic kinds of activities they carried out to get through the day. The activities involved such practices as getting enough rest; eating nutritious food; strategies to escape from reality, such focusing on work or spiritual aspects of their lives to get away from thinking about their problems; social support; and focusing on the positive, which for many involved "patting themselves on the back" for a job well done. Only one of the women identified any kinds of self-care activities that were directed at preventing future health problems or at screening for early detection. Self-care activities carried out by the women were embedded in the contexts of their lives, and carried out for the purposes of "keeping things going" on a daily basis. This theme is developed from the following four categories: "I' $m$ it, there is no one else, so I gotta keep going"; "escaping it all"; "social support, important but only if I can trust" and "focusing on the positive".

\section{I'm it, there is no one else, so I gotta keep going.}

This category refers to the sense of responsibility most of the women felt for caring for themselves. It also refers to the self-care activities that were carried out in order to continue to work, and those that were carried out to manage particular problems. These activities, "kept them going"; they enabled women to get to work, and complete a day's work so that they could continue to provide for their families. Other activities were carried out to manage specific problems such as hypertension, or menopausal manifestations. One woman described her sense of responsibility to care for herself in the following way: 
I Okay, so what does caring for yourself mean to you?

A If I don't do it nobody else is going to do it.

Another woman identified that self-care was related to caring for her children, her children were her primary motivation for caring for herself because no one else was available to care for her children:

F If I care for myself, I can care for my family I found out, I can take care of my kids.

I Okay...

F The kids are my motivation, for my kids.

I Okay.

F Because I don't have family here, and I'm not in any relationship at all.

Most women identified basic self-care activities that were needed to carry out their daily responsibilities such as going to work. These self-care activities involved getting enough sleep and eating a healthy diet:

C Working more for the people is healthy, is more easy for them to go to the work.

C Yes its important to go to the bed early because the other day you have more energy.

I Yes. Anything else that you do to keep yourself healthy?

C Um, eat very good.

One of the women had to pay particular attention to her self-care, because of her health condition, she had to ensure that she ate regularly, that she took her medication, and that she didn't get stressed at work. All of this was in an effort to maintain an equilibrium for herself that permitted her to care for her children and to work. She talked 
about a fine balancing act to maintain this equilibrium. She was able to gain support from her boss to take breaks when she needs them. For her, self-care meant the difference between being able to continue functioning and not being able to:

I The medication, it is very important that I eat.

In Okay.

I Even if it's just toast, I have to eat. I find if I don't, I'm physically ill, I get a headache. I always have high blood pressure which means that the medication has to be taken and I have to eat, but I, like if I have a long shift, I will ask to sit down. or I will make time to sit down, cause you get used to the routine at work and ah, these people that go without breaks I can't do that.

In Okay.

I And I think my boss understands, like I told him I'm a manic depressive, and he's had other problems too, but the thing is, he realizes that, and he knows my limits and we work around that.

In addition women carried out a variety of basic self-care measures to manage physical conditions, various discomforts, and symptoms resulting from the physical demands of their work, physical health problems, and menopausal manifestations. These self-care measures did not figure prominently in the women's lives; women tended to take them in stride, they did not place a lot of emphasis on these measures. For some women it was taking medication as prescribed by the doctor to manage high blood pressure "just to keep it there". Some of the women followed exactly what their physicians had recommended, but many of the women adjusted what their physicians recommended to be more in keeping with either their financial realities, or their personal beliefs. One woman did not take medications as prescribed because she did not want to 
medicate herself. Another woman decreased the amount of medication, she was taking to control the cost of the medication, while monitoring her blood pressure in the mall and watching for symptoms:

G She (sister, nurse) also gets angry, like I cut down, every second day, and she says, since when did you become a doctor, you shouldn't be playing around with pills like that, she said that could be very dangerous, and I said I'm aware of that... I'm taking my blood pressure every day at the mall.

G You know, so she says it's okay but you're taking a chance you shouldn't be doing that and then she doesn't like it when I take control over things like that you know, cause she thinks that I'm just, I'm not being careful, to her something could happen, she says then what. Then I say well if I feel bad, then I go, I'd go and see the doctor right away...

G But she, well what would you tell him, that you've cut down without telling him, you know. I hope I never have to.

One of the women was beginning to discover that self-care activities could enhance her medical treatment. In addition to her medication, she came to recognize she needs to calm down, relax, and get control of her breathing in an effort to get more air into her lungs:

$\mathrm{H}$ I'm, I'm realizing that I need to do this, I need to take that control, so that I don't get as sick, and I'm finding it um, harder and harder, it seems each attack or each one seems to be getting harder and harder to, to, so I'm, I'm more aware of that now, what I need to do.

The women were also not big users of natural health products or alternative healing practices. Only two women reported that they took vitamins. One took vitamins 
to enhance her memory, and the other for premenstrual discomforts. One woman voided more frequently in an effort to control incontinence. Another applied a hot water bottle to ease the pain of a repetitive work injury. Two of the women modified their diets in response to symptoms. One was controlling her intake of caffeine, and altering the "timing" of her meals to manage her gastrointestinal symptoms. The other altered the fat content of her diet to control her cholesterol level. Only two women identified that they engaged in self-care to either prevent a problem, or to detect a problem. One woman tried to alter her weight gain through exercise and the other practiced breast self examination.

Women dealt with the discomforts of menopause, or in their words "the change", in a variety of ways. One woman controlled her hot flashes, that were keeping her awake at night by taking showers, exercising, and eating lightly before bed.

Women carried out self-care activities that assisted them to continue with their daily responsibilities such as work. Few of the women were found to be carrying out activities aimed at promoting their health. Self-care for these women was integrated into their lives and was carried out within the context of their daily lives.

\section{Escaping it all.}

"Escaping it all" was a major self-care activity that facilitated a mental retreat from the circumstances of their daily lives. All of the women escaped their situations by engaging in self-care activities that took them away from thinking about their problems. Trying to "escape it all", was the most frequently used self-care activity by these women. One woman used this strategy to escape the demands of work, several women used it to forget about the loneliness they were feeling from being so far away from their families, and still others from the demands of their children. Women engaged in a variety of activities to facilitate the retreat such as religion, aerobics, going to work, sewing, crafts, 
burning candles and laying down, or simply staying at home alone. One of the women described her "escape":

F when I go to work I don't think about what is happening at home, I concentrate on what the residents problems are that way I don't have to think about my problems, just home problems, kind of separating the two.

I So going to work actually makes that separation?

F It's like it's good for me because when I am work, I enjoy the different people.

All of the women identified that the activity that helped them to "escape it all" was effective in helping them to think about something other than their problems and that they felt good afterward. These self-care activities were used to cope with their circumstances and were carried out within the context of their everyday lives.

\section{Social support, important but only if I can trust.}

The second most frequently identified self-care activity was social support. Social support was identified as having someone to talk to, having someone to whom they could go to if they needed help. Women felt it was important in trying to problem solve certain situations, as one of the women put it "...sometimes I need, I have a problem where I don't know, where is the, I don't know where is the exit, or out'. Other's felt that social support was important in validating their experiences. They identified that it was important to know that other women had similar experiences:

E Sometimes I talk with my friend, I have one woman.

I One woman.

E Sometimes I talk with her and when she talk to me and she talk also about her problems. 
I Yes.

E Her problems, and then I think oh no only me I have a problem.

Most women had at least one person with whom they could talk. Social support was more limited for the immigrant women, than for others. Canadian women tended to have more social contacts and particularly, more extended family available. Most women expressed that they would only talk with certain types of people. The ability to trust the other person to maintain confidentiality was identified as essential for effective social support. One of the women described quite succinctly the importance of social support, the limited sociai support available to immigrant women, and the importance of trust:

F It's, like you said, loneliness mostly because, you know, you are by yourself, you have children still not adult and sometimes I talk to them like an adult and they don't like it.

F It is important because you know, like, you have to have somebody around you.

I Yes.

F It doesn't matter if it is a man or a woman, like, you can have like one close relationship than none at all you know, I used to have one friend but it's probably 19 years and she betray me and I don't trust anybody that way anymore.

I Okay, so you've been betrayed in a friendship and now it's hard for you to trust another.

F Cause I treat her as a sister and I used to call her sister because, you know, we both Muslim... but she was Muslim and I was, I always count on her honesty that I gave her.

I Um hum.

F And then I found out that its not, kind of hurt me bad. 
I Um hum.

F But I don't get that close anymore, I don't want to get hurt again. Getting hurt is bad.

I So do you have somebody close now or not really close?

F I have one friend but still I am needing none of that.

I You're still cautious?

F Cautious, because, you don't know, you never know.

I Yes.

F Even to this day, 19 years later, she can do it to me again.

F Because you know, like, you don't have relationship and you don't have family close by, or friendship, or a friendship like I said, woman friend and betray you and you can't trust men.

Another woman, on the other hand, had a lot of social support, she identified the importance of having someone who could listen:

G Oh yes, lots of people. There's some of them that I um, I listen to and they'd be no good to talk to, and there's others I can talk to, you know, so I know the ones that sometimes I've got, I've got problems I want to solve and these people are coming that, oh, they're just good to listen because they don't listen to you for one minute, they're just yap, yap, yap about their lives, you know, and when it like, those people I try to avoid, because really I have enough, I can't take, I can't take on all their problems when I've got all my own and there're not listening, so that's when I kind of avoid those for a little bit, and then I go to the ones that really do listen and I can talk. 
One of the women in an arranged marriage talked about how the extended family is important to those marriages. She described the extended family as acting somewhat as a buffer to the difficulties encountered in marriage. Without family in Winnipeg, she talked to her relatives on the phone, but identified that was not quite the same:

D Because, I think it's worth it because marriages not, um, it's my only feeling that it's not belong with two peoples, it belongs to families, so when it belongs to families, then if something happens between wife and husband, so we ask help sometimes my husband family and the wife's family, so the wise people come together, they solve the problem whatever it's outcome, so it's worth it sometimes because when the families comes they say that you have to do something like this, be something like that, and be sure what are you doing so all and all when you listen, keep listening to your peoples that they say that before you make any decision, keep thinking, keep thinking about that, maybe it's wrong, maybe it's right, give some time, so sometimes it's worth it.

Many of the immigrant women relied on professionals for both support, and as a source of information. Doctors figured prominently, particularly with regard to physical health problems, and menopause. Most of the immigrant women would not talk with anyone other than their physicians regarding menopausal issues, whereas the Canadian born women tended to talk more with other women, and extended family, both about menopausal and other health issues. When asked who they went to for support, many of the immigrant women identified, teachers in their training programs, clergy and counselors. One woman described the help she got in the shelter, and how if she needed help again, she would go back to that counselor: 
F ...all the people I know was his family and I don't think they think they going to help me because I tried a couple of times, they didn't, they was telling me ignore him a few weeks and ah, is going to be okay, its not that way, but the lady she helped me a lot in the shelter.

I Okay, okay and um, so now if you have concerns where would you go for help?

F I can call her again.

Canadian women identified that they went to their friends for support. They also used support groups more than the immigrant women did. As one woman described: G Yea, well I worry about it because um for awhile there I didn't know if I was going to be able to continue my job, with the chest pains I was getting and, you know, when you're washing floors and vacuuming, wow, could I feel it, and I was toughing it through and I thought, you know, if something happens I'm going to be really, I would really be upset that I pushed myself to that point, you know, but then what do you do, so, you know, I talk to my friends about stuff like that, you know, what do you do, what would you girls do, and they say well, don't push yourself and I say well what do, I don't want to go back on social assistance ever, ever.

Few of the immigrant women used support groups. Only one woman described attending a creative writing group for immigrant women. Most of the Canadian women, on the other hand used social support groups to assist them to deal with their concerns, as one of the women described:

$\mathrm{J}$ And the singles support group too, like I told one of the newcomers in that group "we" went through my daughter's teenage years. 
Social support, although limited was used as a self-care activity by all of the women. Trust was identified as a defining attribute of effective social support. In the absence of family, and friends, the immigrant women used professionals for support.

\section{Focusing on the positive.}

Another self-care activity that women identified as effective, was reminding themselves of all the positive aspects of their lives, and having the faith that things will eventually get better, or the ability to stay positive in the face of adversity. Some women gave themselves a "pat on the back" for a job well done:

D Sometimes I feel like that, but whenever I have feelings like that I give to myself time, I say it's okay, you are saying that you, but I give myself, I explain to myself that you have three beautiful childrens, they have very intelligent, three of them very intelligent. My, the daughter, she is 14 and she's class 9 and she's beautiful and very intelligent, she gets the honor roll for session, all teachers like them, when I go there all them that see that in her, all of them so whenever I get that low part I just thank that what I have good things.

Women also tried to make things a little more positive in their lives by treating themselves. Women identified that they bought small things for themselves. They identified that these small things made them feel special. One woman rewarded herself for having worked for one full year with buying herself "sexy clothing". Another went out for breakfast or coffee, even though she couldn't afford it, she identified it as her selfcare, something for her. In a way, these little splurges, like with the managing of their symptoms, and adjusting their medications allow women to take some control over their situations in ways that don't cost very much. They are taking control where they can, in a life with very little control overall. 


\section{Midlife, a Stage? Not Really. Just Part of the Continuity of Life}

Midlife for these women did not appear to be a particular stage of life, different from other periods of life as an adult; but rather women tended to be focused on their work, their children, and their families. These issues are really just part of the continuity of life, everyday life, struggling to support themselves and their families. Women had difficulty talking about midlife. It didn't matter what question was asked, whether it was "what midlife meant to them", or "what their personal needs were at this time of life", women answered with responses about their children, or issues related to work or training. Like their self-care activities, their concerns were largely linked to issues of daily living.

Even the physical changes, including menopause, were "taken in stride", most women identified that they noticed changes, but that they did not necessarily feel any different. All of the women identified that they felt good at this time of life. Women also expressed a sense of satisfaction. This sense of satisfaction was also related to their children and their work.

Immigrant women struggled with the loneliness they experienced, being so far from their extended families. At the same time, immigrant women were struggling to maintain a sense of family as they viewed family. Some of the women were struggling with the differences between North American values and their own cultural values. This theme is developed from the following three categories: "taking it in stride", "opening doors for my children"; and "maintaining the family as the foundation".

\section{Taking it in stride}

Most of the women in this study took the changes associated with menopause, aging and the onset of chronic illness in stride. The changes were not "front and centre" 
in their lives. They were acknowledged and some women engaged in self-care activities to manage them, but they were not identified by the women as most important to them at this time.

In terms of their personal needs at this time of life, women identified that what they needed was more language classes, employment, training, and contact with their extended families. Many of the women viewed this time of life, as a time to start to live, or to prepare for the future in much the same way that younger people feel. As one of the women described:

C Yea, its never older, the peoples is older.

I The people are older.

C Yea, it's okay for prepare.

I Its still okay to prepare and you still have to prepare for the future.

C Yea, because I made more, my idea is in 6 more years, I need more studying.

Both of the women who left abusive marriages identified that midlife was a time to start to live, or that life had just begun. One woman described a feeling of security and safety that permitted her to enjoy a sense of peace. She also talked about how she was reliving her childhood to some extent as she really didn't have an opportunity to be a child when she was growing-up.

$\mathrm{H} \quad$ It's a coming together of just peace, just, just total peace.

H sometimes I'll just sit down and ah, I'll take out a coloring book and I'll color, ah, and this okay and sometimes I'll say to myself, I don't have to stay inside the lines cause it's okay, you know, like silly things like that but it, it, it's basic cause I never had that validation when I was young and I didn't have that time. 
Most of the women felt both physically and psychologically well at this time, despite experiencing some of the physical changes associated with menopause and aging and chronic illness. Their physical changes were not front and center. Their focus again was linked to work:

C Ah, Yea I feeling very, now I feeling good because ah for I feeling good for my life, actually now is strong...

C I don't feel my ages...

C Now I, I don't know, I feeling good for more working in my life... C Yea, I feeling good now.

The focus for the women in this study was "work", not about how to cope with changes related to aging, menopause, "empty nest" or managing chronic illness. Midlife therefore, was really about continuity of life, not specifically related to midlife in any way.

\section{Qpening doors for my children}

This category refers to the women's focus on their children, particularly their focus on helping their children prepare for the future. Education was viewed as a necessary investment for access to jobs and opportunities that would provide a better life for them. Education was valued by all of the women, both the immigrant women and Canadian born women alike. The immigrant women were hoping that their children would go to university and become professionals, whereas Canadian born women, were hoping that their children would complete grade 12. Either way, education was seen as important to secure future employment. Women spoke of "opening doors" for their children: 
D ...I keep explain my three of them you only spend your 10 years, only I'm asking 10 years, you will spend your 10 years in your education and after 10 years you are in that circle wherever you want to go, you go, wherever you want to get the job you can get.

D ...if you are in good education then...how the peoples surround you to make your friend because you are in good status, you used your life wisely. Everyone else has same things, few peoples mostly because lost in the way because no one guide them, no one give the energy, no one give the right choice, no one pried the doors open for them, these the parents who open the doors for their children.

Even as children became adults, women continued to be involved with their children. One woman with adult children still living with her, described her ongoing involvement in parenting them as follows:

G ...my ears are still popping, you know, I'm still hearing things, you know, and I'll comment, very careful but I'll comment and it's just so they become responsible adults, I want them to become responsible adults, you know, it's very nice to say I raised four kids and ah and they leave and they're all irresponsible, can't pay bills and you know.

Women identified that they had to put aside their own goals or desires because of their children. Children's needs took precedence over their own needs. Women continued to see their responsibility as preparing children for the future.

Maintaining the family as the foundation

A sense of "family" was viewed as a strong foundation for both personal and family development. The family was viewed as a system, something greater than the sum of its parts. Personal development was considered to occur within 
the context of the family. Family members were viewed as having an obligation to the collective in one way or another. Members were important in providing physical, financial, emotional, and social support to each other. For many of the women in this study obligation to the collective was the only thing that "kept it all together" for them. It was only by sharing all of the resources, that housing, education, and food could continue to be available for each member of the family. Women were worried about their ability to keep this sense of "family" alive for both themselves and their children.

The significance of the family as a foundation was apparent in all the interviews. The family was a particularly strong focus for the immigrant women in the study. Culture and experience in their own families of origin was discussed as a major influence on both, their personal development, and that of their families.

Life at this time was generally viewed as easier by the participants in terms of household responsibilities. Children were getting older and therefore more able to be responsible for more of the household tasks. All of the women with children described an expectation that children would participate in household responsibilities. Some were already experiencing these benefits, where children were in fact helping out, others were beginning to delegate tasks. Children participated in a variety of household and family responsibilities, ranging from simple household tasks such as laundry, help with meal preparation, cleaning, child care, to financial responsibilities. One woman described how her children contributed to the family and helped to "keep it all together": C They help me and buy my jeans. 
C Yea, my children help me, sometimes it depends how much money I make, my children will give me the difference so I can pay the rent.

I So you make sure that you, together have enough money to pay the rent.

C Together yea.

Not only were children contributing to the current family and household maintenance, but there were plans for everyone to continue to contribute to the family in the future as well. The idea of the children being responsible in some way for their parents in the future however, was only present among the immigrant women. The Canadian born women did not talk about how their children would contribute to their own futures. An immigrant woman talked about the importance of a good education in helping to ensure that she would be looked after in the future:

D Maybe I don't get these results right now, but I hope after 5, 10 years my son and daughter have a nice place, nice house and I probably say, she's doctor...yet she is that and everyone call me and I go and see them. At least my old age is in good hands.

Some of the immigrant women were concerned about the cultural differences in the ways in which families work together in Canada. This was impacting their ability to maintain the cooperation of all for the benefit of the whole. The women recognized that their children are living in Canada and learning the North American value of self-reliance over that of cooperation for the benefit of the family.

Immigrant women experienced loneliness and were actively grieving the loss of their extended families while at the same time recognizing that their children may eventually move away. One woman expressed her situation in the following way: 
C Sometimes I'm thinking when my sons grow up more, I'm thinking, when they marry, they may move to another province for a job or better future. I ask myself if I will be separated from my sons. I know my sons will marry one day. Everybody will be separated and living with their wives and children. This makes me feel sad, my youngest son, for example says he wants to move to Vancouver, ah I feeling sad, if they have to move to Vancouver.

Another woman was actively trying to lay down roots for her family. She recognized that her children were born in Canada and that it would not be possible to take them back to her country. She talked about the importance of having a home that her children could come back to:

I Okay, um, so you mentioned that you're working and trying to get a house, is there any other situations or conditions that you are trying to create for yourself?

F Because when I was married, I was always hoping to go back home but not now, the situation is the kids, the school education, when they grow up here, I realize that I can not go back anymore and I want put a root, only way you can put a root, get a house, you know.

I You want to put some roots here?

F And my kids can say we have a home, we have a home.

The concept of the family as foundation was illustrated in the women's voices, the need to put down roots, the need to invest in their children, and the need to maintain a sense of collective obligation, all speak to a strong foundation for now and the future. 
The women were focused on work, children and family, not midlife per se, but rather the continuity of life.

\section{Its Connections I need}

In this theme, connections refer to connections with other women, other citizens in the community, connections with sources of information, and connections with resources. Women also identified a need for a sense of community, opportunities for people to get together and to mobilize for the benefit of the people who live in neighborhoods. This need for sense of community was heard in the voices of both the immigrant women and the Canadian born women alike. This theme was developed from the following two categories: "who can I talk to, and where do I go", and "a sense of community".

\section{Who can I talk to, and where do I go?}

Women identified several ways to get connected with both professionals and other women for the purposes of being able to carry on caring for themselves and their families. "Who can I talk to" refers to the need identified by the women to be able to talk to someone, about their concerns, to be connected to professionals for information, to be connected with other women to validate their concerns, and recognize that other women were having similar experiences. "Where do I go" refers to women's need to know where to go for health information, to find out about resources, and to get connected to resources. Women identified the need for information and resources to promote self-care. Women were also quite specific about the approach that professionals should take. They suggested a more supportive approach rather than a directive approach, as one woman said, women need to feel as if in a casual and friendly conversation. Others specifically indicated that support groups should be run by the women themselves and that perhaps 
the role of the nurse was simply to bring women together and to support women in caring for themselves.

One woman talked about the need to have a way of finding out about resources that facilitate social support and self-care, such as support groups. She suggested that nurses might assist women to connect with a support group and even provide women with the opportunity to start a support group:

$\mathrm{H}$ To me I'm going like the basic, like I wouldn't look up in the phone book to find something cause I wouldn't even know where to, or what is out there where.

I suggest resources?

$\mathrm{H} \quad$ Suggest resources. like, like talking to somebody.

I Right.

H And, and see if that, if that ah, I, I don't know if, if you could get ah,... or someone to, to maybe meet that person from that group or something somewhere ah, maybe to bring them or, or, I'm not sure or how, how that would be in, in place but ah.

I To provide the support that they need?

$\mathrm{H}$ That's right for them to, to, to move their, yea, to move them on elsewhere or what other resources... maybe it might even start with maybe, or maybe they can even start something in their community if there isn't anything in, in there, like start off with a coffee party, just two women getting together or, or meeting for coffee just to kind of, and then now you're friends kind of thing... Others talked about getting particular types of information with regard to child development or a specific health problem to assist them in managing their own health situations: 
$\mathrm{H}$ And stay healthy, ah, how can I, help me with my, with, with, with my child ah, what is, like a balancing act as far as his food and balancing and, and hyperactivity there's, like where do you go other than that but and that's one thing they said in the very beginning we are there for the child, for the asthma, they're there for the child, okay.

I But you have to cope.

$\mathrm{H} \quad$ But I have to cope, I have to deal, I have to educate myself.

This same woman talked about needing to have resources that would provide her with the education to be able to care for her daughter "close to home" she talked about how difficult it was for her to access resources in another community:

$\mathrm{H} \quad$...for me to get from here to the hospital, have our meeting and get back within a respectable hour and that could be eleven o'clock, it doesn't work and she's kind of in between where she doesn't want a baby-sitter, ... so that's where I'm having a problem is getting to these meetings and to get the support that I feel I need to be able to educate myself to support her and ah kind of thing...

Women were not asking for people to solve their problems necessarily, but rather for connections to other women and professionals for the purposes of information sharing and social support. Women wanted to be connected to women and to resources in their community to care for themselves and their families within the context of their lives.

\section{A sense of community}

Many of the women identified the need for a sense of community. A need to know other people in the neighborhood, to know your neighbors, to get together and just share food or talk about common issues. One woman recalled what it was like in her country of origin: 
F They have like every morning, 10 o'clock ... and my mom backyard and each one have a turn to bring their own cooking and they are doing like that cause nobody have to raise money and they have fun that way.

I Right.

F They have an hour together and everybody go their own house.

I So that's really important for you.

F Everyday routine for them and it's kind of nice.

I Yea, we don't have that here.

F No, no neighbor here.

Two women talked about bringing people together for the purposes of community mobilization. Both women provided examples how community members could come together and work towards something that would be of benefit to the community as a whole. This idea reflects that communities can determine for themselves what their communities need and work towards identified goals. This is self-care at another level, the community level. One woman describes one of her experiences as follows:

G I thought the teenagers were the worst. Lets do something for these teenagers, you know, and I fought, have a basketball court where they can all go play basketball, they have nothing to do. Why do you think they're going by the river and drinking, there's nothing to do but Manitoba Housing took it as the little ones are more important let's put in a little playground.

Women were interested in developing a sense of community, coming together to get to know each other to provide mutual support, as well as to work together around particular issues for the benefit of the community as a whole. 


\section{Summary}

In this chapter the self-care activities of low-income women at midlife were presented. Of prime importance in these findings is the strong linkages between women's needs, and self-care activities in terms of the issues of daily living, children, and work. Women experienced a variety of circumstances with which they had to live with. Some of these circumstances led them into poverty, others prevented them from getting out of poverty.

Poverty was not a way of life for most of these women. All of the women had made, or were currently making a major transition. The process of making the transition was positive as it built up the women's self esteem and their ability to believe in themselves. This increased self-esteem from the transition served to encourage women to continue to build a better future for themselves. Self-care activities were found to be embedded within the contexts of women's lives. 


\section{Chapter 5}

Discussion

Introduction

In this chapter the methodological issues inherent in carrying out the study are discussed, followed by a discussion of the findings as they relate to the empirical literature, and theoretical perspectives in the literature. The researcher's prior preconceptions and interpretations brought to the study are also acknowledged. The final sections of the chapter offers recommendations for practice, education, research and policy.

\section{Methodological Issues}

The issues related to the research design and methodology will be discussed in this section. The qualitative methodology and ethnographic method facilitated the uncovering of self-care activities. Self-care activities were found to be embedded within the context of women's lives. The method permitted the researcher to go beyond the identification of self-care activities to uncover the meaning of these activities within the context of women's lives. As such, the qualitative methodology was appropriate for this study.

The feminist perspective facilitated the development of a relationship with the women that encouraged women to teach the researcher about their cultures, their circumstances, and their lives. Each of the women had unique experiences and stories. The women taught the researcher willingly and freely about how their culture, and personal circumstances impacted their lives. The feminist perspective also permitted the researcher to connect with the women and share common feelings and thoughts. As 
Streubert and Carpenter (1995) identify the objective/positivist ontological position defies the authentic fiber of women and their social interactions.

Women recognized that the information surfacing through their voices and their stories was important, and that their stories had to be shared. Women recognized that they were playing a critical part in raising consciousness about their circumstances. It became readily apparent that the context of women's lives were largely a function of being female. The breach of faith by a partner, the low-paying service jobs, the sole responsibility for children, the lack of educational preparation and skill development, were all at least, in a large part, a factor of being female. The women urged the researcher to publish the findings, for the purposes of raising consciousness about the circumstances of their lives.

The interview guide was derived from Orem's (1995) Model of Self-Care which proved to be limiting in this study. Women had difficulty answering the questions related to self-care. This was in contrast to the literature. Hartweg (1993) also using Orem as a conceptual framework, identified that the women in her study were readily able to answer questions derived from the model on self-care. Her sample was slightly different in that only $35 \%$ were low-income. The women in this study responded with answers about their children or work, reflecting the centrality of those foci in their lives. The questions were not changed, as the answers reflected the focus of their lives, rather than a poorly worded question. The problems with using Orem's model of self-care will be discussed in the next section.

The focus on a baby-boom population, defined in Canada, as those born between 1947 and 1966 (Foot, 1996) did not contribute to the identification of any findings that could be said to specifically apply to this cohort of women. In fact the post World War II 
era as described by Jacobson (1995) was not relevant to many of the women, particularly the immigrant women. Even the Canadian born women in this sample were not found to have experienced the greater career and educational opportunities, later marriage, and the benefits of equal opportunity, as described by Jacobson. In fact, the women in this study were in traditional low paying female dominated occupations. These women did not benefit from reform of the divorce property legislation, affirmative action, or pay equity. The Canadian born women also did not grow up in the child-centered households as described by Jones (1980), but rather in households in which they experienced abuse and the effects of alcoholic parents. The experience of the baby boomer is likely a middle class phenomenon and irrelevant to women living with a low income. Perhaps the only use for the term "baby boomer" is in marketing, where products are designed to target the pocket books of a large cohort of the population.

The study was limited somewhat by the fact that the participants were recruited from only two sources, and the small sample size. The women were either focused on work, or on dealing with the childhood experiences of abuse. This finding may have been related to the fact that women were recruited from a job re-entry program and from a resource centre. Although other studies also found that low-income women were similarly focused (Belle, 1982; Holloway, Fuller, Rambaud, Eggers-Pierola, 1997; Shein, 1995; University of Regina, 1996), it is recommended that future studies recruit lowincome women from the community at large.

In summary, the methodology and method were definite strengths to a study of this nature. Despite some limitations with regard to the use of Orem's Model of Self-Care as a conceptual framework, the limited sample size, and recruitment sources, study 
findings provided a glimpse of the self-care activities and circumstances within which self-care activities are carried out by low-income women in midlife.

\section{Conceptual Frameworks}

This study was guided by two conceptual frameworks, Orem's (1995) Model of Self-care and Bronfenbrenner's (1979) Ecology of Human Development Framework. As mentioned there were limitations to using Orem's Model of Self-care. Orem describes self-care as learned, deliberate and purposeful. As mentioned, many of the self-care activities were not necessarily deliberately carried out by women and therefore not purposeful or goal directed, as such. Women carried out self-care activities that assisted them to carry out the tasks that need to be accomplished on a daily basis, related to their roles of provider and parent. Self-care was not considered by the women in this study to be something that is separate from other activities of everyday life, but rather self-care was integrated into the contexts of their lives.

Orem's (1995) model of self-care was also found to be limiting in a number of other ways. The model mainly addresses biomedical type self-care practices, and as such it fails to recognize the types of self-care practices identified by the women in this study. Another major problem with the model, is that it assumes that people can exert control over their environments; as this study demonstrates women have little control over the environmental and sociocultural factors that affect their lives. In addition its individualistic orientation conflicted with the sense of obligation to the collective, characteristic of the cultures of the immigrant women in this study.

Bronfenbrenner's (1979) Ecology of Human Development framework, on the other hand, proved to be particularly useful in understanding how the interconnections within immediate settings such as the family, home, and workplace influenced the self- 
care activities of the women in the study. This was particularly evident with one of the Islamic women, who was unable to engage in self-care activities to protect herself and her children from abuse. The microsystem of the immediate settings of the family and home prevented her from calling for help because of the lack of a phone, and lack of knowledge about resources. Once the neighbor (mesosystem interconnection), and the police and Child and Family Services became connected (exosystem interconnection), the woman was able to escape to safety. Our societal intolerance for abuse and zero-tolerance policies are examples of macrosystem interconnections.

The macrosystems level was particularly helpful in understanding how the overarching patterns of ideology and the organization of our social institutions affected the women in the study. It is clear for example, that current welfare reforms that focus on getting women off the income assistance rolls does nothing to get them out of poverty, but rather serves to keep them in poverty and dependent to a great extent on the patriarchal institutions and systems in our society (Schein, 1995).

The framework assisted in bringing to the forefront the various factors, individual, historical, cultural, and societal that impinge on women's self-care activities. It is only with this broad understanding, that health care providers can begin to work with lowincome women and their families in ways that are relevant and meaningful to them.

The self-care activities were largely determined by their ecological environment. Bronfenbrenner's (1979) Ecology of Human Development Framework proved to be more useful in understanding the self-care activities of low-income women at midlife than Orem's (1995) Model of Self-care. Self-care activities were found to be integrated and as such women had a difficult time answering some of the questions that were derived from 
Orem's Model of Self-Care. (Appendix H). The model therefore proved limiting as a conceptual framework for the study.

\section{Midlife, a stage? Not Really, Just the Continuity of Life}

The findings of this study led to the question of whether in fact there is such a thing as a stage of midiife. Women in this study viewed this time of life in a variety of ways. Most, however did not seem to relate to the concept of midlife at all, but rather that this was a time to be a good mother, a time to work, and educate their children. The women had difficulty answering questions about midlife without reference to their children or work. This time of life was defined in terms of their children, work and families. Unlike the middle class women in other studies (Dickson, 1994; Dosey \& Dosey, 1980; Jones, 1994), the women in this study were not found to be in the process of coming to terms with midlife or aging. They were not particularly concerned with any of the issues commonly associated with midlife, such as menopause, the launching of children or the "empty nest", aging, or the achievement of particular developmental tasks (Erikson, 1950; Neugarten, 1968). Changes associated with menopause and changes related to aging were acknowledged by the women, however consistent with the findings of other studies (Matthews, Wing, Kuller, Meilahn, \& Kelsey, 1990; Severne, 1982) these concerns were largely taken in stride.

The centrality of work and family was however found to be consistent with the findings of Woods and Mitchell (1997). Woods and Mitchell also found that women linked their goals to family and work roles. They also noted the centrality of work in their lives and that women were still juggling the multiple roles of integrating work and family. The similarity in findings might be related to the fact that the median age of the women ( 41 years) was similar to that of the women in this study ( 45.6 years) and that 
they were from the same cohort of women. The women in the Woods and Mitchell study were born between 1935 and 1955, similar to the cohort of women in this study (19471958). Life for the women in this study was really about supporting themselves and their families, as providers and as parents, issues more related to the continuity of life, rather than midlife in particular. The findings in this study are strikingly similar to the findings of three other studies (Belle, 1982; Holloway et al., 1997; Schein, 1995). These studies were all conducted with younger low-income women. The women in this study were concerned about similar issues to the younger women in the other studies.

\section{Taking it in stride.}

The centrality of work and children in women's lives has been clouded by a number of issues. As identified in the literature review, the research on midlife has largely been conducted in the context of menopause, from the biomedical perspective. Further clouding the issues for women, is that most of the research has been done with clinical populations drawing conclusions and inferences from the experiences of ill women rather than from healthy women (Koeske, 1982; McKinlay, \& McKinlay, 1973; Wilbur, Miller, \& Montgomery, 1995). Within this model, menopause is viewed as a deficiency disease with particular symptoms. As a result a panacea of medical treatments are considered to be the remedy of choice (Jacobson, 1995).

Despite the serious effects of estrogen on women during the 1960s and 1970s (Smith, Prentice, Thompson, \& Herrmann, 1975; Ziel, \& Finkle, 1975), pharmaceutical companies continue to find ways to promote estrogen use by women. By combining estrogen with progestin, pharmaceutical companies have found a way to mitigate the endometrial cancer risk associated with estrogen therapy (Grady et al., 1992). As the body of evidence indicating that the short-term effects of decreased estrogen symptoms 
were not troublesome for the majority of women grew, pharmaceutical companies and medical research shifted their attention to the long term effects of decreased estrogen on the cardiovascular system and the skeletal system (Wilbur et al., 1995). Menopause has been linked with cardiovascular disease, osteoporosis and cancer, all high profile health issues that attract large sums of money with which to conduct research.

Despite the fact that data from long term randomized trials to definitively establish the risk and benefits of hormone replacement therapy are lacking (Butler, 1995), long term estrogen replacement is widely promoted in both the medical and popular literature. In addition, pharmaceutical companies have been promoting estrogen through pamphlets, videos and by hosting public forums. As women between the ages of 40 and 60 become the fastest growing segment of the population, the pharmaceutical companies stand to make huge profits by encouraging women to take estrogen. As Coney (1994) asks, are healthy women becoming a commodity to be exploited for commercial gain?

\section{Qpening doors for my children.}

The findings in this study indicate that women are focused on their children at this time. Preparing children for the future was a central theme for women in this study. The "empty nest" syndrome was not found to be relevant to this study. Only one woman had launched all of her children. She expressed relief in finally being able to work and support herself free from Income Assistance. Consistent with literature, none of the women were found to be grieving the loss of their fertility or grieving the loss of the responsibility for caring for children (Datan, Antonovsky, \& Maos, 1985; Kaufert, 1985).

For most women in this study, midlife was a time to focus on educating children so that their children could get a good job and have a better life. Women viewed education as an investment in their children's future. Holloway et al. (1997) also found 
that women were focused on their children's education. Women viewed education as essential for social mobility. Women in this study and others consistently identified that they wanted a better life for their children (Belle, 1982; Holloway et al., 1997; Schein, 1995).

\section{A developmental stage?}

Midlife has been conceptualized as a time of multiple transitions (Frank (1991). Women in this study were found to be experiencing a variety of transitions. For some women it was a transition to work, transition to a life without abuse, or a transition in terms of gaining an understanding of early life experiences of abuse. The transitions experienced by the women in this study were found not to be any different from the ones being experienced by the younger women in other studies of low-income women (Belle, 1982; Holloway et al. 1997; Nelson, 1997; Schein, 1995). Most of the women were found to be struggling with making the transition from welfare to work, and many were making the transition from an abusive marriage to that of a lone-parent. These transitions were not necessarily associated with midlife, but rather life changes that have been shown to occur throughout the adult years. As Belle, Holloway et al., and Schein, demonstrate in their studies these same changes occur with women as young as 21 years of age.

Cowan (1991) questions whether adult developmental milestones can be described as developmental stages in the same sense as children's movement from one stage to another. He suggests that adult life changes violate most of the defining criteria such as: occurring in an invariant sequence, across all cultures, and that hierarchically integrates rather than replaces previous stages. Likewise Gerber, Wolff, Klores, and Brown, (1989) identify that viewing midlife as a developmental stage where adults are considered to go through defined stages has been found to be inappropriate, particularly 
when applied to the development of women. Cowan (1991) and Bridges (1980), argue that people are in transition most of the time irrespective of developmental stage. Cowan argues that transition is not defined simply by the passing a life marker, such as launching children, but rather as long term processes that results in a qualitative reorganization of both internal life and external behaviour.

\section{The Transition: a struggle in itself.}

Conceptualizing the experiences of these women as those associated with transition, transitions that occur throughout life, is far more consistent with the circumstances of their lives than with the concept of midlife as a particular developmental stage. Cowan's idea about people being in transition a great deal of the time is consistent with the lives as recounted by the women in this study. The idea of midlife being characterized by a time of transition different from other times of life, as mentioned, was not found to fit with the findings of this study. As Lengermann and Niebrugge-Brantley (1994) identify feminist research shows that women's lives have not been characterized as linear courses of action, or as events that occur in invariant sequences as developmentalists suggest, but rather women's lives, as noted by the women's circumstances in this study, have a quality of incidentalism, as women find themselves caught up in agendas that shift and change with husbands' courses of action, children's unpredictable impact on life plans, divorce, and the precariousness of most women's occupations.

The women did not appear to live in a culture of poverty as was described in the literature of the 1960s. Lewis (1966) first coined the term "culture of poverty" (p. xlii). A "culture of poverty" according to Lewis, refers to a way of life that is passed down from generation to generation through the family. It is a way of life that is considered to foster 
unemployment and reliance on Income Assistance. Consistent with the findings in other studies (Holloway et al., 1997; Schein, 1995), none of the women in this study wanted to be on Income Assistance. Poverty was a consequence: of a breach of faith by the father of their children; immigration to a new country without education, and fluency in English; being laid off from a job; and having experienced abuse as a child. The early experiences of abuse did not necessarily "throw" women into poverty, but rather, made it difficult for them to climb out of poverty. As Hall, Sachs, and Rayens (1998) identify, the lack of financial resources, coupled with a lack of social resources, and a history of childhood abuse, places low-income, particularly single mothers at risk for abusive parenting. Domestic violence exacts a severe physical and psychological toll.

The complex circumstances of the women's lives in this study and others (Belle, 1982; Holloway et al., 1997; Schein, 1995) illustrate how hard these women worked to climb out of poverty. Their strong motivations, persistence, and hard work in overcoming adversity was heard through their voices. They could not in any way be described as living in a culture of poverty, but rather as Lengermann and Niebrugge-Brantley (1994) describe a consequence of incidentalism.

As mentioned, the women in this study, as in other studies (Belle, 1982; Holloway et al., 1997; Schein, 1995) were victims of childhood abuse, divorce, of husbands who were not providing for their families, of husbands who abused them and their children, of fathers who abandoned their children and victims of war. They had experienced life changes that required them to make a transition. For some, the transition involved all aspects of their lives from obtaining shelter, to protecting their children, feeding their children, while at the same time having to learn a new language, complete training, and find employment. For others it was having to cope with their childhood experiences of 
abuse. Despite the adversity faced by these women, most of them had successfully made the transition from relying solely on Income Assistance to working for income.

Women were also left to deal with the effects of the father's behaviours on the children. The women in Schein's (1995) study were also found in this position. Very much like some of the women in this study, the women were left to deal with the effects of an absent father, mistreatment of the children requiring explaining, and healing by the mothers, in addition to suddenly becoming the sole caregiver and provider.

As Lengermann and Niebrugge-Brantley (1994) identify, women find themselves not so much pursuing goals in linear sequences, but responding continuously to the needs and demands of others. She asserts that women are not so much oriented to their own goals, as to the tasks of monitoring, coordinating, facilitating, and moderating the wishes, actions, and demands of others. Two of the women in this study were Muslim, their cultures further complicated the breach of faith that they were experiencing from their husbands. In both of these marriages, the men were not providing for their families. Both women struggled with their ethnic and cultural responsibilities, and with what they thought needed be done in the interests of securing income for themselves and their families. Their sense of feeling trapped came through in their voices. Culturally, Meleis (1991) identifies that early in their lives, these women learn that their power is derived from a strong sense of mission. They are committed to raising their children to become productive members of society, to maintain their heritage, and to keeping their families together.

As is demonstrated through the findings of this study, poverty was not a way of life for these women, but rather a consequence of their circumstances. 


\section{The Struggle Continues}

Although women obtained employment, it was largely in the service sector, and in traditionally female types of low-paying work. Similarly Tebbets (1982) and Schein (1995) found that the low income women in their studies also worked in service type jobs, largely factory work, waitressing, kitchen work, housekeeping and as aides in health care. Life continued to be "hard". For some after becoming employed their financial pressures eased, for others it was no different. Most women remained in poverty, and had to continue to rely on Income Assistance to some degree to make ends meet, despite having secured employment. The continued reliance on Income Assistance and the lack of money was disappointing, and some were beginning to wonder if their work was all worth it; even after becoming employed they still could not afford to educate their children so that they could have a better life.

Schein (1995) identifies that simply getting women off the welfare rolls and employed does nothing to address women's poverty. This perspective she asserts, uses cost reduction as a primary indicator of policy or program success. Evaluations of welfare-to-work programs, like that which many of the women in this study had participated in, tend to look more at reductions in welfare payments than the earnings to the participants. Gueron and Pauly (1991) identified in their review of welfare-to-work studies, that "while...welfare-to-work programs modestly improved people's income, they proved unlikely to move people out of poverty" (p.33). In other words, welfare-towork programs do not reduce poverty.

The inability of the women to climb out of poverty, once employed, was consistent with the findings of other studies reported in the literature (Cocoran et al, 1984; Holloway et al, 1997; Schiller, 1973; Schein, 1995). As Cocoran et al. identify 
women's wages are so low that women's full time employment provides no automatic solution to female poverty.

The focus on cost reduction and reducing the number of Income Assistance recipients through employment, has been criticized for its attempts at social engineering and the regulation of women's lives (Schein, 1995). Schein states that some measures seek to keep women in the traditional role of wife, others in low-paying "women's" jobs. Miller (1990) argues that programs that are not successful in helping women achieve financial independence, and simply find women jobs, are solutions to welfare that flow out of a patriarchal society that seeks to perpetuate women's dependence on men or male dominated systems. Schein argues that this narrow perspective of cost and recipient reduction, keeps us on a "merry-go-round" (p. 8) of blaming the Income Assistance systems and the people in them for the continued rise in costs and the number of people receiving benefits. It fails to address the core issues of poverty or the impoverished circumstances of women. She asserts that if we continue to follow this narrow perspective, poor women and their families go nowhere. "They remain in poverty" (Schein, p. 8).

Immigrant women may even be more severely affected as Human Resources Development Canada (1994) in a publication on social security in Canada identified that immigrant women may in fact be subject to "triple discrimination"(p. 132) by being women, immigrants, and often members of racial minority communities.

Working to improve their situations was not easy for any of the women. Women in the Schein (1995) and Holloway et al. (1997) studies also spoke of the tremendous amount of effort and energy it took to get an education and subsequent employment. Holloway et al. describe the women in their study as "pushing hard, despite stark 
financial constraints, to achieve a better life, hold down a job, and care for their children" (p. 11).

Despite the struggles, women emerged from the transitions to either employment, or to a better understanding of their situations, with a greater sense of self esteem and confidence. They identified that they were only in one place along their journeys, that they had aspirations and plans to move on to something else. After going through a process of self exploration, most of the women developed clear directions for the future that were largely realistic for them. They were clearly aware of their interests and strengths. These findings were consistent with the findings in other studies (Belle, 1982, Holloway et al., 1997, O'Leary, 1972, \& Schein, 1995).

Schein (1995) identified that a job re-entry program also did more for the women than simply provide basic resources; the women left aware of a much wider range of possibilities for their lives. Like the women in this study, they were all on a journey of self-discovery and self-development. In the words of Schein, "they found help, understanding, and the support they needed to begin moving themselves and their children out of poverty" (p. 100).

Lengermann and Niebrugge-Brantley, (1994) state that feminist research presents a model of women who are "in their daily lives are responsively located at the center of a web of others' actions and who in the long term find themselves located in one or another of these situations by forces that they can neither predict nor control" (p. 341).

\section{Self-care: Survival Strategies}

The self-care activities uncovered in this study were embedded in women's lives. Women were not found to cognitively determine which self-care activities they would carry out, and which ones they would not. Women were not found to separate self-care 
related activities from other activities of daily living. Self-care activities were carried out largely to get through the day, and survive their circumstances. Self-care activities were embedded in, and carried out as a part of their daily lives. Women were found to value self-care as most had no one else to care for them, and no one else to care for their children, they were it.

Self-care activities were found to be of two main types, those carried out for the purposes of managing particular problems, in other words, problem-focused and those carried out for the purposes of managing emotions, emotion-focused. This delineation between problem-focused and emotion-focused activities is consistent with how behavioural and cognitive efforts to manage external and/or internal demands are described in the coping literature (Lazarus \& Folkman 1984).

Consistent with the findings of the Hartweg (1993) study on self-care activities carried out by midlife women, few self-care activities were carried out to manage physical health problems. Self-care activities were also more directed towards getting through the day than they were at promoting health, or preventing illness and disability. Unlike the women in Hartweg's (1993) study, few of the women obtained annual examinations or participated in screening activities. Other than the women from Central America, and those with a chronic illness, few women identified seeing a doctor. Only one woman reported carrying out breast self examination. One woman actually identified that the doctor could not help her with the types of problems she had.

Many of the women identified changes in their physical appearance. Similar to the women in the Jones (1994) study, women reported graying of hair, skin changes (wrinkles), general sagging, and weight gain. Few of the women reported any self-care measures related to these changes. Only one woman talked about needing to change her 
style of dress, hairstyle and to use make-up to look more youthful, more North American and professional. Her motivation for these changes was largely related to being able to get a job.

Consistent with the findings in this study, Nelson (1997) found that low-income working women gave priority to those practices that "kept them going" (p.204), that enabled them to continue to carry out their work and home responsibilities. Like the women in this study, Nelson identified that eating a healthy diet and getting sufficient rest and sleep were commonly reported. As Nelson hypothesizes, eating a healthy diet may reflect a perceived need to fuel the body, so as to provide the energy needed for work. The self-care activities were integrated into the daily activities of the women in this study. For example, one woman worked hard to maintain the delicate balance between rest and activity, food, and medication. These self-care activities were essential to maintain her mental health so as to be able to continue to work and care for her children.

Also consistent with other studies, the women in this study identified that they felt exhausted after their long arduous days at work (Nelson, 1996; Popay; 1992). As mentioned women identified that their jobs were physically demanding and that they worked long hours, particularly during peak activity periods at work such as at Christmas and during the summer. Women identified that they were too tired to make meals for their children, or to take English language classes during their off hours. The women in this study linked tiredness and exhaustion to their roles as providers. Popay on the other hand, found that the experience of severe or chronic fatigue was linked by women to their experience as housewives and mothers, either alone or in combination with other roles.

There were three self-care behaviours that were found to be used by most of the women, namely, escaping reality, social support and focusing on the positive. These self- 
care activities tend to be more emotion-focused than problem-focused. These emotionfocused activities mediated the women's emotional response to their circumstances. These activities are really the activities that Graham (1987) refers to as no-choice options for people struggling to make ends meet and make the best in difficult circumstances. The activities were all fairly easy for women to engage in within the context of their daily lives, to help them get through the day. For the most part, the behaviours were supportive of health and well being. One woman however, engaged in gambling behaviour as a way of escaping her situation. This is an example of a self-care activity that operates on the one hand to promote a sense of well being, while on the other, threatening financial viability and possibly mental health.

As the women in this study identified, work occupied a central position in the women's lives. Nelson (1996) identifies that work exerted the greatest influence on the health practices of the women in her study.

\section{Escaping it all.}

Trying to escape it all, was the most frequently used self-care activity by these women. One woman used this strategy to escape the demands of work, several women used it to forget about the loneliness they were feeling from being so far away from their extended families, and still others from the demands of their children. This activity served to keep the women's reactions to their circumstances from reaching unbearable proportions. Women engaged in a variety of activities to facilitate the retreat or escape. This self-care activity was consistent with the literature. Hartweg (1993) also identified escapism type activities such as reading and religious and spiritual activities in her study of midlife women. 
Religion and spirituality were identified by several of the women as important. Two of the immigrant women identified that it helped them to forget about their worries and loneliness. Choudhry (1998) identified that the Indian women in her study also used religion as a way to achieve mental peace. The women in her study identified being worry free and having mental peace as being healthy. Spirituality and religion either separately, or together, have been known to provide a framework that is facilitative in helping people to make sense of their world and provide a ready resource for coping with life (Charnes \& Moore, 1992). As a coping strategy, spiritual support may allow for greater well-being and emotional development, which could protect against stress-related diseases that have devastating effects (Levin \& Vanderpool, 1989).

\section{Social support, important, but only if I can trust.}

Like the women in Hartweg's (1993) study, women identified social support as a major self-care activity. It is well known that social support, like other emotion focused activities can modify the impact of chronically stressful conditions on health status (Stewart, 1993). Thoits (1982) identifies that chronic strains that produce stress, interfere with an individual's performance of role-related activities. She identifies that social support may enable the individual to cope more successfully. As mentioned above, women engaged in self-care activities that kept them going, and helped them to get through the day. All of the women talked about the importance of social support, and all of the women had at least one person that they could identify that provided support to them in one form or another. For some women it was a friend, for others it was a family member living in another city, and for still others, it was a teacher in the job re-entry program, a pastor at church, or the counsellor in the women's shelter. Schein (1995) and Belle (1982) also found that women in their studies had a variety of types of social 
support, friends, bosses, teachers, social service counsellors and job training programs. Like this study, they found that some women had more sources of social support than others.

The women identified several key qualities of social support that they felt were important. These qualities were consistent with the dimensions identified by Stewart (1993) namely those of "received support", meaning that women need to feel listened to or feel that the support was helpful, and "perceived support", meaning that one feels reliably connected to others.

Most of the women in this study, identified that in order for social support to be effective it had to be confidential in nature, the person from which social support was to be received had to be trustworthy. They could not just talk to anyone about their concerns. In other words, "perceived support" had to be in place.

The Canadian born women tended to have more informal types of supports, namely, friends, family, and church supports available to them. The immigrant women, on the other hand, had limited sources of social support and tended to rely more on professional types of support. Stewart (1993) identifies bidimensional support over time, as important to prevent unpleasant feelings and dependence. The problem with professional support is that it is usually unidimensional. Stewart asserts that it is the reciprocity in relationships that preserves self-esteem and prevents feelings of inadequacy and lack of control in recipients. The professional types of support are therefore likely to have limited effects in mediating emotional responses. The importance of fostering social support among peers, family members and neighbors is therefore important to consider as health professionals. 
It is not clear why the immigrant women tended to rely more on professional support, particularly the Central American women. Smart and Smart (1994) however identify that Central Americans in particular, turn to family members as opposed to friends or professional help in time of need. It may very well be that in the absence of family members, professionals may seem as the more likely people to trust. Central American women identified that they would only talk to their physicians about menopause. Menopause may in fact continue to be a taboo topic for these women, just as is have been for North American women up until just recently (Sheehy, 1995).

The women identified that the social support from the teachers in the job re-entry program was critical in facilitating their success. The women in this study who were fearful, identified that they were able to gain confidence and the self esteem necessary to seek and maintain employment. For many of the women in both this study and in Schein's (1995), the teachers in the job re-entry programs were found to play pivotal roles in assisting women to develop their roles as providers for their families.

\section{Focusing on the positive.}

Focusing on the positive was another major self-care strategy for the women in the study. Despite the long hours, and arduous work that characterized most of the women's jobs, and the lack of future opportunity with those jobs, the women were, like the women in Schein's (1995) study, generally positive about their current job and about working. Most of the women identified that they frequently reminded themselves how well their children were doing in school, how they were fortunate to have a job, how they were able to raise their children on their own, among other positive aspects of their lives. The women identified this cognitive activity as assisting them to carry on with their roles and activities despite the hardship. Lazarus and Folkman (1984) identify that viewing 
oneself positively can also be regarded as a very important psychological resource for coping.

Self-care activities were found to be much more consistent with studies that included low-income women in their samples, such as Hartweg's (1993) study in which $35 \%$ of the women were low-income and Nelson's (1997) study on health practices and role involvement among low-income working women.

Maintaining the family as the Foundation

The obligation to the collective by every member of the family was what "kept everything together" for the women. With the help of income from working children, women were able to continue to provide shelter, food and education for the children. Holloway et al. (1997) identify that social linkages among kin and close friends offer resources, labor, shared income for millions of low-income and working poor families. The focus on the collective was considered by the women as important to maintain and foster within their families.

Women were worried about their ability to keep this sense of "family" alive for both themselves and their children. Holloway et al. (1997) also found that many of the women in their study pondered the bicultural character of their lives, roles and child-rearing practices. They found that women were concerned with raising their children to be self-reliant, but at the same time were focused on creating a spirit of obligation to the family. The women in this study struggled to maintain a sense of obligation to the family in their children while, at the same time preparing them to succeed in Canadian society that values self-reliance.

Meleis (1991) identifies that for Middle Eastern and Indian women a potential problem arises when children become "Westernized" and therefore become independent 
units and decision makers. That, as Meleis describes, constitutes a significant loss of power base for women that they want to prevent at all costs. The alternative, Meleis identifies, is that the long awaited power and status may be lost forever, adding to that, the North American value of youthfulness that she describes, as relegating aging to antiquity and putting aside aging people to be stripped of all humanitarian respect.

Many of the women worked hard, just as the women in Holloway et al.'s (1997) study did, to accommodate the goals of nurturing individual strengths, and fostering a spirit of collective obligation, to the family. This is not an unusual observation. As Greenfield (1994) identifies, we have discovered that the independent individual is not a universal fact, but a culture specific belief system; there is an important alternative belief system that is held by about $70 \%$ of the world's population, it is called interdependence or collectivism. Greenfield also identifies the importance of ancestral scripts as a major source of continuity in the transition to a new sociocultural environment.

The sense of collective obligation was also present in the Canadian families, but to a much lesser extent than in the immigrant families. Women helped their siblings out, and they themselves were assisted by family members in times of need, but there was no expectation that their children would provide for them in the future, they viewed themselves on their own. For the immigrant women the sense of collective obligation penetrated aspects of everyday life rather than simply in times of need. Greenfield (1994) identifies that to raise children to contribute economically to the whole family, are normal developmental goals in cultures that are oriented to collectivism. Lebra (1994) describes the focus on interdependency, relationality, connectedness, empathy, 
and caring as the feminine character, orientation and identity, versus the focus on separation, independence, individuation and self-creation as the masculine character.

Its Connections I Need

Women identified the need to be connected with both, other women and resources in the community. Women did not identify they wanted people to solve their problems, but rather, resources to care for themselves. By resources women identified information and social support. Resources however were identified as needing to be close to home and accessible to women considering the circumstances of their lives. Similarly Schein (1995) identified a need for a work and community support system, a broad based social support and linking system which include information networks, communal housing, resource sharing, learning links between the women and other members of the community, and a work-family partnership perspective.

Women were also quite specific in the approach they wanted professionals to take. They identified professional roles that are more supportive rather than the traditional directive service type of role. As Stewart (1993) identifies professional roles may need to be redefined to enable help seeking and to enhance relevance to contemporary consumer needs.

Many of the women identified a need for a greater sense of community and the need to mobilize for the benefit of the people who live in their neighborhoods. This need for sense of community was heard in the voices of both the immigrant women and the Canadian born women alike. The approaches women suggested were particularly consistent with the literature on empowerment in the area of health promotion. Lord and 
Farlow (1990) identified that involvement in community life was mentioned by most of the participants in their study, as being key to the growth in their personal empowerment. They further identify, as the women did in this study, that health care professionals should help people to build support from family, social networks and the community.

Bronfenbrenner's (1979) Ecology of Human Development Framework was particularly useful in analyzing how the environment at all levels and particularly at the macrosystem level, affects women's health and their lives in such profound ways as to keep them dependent on those systems. The framework also assisted the researcher to see how those macrosystems operate to affect the health of women through the determinants of health. Women talked about how each of the determinants affected their lives. The women reaffirmed the significance of the following determinants: (1) income and social status, (2) education; (3) employment and working conditions; (4) social support networks; (5) personal health practices and coping skills; and (6) healthy child development (Hamilton \& Bhatti, 1996). The importance of these determinants on their health and well being were clearly articulated by the women.

Expectations Regarding Findings from the Literature

The researcher's expectations regarding the findings of this study, at the outset, were quite different from the actual findings. Based on the literature (Dickson, 1994; Dosey \& Dosey, 1982; Jones, 1994) and current attention on menopause and aging as major issues for women in midlife, the researcher expected the women to talk more about those aspects of midlife and the self-care activities engaged in to manage their effects. Hormone replacement therapy, and alternative therapies were rarely mentioned by the women in this study. Menopause was not a major concern for these women. Few of the 
women experienced physical or psychological changes, in fact many identified that they did not feel any different since tuming forty.

Based on the findings of Dickson (1994), it was expected that the women would talk more about the need to have time for themselves, and for their own personal development. Dickson (1994) found that women viewed midlife as an opportunity to work towards a new and different kind of life. Although women were involved in learning the language, obtaining job skills, and making the transition from income assistance to work, the focus was not on themselves, but rather on supporting their families. In fact women actually talked about putting aside some of their needs in the interests of their children. Contrary to the researcher's expectations and the literature on the "baby boom" generation, the women did not complain about this circumstance of their lives, but rather accepted it, and continued to work towards a better future for their children. Only two studies (Hartweg, 1994; Woods $\hat{\dot{x}}$ Mitchell, 1997) identified women's focus on work, children and family.

The degree to which women's circumstances affected every aspect of their lives was also not anticipated. Although the literature on poverty identified the circumstances which keep women in poverty, it did not in any way describe how women without money, shelter and food struggle to care for their children.

Unlike the women in Jones' (1994) study, the participants were just beginning to experience a stronger sense of self as a result of successfully completing a training program, rather than having developed this sense of self from a life time of progressive success and reaching a peak in one's occupation. The degree to which the women were in a way, just getting started, was not expected. 
Unlike the women in Hartweg's (1993) study, few of the women in this study talked about preventive and early detection activities. Women talked about few health promotion activities. Self-care activities were directed towards getting through the day rather than directed towards any type of goals for the future. Orem's (1995) Model of Self-Care tends to separate out self-care activities from activities of daily living, the degree to which self care was integrated into women's lives was also unexpected.

The researcher was also surprised by the lack of health damaging behaviours identified by the women in this study, none of the women talked about smoking, alcohol or illicit drugs as a coping mechanism. Most of the women engaged in healthy emotion focused types of self-care activities. The significance of the these self-care activities in assisting women to carry out their daily activities was not anticipated.

Lastly, the importance of the contribution to the collective by the children in the immigrant families was not an expected finding. The lack of research on immigrant women at midlife prevented the development of any particular expectation in terms of this finding.

\section{Recommendations for Practice}

The findings of this study demonstrate the importance of taking time to understand the context of women's lives as self-care activities are embedded within their everyday lives. As is evident in both the findings of this study and in the review of the literature, women, particularly low-income women, prioritize self-care activities that assist them in carrying out activities related to work, children and family, the central aspects of their lives. As Nelson (1997) identifies self-care practices that are not considered to be directly relevant to carrying out the activities of daily living are not likely to be practiced. 
In order to assist low-income women with self-care, we must not only learn about the contexts of their lives, but support the self-care activities that they have been carrying out which promote health and are found to be effective. These are the self-care activities that women have been able to successfully integrate into their lives, perhaps all that may be needed is validation of those activities as valuable and health promoting in themselves. As the findings in this study and those of the Hartweg (1993) study demonstrate, women have knowledge of self and many creative and diverse self-care activities that promote their individual well being. As Hartweg suggests, nurses and other health professionals can assist women to develop and enhance those actions that comprise their identified selfcare system. Nelson (1997) concludes that strategies that are effective in motivating higher income women to devote more of their time to engage in health promotion activities will not likely be effective with low-income women.

As demonstrated in this study, it is important to view women within the contexts of their lives and not the biomedical or developmental contexts so often prescribed in professional education. Health care practitioners must get beyond "menopause" and "midlife" to understand the circumstances within which low-income women live.

The immigrant women in the study illustrated the importance of facilitating selfcare that is congruent with their way of being and without imposing our own cultural values. Women need to be supported in maintaining their cultural traditions while at the same time learning to function in North American society. Women, as demonstrated in this study, need some continuity from the past to function in their new environments. It is important that health professionals do not increase women's challenges by viewing their situations through a Western feminist context. Such views, as Meleis (1991) states tends to alienate them further. However as demonstrated by the findings in this study, women 
need to know about the availability of resources, how to access them, and about opportunities to connect with other women in the community.

Efforts to encourage and provide the opportunities for the sharing of information and experiences among women are essential parts of a social support system. Most of the women had limited information as to what opportunities were available to them. Women need networks linking them to each other for information-sharing and support. By sharing ideas and experiences the women also learn to help each other. Opportunities for social support are also important for immigrant women in overcoming isolation and alienation resulting from the loss of their extended family as a source of social support, however further research is required to determine the type of social support that might be culturally relevant and acceptable to various ethnic groups. Group interventions for Central Americans in particular have been supported as effective in the empirical literature (Epsin 1987). Social support networks can also be the start of community organizing for betterment of the community, that some of the women in the study identified as a need.

Nurses need not only to be in communities where women live, but also to be known and visible, so as to be more accessible to the citizens. Nurses however, cannot work with low-income women alone. As Schein (1995) identifies the difficulties and complexities of women's life situations call for a broad and multifaceted view of support needs. Nurses need to work with interdisciplinary and intersectoral teams to support women as mothers, and as providers, and with the balancing these roles require. "If it takes a village to raise a child, then it takes a community of efforts to support the women as they attempt to move themselves and their children out of poverty" (Schein, $1995 \mathrm{p}$. 138). 


\section{Recommendations for Education}

Educational programs at both the undergraduate and graduate levels need to include more information regarding the circumstances that low-income women experience and how they care for themselves within the contexts of their lives. The myths surrounding a culture of poverty need to be ferreted out. Students need to recognize early in their professional careers that stereotypes only serve to alienate the very people that need access to health care. Education needs to focus on how to work with women to effectively care for themselves while meeting the complex demands of work, children and family.

There is a great need for nursing education to address the various cultural differences, particularly as our communities become increasingly diverse. It is important for nurses and health care professionals to learn the importance of listening to a person's story, as it is only by listening to their stories that care can be relevant and appropriate to the context and complexities of their lives. Students need to acquire an ecological view of health, in order to facilitate their understanding of the interconnections between the various ecological levels in women's environments and their impact on their health.

In addition attention needs to be given to developing skills in working with communities to rebuild a sense of community and to begin to build social capital inherent in closely knit communities. Attention must be given to the development of community organization, group process and consultation skills. Modifications to role preparation must include a shift from expert provider to that of consultant, coordinator, and collaborator to facilitate more equal types of relationships with women in the community (Stewart, 1993). Health professionals and social service providers, need to recognize the determinants of health and work at the community level to address these determinants to 
improve the health and well-being of the citizens. Not only does this education need to occur at the undergraduate level, but also in the form of continuing education for practicing health and social service providers.

\section{Recommendations for Research}

Research of this nature needs to be expanded to include the voices of large numbers of women. An expanded study would allow for possible demographic differences within the common themes and categories to emerge. A wider range of selfcare activities might also be uncovered in studies with larger sample sizes. The sample in this study can be largely categorized as "working poor" and was limited by virtue of having been drawn from a job re-entry program and a women's resource centre. A more diverse population of women is required in order to gain a greater understanding of the self-care activities of low-income women. It is suggested that the age range for midlife, include older women. It may be that the women in this study were simply too young to identify with a concept of midlife.

It is recommended that further research in this area use Bronfenbrenner's (1979) Ecology of Human Development Framework as a conceptual framework, rather than Orem's Model of Self-Care. Research questions generated from Bronfenbrenner's framework would be more appropriate to women's experience at midlife, as self-care was found to be integrated into women's lives within their ecological environments.

The issues of poor women and work need more research attention. From a broad perspective, more information on who the low-income women are, what circumstances bring them to poverty, how they live and raise their children is needed. The multiple factors contributing to women's poverty need to be identified. A research methodology such as the one used in this study that illustrates the experiences of the women so directly 
is likely to yield the kind of information that will hopefully help to move the public debate toward eliminating poverty among women and their families rather than decreasing welfare rolls. This approach is more likely to be more meaningful than tables of statistics to illustrate the context of women's lives and the factors that keep them in poverty.

More specifically the impact of job re-entry programs over the long term needs to be identified. It is important to know whether the positive sense of self-esteem and a strong desire to work towards a better future, continues despite the low-paying jobs that these women receive upon entering the labor market. It is also important to know whether the women do in fact stay in these jobs, change jobs for more high paying ones, or simply go back on Income Assistance because the hurdles are just too high to jump.

As demonstrated in the outcomes of this study immigrants are constantly attempting to balance the values of their cultural heritage with those of the new host society. More research is urgently needed to develop an understanding regarding the delicate interactions between the being a woman and an immigrant. We need to learn how women who live between two cultures understand, interpret, and communicate their experiences. Their situations need to be identified from their own perspectives and through their own lived experiences.

Social support needs to be examined with diverse groups of women, as noted in the study some women had greater social support networks than others, and it was the immigrants who did not have as much social support.

\section{Recommendations for Policy}

Research findings such as the one's in this study and others (Belle, 1982; Holloway et al., 1997; Schein, 1995) need to be disseminated to both the public and to 
the bureaucrats that are reforming the welfare system. There needs to be greater awareness of the need to not simply decrease the numbers of women on the welfare rolls but to create conditions and provide supports that are relevant to the unique circumstances and realities of women's lives, not only for young women but for women at midlife. There are few resources to assist women at midlife to climb out of poverty. Policies are needed to mobilize the efforts of a variety of institutions - local, provincial, and federal, governments; for-profit and not-for-profit organizations; educational, social, and religious groups; communities, and families to address the pay inequity, occupational segregation, as well as ethnic, and age discrimination. Policies that promote the creation adequately paying jobs need to be developed, rather than promoting the creation of low-paying service type jobs that are at least partially subsidized by the social welfare system.

Women need more education and training, immigrant women need intensive language training prior to embarking on a training program to facilitate the pursuit of satisfying occupations. Women need support to deal with the early experiences of child abuse, the later experiences of spousal abuse, and the effects of domestic violence on their children. Women also need the abilities to feed, clothe and house themselves and their children as well as access to adequate, flexible child care while they prepare for work and make the transition from Income Assistance to work. The public debate over welfare reform needs to be shifted from that of decreasing welfare costs to that of poverty reduction.

There also needs to be more enforcement of laws that force fathers to be at least financially responsible for their children, if not present for them. Women can no longer be the sole parent responsible for raising and providing for their children. 
Furthering the knowledge development in the area of self-care, midlife and women's health using qualitative methodologies is as important as the biomedical research we have come to know so well. More research dollars need to be made available to researchers looking at the whole of the experience of women. Funding agencies need to further ensure that studies are multidisciplinary. As this study has demonstrated, the biomedical perspective clouds the issues for midlife women within the disease model. More funding also needs to be made available for research projects that are more participatory in nature, projects that involve women themselves in the design, implementation, analysis and dissemination of the findings. Action research is also another research strategy that requires more attention by funding agencies. Conclusion

As the findings of this study demonstrate, it is only by looking closely at the women's lives, through their stories and hearing their voices that the self-care activities of low-income women in midlife emerge. The self-care activities were found to be deeply embedded within the context of their daily lives. The voices of the women revealed their immense personal strengths and capabilities that help them to carry on in the face of adversity. They are women overcoming hardships of poverty to create a better life for themselves and their families. Focused on work, raising their children and maintaining the family as a foundation, they use escapism, social support and reminding themselves of the positive aspects of their lives to carry on. Perseverance and willingness to work hard were among their strengths.

\section{Reflection}

A feminist perspective includes the consideration of the researcher's point of view to be an essential component of the data (Allen, 1994). It is critical that this view be made 
explicit. Just prior to defending my thesis proposal I felt it important to sit down and reflect on my life and think about how it was I got to this particular point in my life. During the reflection, I realized how privileged I was to have grown up in a home with love and support. I grew up in a home that valued higher education. My parents opened all the doors for me, offering to support me in obtaining the highest level of education possible, in any field I chose. As a result, our home was very much child-centered. Home life was organized around school and homework. As a teen and young adult attending college, I was abstained from household chores in the interests of being successful at school. My parents believed that an education, particularly for a female was critical in terms of having choices in life. My mother wanted me to have it all, marriage, children and a career. My parents encouraged every effort to that end. When I graduated from University with my Bachelor's degree and told my father I'd be interested in working on my Masters degree, he told me to feel free to do that and to not let anything stop me, if that was what I chose to do.

I never did forget those words, when the time came, I enrolled, feeling that I had his confidence and support behind me. I frequently remembered those words during times of despair and they helped me to carry on. It was only through this reflection that I came to recognize that it was the love, support and never ending belief that my parents had in me, that were the essential elements of my life that got me to where I was. I also came to realize how really privileged I was, there was nothing in my way. It was then that I truly felt concerned about my how my privileged position would affect my ability to conduct this study. I asked myself, how the women might relate to me, I didn't know if I could truly understand what it was like to live without choices. 
During one of the interviews, one of the immigrant women talked about how her father had always encouraged her to take advantage of the opportunities that were presented to her. She also told me how that helped her to get through her training program and how that was helping her to continue to try to work towards a better life for herself and her children. The strength of her father's influence was evident, in how she worked to support her adult aged children through school on a part-time job paying just above the minimum wage. I connected with her and we talked about how important our father's influence was on our lives. We shed a tear together as neither of us had our fathers close by.

It was the women who talked to me about childhood's ridden with abuse, alcoholic parents, and parents who told them they would never amount to anything, that made me realize that I would never quite understand what that was like. I wondered how they survived thus far, how they carried on without the elements of love, support and someone believing in them. I realized then, that I would really never be able to fully understand.

I tried to be so careful not to exploit the women. I didn't want to just take, as I had very little to offer. I was so grateful for their time, I didn't know if I could have given what these women gave to me. I knew they were busy with work and their families, yet they fit me in. I felt this way before each of the interviews, but by the end always felt a little better about it, as they made me feel that I was able to give a little something to them, some of the women became passionate about telling their story, as they felt it was important for others to know what their lives were like, and for other women it was simply the company that they enjoyed. In reporting the findings of this research I 
acknowledge and own the many preconceptions and prior interpretations that I bring to this study. 


\section{References}

Abplanalp, J.M., Donnelly, A.F., Rose, R..M., \& Livingston-Vaughan, B.S. (1979). Psychoendocrinology of the menstrual cycle: II. The relationship between enjoyment of activities, moods and reproductive hormones. Psychosomatic Medicine, $\underline{41}(8), 605-615$.

Allan, J.D. (1988). Knowing what to weigh: Woman self-care activities related to weight. Advances in Nursing Science, 11 (1), 47-60.

Allen, J. (1994). A biomedical and feminist perspective on women's experiences with weight management. Western Joumal of Nursing Research, 16(5), 524-543.

American College of Physicians. (1992). Guidelines for counseling postmenopausal women for long term hormone replacement therapy. Annals of International Medicine, 117, 1038-1041.

Aamodt, A.M. (1991). Ethnography and epistemology: Generating nursing knowledge. In J.M. Morse (Ed), Qualitative nursing research: A contemporary dialogue (pp. 127-145) (Rev. ed.). Newbury Park: Sage Publications.

Atkinson, P., \& Hammersley, M. (1994). Ethnography and participant observation. In N.K. Denzin \& Y.S. Lincoln (Eds.), Handbook of qualitative research (pp. 248-261). Thousand Oaks, CA: Sage Publications.

Ballinger, C.B. (1975). Psychiatric morbidity and the menopause: Screening of general population sample. British Medical Journal, 3 , 344-346.

Barofsky, I. (1978). Compliance, adherence and the therapeutic alliance: steps in the development of self-care. Social Science and Medicine, 12, 369-376.

Belle, D. (Ed.). (1982). Lives in stress: Women and depression. Beverly Hills, California: Sage. 
Benner P. \& Wrubel, J. (1989). The primacy of caring: Stress and coping in health and illness. Don Mills, Ontario: Addison-Wesley Publishing Company.

Bemhard, L.A., \& Sheppard, L. (1993). Health, symptoms, self-care and dyadic adjustment in menopausal women. JOGNN, 22(5), 456-461.

Bleier, R. (1984). Science and gender: A critique of biology and its theories on women. Willowdale: Pergamon Press.

Bridges, W. (1980). Transitions: Making sense of life's changes. Reading, MA: Addison-Wesley.

Bronfenbrenner, U, (1979). The ecology of human development: Experiments by nature and design. Cambridge: Harvard University Press.

Buck, M.M., \& Gottlieb, L.N. (1991). The meaning of time: Mohawk women at midlife. Health Care for Women International, 12(1), 41-50.

Burnell, B.S. (1990). Images of women: an economic perspective. In M. Paludi \& G.A. Streuernagel, G.A. (Eds.), Eoundations for a feminist restructuring of the academic disciplines (pp. 127-165). New York: The Haworth Press.

Burnard, P. (1991). A method of analyzing interview transcripts in qualitative research. Nurse Education Today, 11, 461-466.

Butler, R.N., (1995). Older women's health: Clinical care in the postmenopausal years. Geriatrics, 50(6), 33-41.

Canadian Menopause Consensus Conference. (1994). Hormone replacement therapy and cancer. Journal SOGC. May, 17-23.

Cauley, J.A., Cummings, S.R., Black, D.M., Mascioli, S.R., Seeley, D.G. (1990). Prevalence and determinants of estrogen replacement therapy in elderly women. American Journal of Obstetrics and Gynaecology, 163(5), 1438-1444. 
Chang, R.J., Plouffe, L., Jr., \& Schaffer, K. (1994). Physiology of the menopause. In J. Lorrain, L. Plouffe, Jr., Speroff, L., Watts, N. (Eds.), Comprehensive management of menopause, New York: Springer-Verlag.

Charnes, L. \& Moore, P. (1992). Meeting patients' spiritual needs: The jewish perspective, Holistic Nursing Practice, 6(3), 64-72.

Chiazze, L. Jr., Brayer, F. T., Macisco, J.J., Jr., Parker, M.P., \& Duffy, B.J. (1968). The length and variability of the human menstrual cycle. Journal of the American Medical Association, 203(6), 89-92.

Chourdhry, U.K. (1998). Health promotion among immigrant women from India living in Canada, Image: Journal of Nursing Scholarship, 30(3), 269-274.

Clark, C.C. (1996). Wellness practitioner: Concepts, research and strategies (2nd ed.). New York: Springer Publishing Company.

Cocoran, M., Duncan, G.J., \& Hill, M.S. (1984). The economic fortunes of women and children: Lessons from the panel study of income dynamics, Signs: Journal of Women and Culture in Society, $10(2), 232-248$.

Coney, S. (1994) The menopause industry Alameda: Hunter House.

Cook, J.A., \& Fonow, M.M. (1986). Knowledge and women's interests: Issues of epistemology and methodology in feminist sociological research, Sociologica! Inquiry. 56(1), 2-29. In J.M. Neilson (Ed.), Feminist research methods: Exemplary readings in the social sciences. (pp. 58-68). Boulder: Westview Press Inc.

Cowan, P.A. (1991). Individual and family life transitions: A proposal for a new definition. In P.A. Cowan, \& M. Hetherington (Eds.), Family Transitions (pp. 3-30). Hillsdale, N.J. Lawrence Erlbaum Associates. publishers. 
Cowles, K. V. (1988). Issues in qualitative research on sensitive topics. Western Journal of Nursing Research, 10(2), 163-179.

Cutler, W.B., \& Garcia, C.R.. (1992). Menopause: A guide for women and the men who love them (Rev., ed.). New York: W.W. Norton \& Company.

Daschiff, C.J. (1992). Self-care capabilities in black girls in anticipation of menarche. Health Care for Women International, 13, 67-76.

Datan, N., Antonovsky, A., \& Maoz, B. (1985). Tradition, modernity and transitions in five Israeli subcultures. In J.K. Brown \& V. Kerns (Eds.), In her prime: A new view of middle aged women (pp. 173-179). South Hadley, Massachusetts: Bergin \& Garvey Publishers, Inc.

Daykin, N. \& Naidoo, J. (1997). Poverty and health promotion in primary health care: Professionals' perspectives. Health and Social Care in the Community, 5(5), 309 317.

Dege, K., \& Gretzinger, J. (1982). Attitudes of families toward menopause. In A.M. Voda, M. Dinnerstein, \& S.R. O'Donnell (Eds.), Changing perspectives on menopause (pp. 60-69). Austin: University of Texas Press.

Denzin, N.K., \& Lincoln, Y.S. (1994). Introduction: Entering the field of qualitative research. In N.K. Denzin \& Y.S. Lincoln (Eds.), Handbook of qualitative research (pp. 1-17). Thousand Oaks, CA: Sage Publications.

Denyes, M.J. (1988). Orem's model used for health promotion: Directions from research. Advances in Nursing Science, 11(1), 13-21.

Derby, C.A., Hume, A.L. Barbour, M.M., McPhillips, J.B., Lasater, T.M., Carleton, R.A. (1993). Correlates of postmenopausal estrogen use and trends through the 
1980s in two southeastern New England communities.American Journal of Epidemiology 137(10), 1125-1135.

Deutsch, H. (1945). The psychology of women (Vol. 2). New York: Grune and Stratton.

Dickson, G.L. (1990). A feminist poststructuralist analysis of the knowledge of menopause. Advances in Nursing Science. 12(3), 15-31

Dickson, G.L. (1994). Fifty-something: A phenomenological study of the experience of menopause. In P.L. Munhall, In Women's Experience (NLN Publication \# 14-2612), (pp. 117-157). New York: National League For Nursing 117-157.

Dobson, S. (1986). Ethnograph: A tool for learning, Nurse Education Today, 6 , 76-79.

Dosey, M.A., \& Dosey, M.F. (1980). The climacteric woman.Patient Counseling, 2. 14-21.

DuBois, E. C., Kelly, G.P., Kennedy, E. L., Korsmeyer, C.W., \& Robinson, L. S. (1985). Feminist scholarship: Kindling in the groves of academe. Chicago: University of Illinois Press.

Duffy, M.E. (1984). A critique of research: A feminist perspective. Health Care for Women International, $6,341-352$.

Egeland, G.M., Mathews, K.A., Kuller, L.H., \& Kelsey, S.F. (1988).

Characteristics of noncontraceptive hormone users. Preventive Medicine, 17, 403-411.

Ehrenreich, B., \& English, D. (1973). Witches, midwives and nurses. New York: Feminist Press. 
Espin, O. M. (1987). Psychological impact of migration of Latinas: Implications for psychotherapeutic practice, Psychology of Women Quarterly. 11, 489-503.

Erikson, E.H. (1963). Childhood and society (2nd. ed.). New York: W.W. Norton \& Company.

Ernster, V.L., \& Petrakis, N.J. (1981). Effect of hormonal events in earlier life and socioeconomic status on age at menopause. American Journal of Obstetrics and Gynecology, 140, 471-472.

Estok, P.J., \& O'Toole, R. (1991). The meanings of menopause. Health Care for Women International 12(1), 27-39.

Faludi, S. (1991). Backlash: The undeclared war against American women. New York: Crown Publishers, Inc.

Ferguson, K.J., Hoegh, C., Johnson, S. (1989). Estrogen replacement therapy a survey of women's knowledge and attitudes. Archives of Internal Medicine. 149, 133136.

Fetterman, D. (1989). Ethnography step by step. Newbury Park: Sage Publications.

Flint, M. (1975). The menopause: Reward or punishment? Psychosomatics, 16 , 161-163.

Flint, M. (1976). Cross-cultural factors that affect age of menopause. In P.A. van Keep, R.B. Greenblatt, \& M. Albeaux-Fermet (Eds.), Consensus on menopause research (pp. 73-83). Baltimore: University Park Press.

Foot, D.K. (1996). Boom bust and echo: How to profit from the coming demographic shift. Toronto: Macfarlane Walter \& Ross. 
Frank, M.E. (1991). Transition into midlife, NAACOG's Clinical Issues in Pernatal and Womens's Health Nursing. 2, 421-428.

Frommer, D.J. (1964). Changing age of the menopause. British Medical Journal. $\underline{2}, 349-351$.

Gath, D., Osborn, M., Bungay, G., Iles., S., Day, A., Bond, A., \& Passingham, C. (1987). Psychiatric disorder and gynaecological symptoms in middle aged women: A community survey. British Medical Journal, 294, 213-218.

Gerber, J., Wolff, J., Klores, W., \& Brown, G. (1989). Lifetrends: The future of baby boomers and other aging Americans. New York: The Stonesongs Press Incorporated.

Germain, C. (1993). Ethnography: The method. In P. Munhall \& C. Boyd (Eds.), Nursing research: A qualitative perspective (pp. 237-267). New York: National League for Nursing Press.

Gilligan, C. (1982). In a different voice: Psychological theory and women's development. Cambridge: Harvard University Press.

Glossop, R.G. (1988). Bronfenbrenner's ecology of human development: A reappreciation. In A.R. Pence (Ed.), Ecological research with children and families: From concepts to methodology. New York: Teachers College Press.

Goffman, E., (1963). Behaviour in public places. New York: The Free Press of Glencoe.

Golub, S. (1992). Periods: From menarche to menopause, Newbury Park, Ca: Sage. 
Goodman, M.J., Grove, J.S., \& Gilbert, F., Jr. (1978). Age at menopause in relation to reproductive history in Japanese, Caucasian, Chinese, and Hawaiian women living in Hawaii. Journal of Gerontology, 33, 688-694.

Gordon, T., Kannel, W.B., Hjortland, M.C., \& McNamara, P.M. (1978). Menopause and coronary heart disease: The Framingham study. Annals of Internal Medicine, 89(2), 157-161.

Grady, D., \& Rubin, S.M. (1993). The postmenopausal estrogenlbreast cancer controversy. Journal of the American Medical Association, 268(8), 990-991.

Grady, D., Rubin, S.M., Petitti, D.B., Fox, C.S., Black, D., Ettinger, B., Ernster, V.L., \& Cummings, S.R. (1992). Hormone therapy to prevent disease and prolong life in postmenopausal women. Annals of Internal Medicine, 117(12), 1016-1037.

Graham, H. (1989). Women and smoking in the United Kingdom: The implications for health promotion. Health Promotion, 3 371-382.

Greenfied, P.M. (1994). Independence and Interdependence as developmental scripts: Implications for theory, research, and practice. In P.M. Greenfield, \& R.R.Cocking, (Eds.), Cross-cultural roots of minority development (pp. 1-37). Hillsdale, N.J.: Lawrence Erlbaum Associates.

Gueron, J.M., \& Pauly, E. (1991). From welfare to work. New York: Russell Sage Foundation.

Gunter, L. (1992). Notes on a theoretical framework for nursing research. In L.H. Nicoll (Ed.). Perspectives on nursing theory (2nd ed., pp. 5-12). New York: J.B. Lippincott Company. 
Guttman, D. (1985). Beyond nuture: Developmental perpectives on the vital older woman. In J.K. Brown \& V. Kerns (Eds.), In her prime: A new view of middle aged women (pp. 198-211).

Hagen, L., O'Neill, M., \& Dallaire, C. (1995). Linking health promotion and communityhealth nursing: Conceptual and practical issues. In M.J. Stewart (ed.), Community nursing: Promoting canadians' health (pp. 413- 429). Toronto: W.B. Saunders of Canada.

Hall, L.A., Sachs, B., \& Rayens, M.K. (1998). Mothers' potential for child abuse: The roles of childhood abuse and social resources, Nursing Research, 47(2), 87-95.

Hamilton, N. \& Bhatti, T. (1996). Population heath promotion: An integrated model of population health and health promotion. Ottawa: Health Promotion Development Branch, Health Canada.

Hammersley, M., \& Atkinson, P. (1995). Ethnography: Principles in practice (2nd ed.). New York: Routledge.

Harding, S. (1987). Introduction: Is there a feminist method? In S. Harding (Ed.), Feminism and methodology (pp. 1-14). Bloomington, Indiana: Indiana University Press.

Harris, R.B., Laws, A., Reddy, V.M., King, A., Haskell, W.L. (1990). Are women using postmenopausal estrogens? A community survey. American Journal of Public Health. $80(10), 1266-1268)$.

Hartley, L.A. (1988). Congruence between teaching and learning self-care: A pilot study. Nursing Science Quarterly, 1(4), 161-167.

Hartweg, D.L. (1990). Health promotion self-care within Orem's general theory of nursing. Journal of Advanced Nursing $15,35-41$. 
Hartweg, D.L. (1993). Self-care actions of healthy middle-aged women to promote well being, Nursing Research, 42(4), 221-227.

Hautman, M.A. (1996). Changing womanhood: Perimenopause among FilipinaAmericans. JOGNN, 25(8), 667-672.

Health and Welfare Canada. (1990). The active health report on women. Ottawa: Author.

Hemminki, E., Malin, M., Topo, P. (1993). Selection of menopausal therapy by women's characteristics. Journal of Clinical Epidemiology, 46(3), 211-219.

Hill, J. (1982). Smoking, alcohol and body mass relationships to early menopause: Implications for risk of cardiovascular disease. In A.M. Voda, M. Dinnerstein, \& S.R. O'Donnell (Eds.), Changing perspectives on menopause (pp. 160 169). Austin: Universty of Texas Press.

Hill, L. \& Smith, N. (1990). Self-care nursing: promotion of health (2nd. ed.). Norwalk: Appleton \& Lange.

Holloway, S.D., Fuller, B., Rambaud, M.F., \& Eggers-Pierola, C. (1997).

Through my own eyes: Single mothers and the cultures of poverty. Cambridge: Harvard University Press.

Human Resources Development Canada. (1994). Social security in Canada: Background facts (CS-001-1-94). Hull: Author.

Jackson, B.B., Taylor, J., \& Pyngolil, M. (1991). How are conditions the relationship between climacteric status and health symptoms in African American women. Research in Nursing \& Health, 14, 1-9. 
Jacobson, J.M. (1995). Midlife women: Contemporary Issues. Boston: Jones and Bartlett Publishers.

Jick, H., Porter, J., \& Morrison, A.S. (1977). Relation between smoking and age of natural menopause. Lancet 1354-1355.

Jirovec, M.M., \& Kasno, J. (1993). Predictors of self-care abilities among the institutionalized elderly. Western Joumal of Nursing Research, 15, 314-323.

Jones, J. (1994). Embodied meaning: Menopause and the change of life. Women's Health and Social Work: Feminist Perspectives, 19(3/4), 43-65.

Jones, L.Y. (1980). Great expectations. New York: Coward, McCann \& Georghegan.

Kaufert, P. A. (1985). Midlife in the midwest: Canadian women in Manitoba. In J.K. Brown \& V. Kerns (Eds.), In her prime: A new view of middle aged women (pp. 181-197). South Hadley, Massachusetts: Bergin \& Garvey Publishers, Inఢ̣.

Kaufert, P., \& Syrotuik, J. (1981). Symptom reporting at the menopause. Social Science and Medicine, 15E, 173-184.

Kennedy, D., Baum, C., \& Forbes, M. (1985). Noncontraceptive estrogens and progestins: Use patterns over time. Obstetrics and Gynecology, 65(3), 441-446.

Koch, T. \& Webb, C. (1996). The biomedical construction of aging: implications for nursing care of older people. Journal of Advanced Nursing, 23, 954-959.

Koeske, R.D. (1982). Toward a biosocial paradigm for menopause research. Lessons and contributions from the behavioural sciences. In A.M. Voda, M. Dinnerstein, 
\& S.R. O'Donnell (Eds.). Changing perspectives on menopause (pp. 3-23). Austin: Universty of Texas Press.

Kubricht, D. (1984). Therapeutic self-care demands expressed by outpatients receiving external radiation therapy. Cancer Nursing . 7 43-52.

Ladner, J.A. (1987). Introduction to tomorrow's tomorrow: The black woman. In S. Harding (Ed.), Feminism and methodology (pp. 74-83). Bloomington: Indiana University Press.

Lazarus, R.S., \& Folkman, S. (1984). Stress, appraisal and coping. New York: Springer Publishing Company.

Lebra, T.S. (1994). Mother and child in Japanese socialization: A Japan-U.S. comparison. In P.M. Greenfield, \& R.R.Cocking, (Eds.), Cross-cultural roots of minority development (pp. 259-274). Hillsdale, N.J.: Lawrence Erlbaum Associates.

Lee, K, H. (1997). Korean urban women's experience of menopause: New Life. Health Care for Women International, 18, 139-148.

Lengermann, P.M., \& Niebrugge-Brantley, J. (1994). Contemporary feminist theory. In G. Ritzer (Ed.), Modem sociological theory (4th ed., pp. 229-350.). New York: McGraw-Hill, Inc.

Levin, J., \& Vanderpool, H. (1989). Is religion therapeutically significant for hypertension? Social Science and Medicine, 29, 69-78.

Levin, L.S., Katz, A., \& Holst, E. (1979). Self-care: Lay initiatives in health. London: Croom Helm.

Lewis, O. (1966). La vida: A Puerto Rican family in the culture of poverty - San Juan and New York. New York: Vintage Books. 
Lincoln, Y.S., \& Guba, E.G. (1985).Naturalistic Inquiry, Beverly Hills: Sage Publications.

Lipson, J.G., \& Steiger, N.J. (1996). Self-care nursing in a multicultural context. Thousand Oaks, CA: Sage Publications.

Lord, J., \& Farlow, D.M. (1990). A study of personal empowerment: Implications for health promotion, Health Promotion, 29(2), 2-8.

MacPherson, K.I. (1987). Menopause as disease: The social construction of a metaphor. Advances in Nursing Science, 3(2), 95-113.

MacPherson, K.I. (1981). Osteoporosis: The new flaw in woman or in science? Health Values. 11(4), 57-62.

Malveaux, J. (1993). Race, poverty, and women's aging. In J. Allen \& A. Pifer, (Eds.), Women on the front lines: Meeting the challenge of an aging America (pp. 167179) Washington: The Urban Institute Press.

Mansfield, P.K. \& Jorgensen, C.M. (1992). Menstrual pattern changes in middleaged women. In A. Dan \& L.L. Lewis (Eds.), Menstrual health in women's lives (pp. 213-225). Urbana: University of Illinois Press.

Mansfield, P.K., Jorgensen, C.M., \& Yu, L. (1989). The menopausal transition: guidelines for researchers. Health Education, 20(6), 44-49, 56.

Mansfield, P.K., \& Voda, A.M. (1997). Woman-centered information on menopause for health care providers: Findings from the midlife women's health survey. Health Care for Women International, 18, 55-72. 
Marmot, M.G. Rose, G., Shipley, M., \& Hamilton, P.J.S. (1978) Employment grade and coronary heart disease in British civil servants. Journal of Epidemiology and Community Health, 32, 244-249.

Marmot, M.G., Shipley, M.J., \& Rose, G. (1984). Inequalities in death: Specific explanations of a general pattern? The Lancet, 1, 1003-1006.

Marmot, M.G. Smith, G.D., Stansfeld, S., Patel, C., North, F., Head, J., White, I., Brunner, E., \& Feeney, A. (1991) Health inequalities among British civil servants: The whitehall II study. The Lancet, 337, 1387-1393.

Matthews, K.A., Wing, R.R., Kuller, L.H., Meilahn, E. N., Kelsey, S.F., Costello, E.J., \& Caggiula, A.W. (1990). Influences of natural menopause on psychological characteristics and symptoms of middle-aged healthy women. Journal of Consulting and Clinical Psychology, 58(3), 345-341.

McCrea, F.B. (1983). The politics of menopause: The "discovery" of a deficiency disease. Social Problems, 31, 111-123.

McElmurry, B.J., \& Huddleston, D.S. (1991). Self-care and menopause: Critical review of research. Health Care for Women International, 12(1), 15-26.

McKinlay, S.M., Bifano, N.L., \& McKinlay, J.B. (1985). Smoking and age at menopause in women. Annals of Internal Medicine, 103(3), 350-356.

McKinlay, S.M., \& McKinlay, J.B. (1973). Selected studies of the menopause. Journal of Biosocial Science, 5, 533-555.

McKinlay, J.B., \& McKinlay, S.M., \& Brambilla, D.J. (1987). Health status and utilization behaviour associated with menopause. American Joumal of Epidemiology $125,110-121$. 
Mechanic, D. (1978). Medical sociology (2nd ed.). New York: The Free Press.

Meldrum, D.R. (1983). Perimenopausal menstrual problems. Clinical Obstetrics and Gynecology, 26(3), 762-768.

Meleis, A.I. (1991). Between two cultures: Identity, roles and health. Health Care for Women International, 12, 365-377.

Melnyk, K.A.M. (1983). The process of theory analysis: An examination of the nursing theory of Dorothea E. Orem. Nursing Research, 32(3), 170-174.

Miller, D.C. (1990). Women and social welfare: A feminist analysis. New York: Praeger.

Morse, J.M. (1991). Strategies for sampling. In J.M. Morse (Ed), Qualitative nursing research: A contemporary dialogue (pp. 127-145) (Rev. ed.). Newbury Park: Sage Publications.

Morse, J.M., \& Field, P.A. (1995). Qualitative research methods for health professionals (2nd ed.). Thousand Oaks, CA: Sage Publications.

Munhall, P.L. (1988). Ethical considerations in qualitative research. Western Journal of Nursing Research, 10(2), 150-162.

Naisbitt, J. (1984). Megatrends. New York: Warner Books Incorporated.

National Council on Welfare. (1990). Women and poverty revisited (Catalogue No. H68-25/1990E). Ottawa: Minister of Supply and Services Canada.

National Council on Welfare. (1998a). Poverty profiles 1996 (Catalogue No. H67-1/4-1996E). Ottawa: Minister of Public Works and Government Service Canada. 
National Council on Welfare. (1998b). Profiles of welfare: Myths and realities (Catalogue No. H58-44/1998E). Ottawa: Minister of Public Works and Government Service Canada.

Nelson, M.A. (1997). Health practices and role involvement among low-income working women. Health Care for Women International, 18, 195-205.

Neugarten, B. (1968). Middle age and aging. Chicago: University of Chicago Press.

Nightingale, F. (1860) Notes on nursing: what it is and what it is not (unabridged 1969 republication of the 1st American edition as published in 1860 by D. Appleton \& Co.). New York: Dover.

Nilas, L. \& Christiansen, C. (1987). Bone mass and its relationship to age and menopause status. Journal of Clinical Endocrinology and Metabolism, 65(4), 697-702.

Nordin, C., Need, A.G., Catterton, B.E., Horowitz, M., \& Morris, H.A. (1990). The relative contributions of age and years since menopause to postmenopause bone loss. Journal of Clinical Endocrinology and Metabolism, 70(1), 83-88.

Oakley, A. (1981). Interviewing women: A contradiction in terms. In H. Roberts (Ed.), Doing Feminist Research (pp. 30-61). London: Routledge and Kegan Paul.

Oakley, A. (1989). Women's studies in British sociology: To end at our beginning? British Joumal of Sociology $40(3), 442-470$.

O'Leary, V. (1972). The hawthome effect in reverse: Trainee orientation for the hard-core unemployed woman. Journal of Applied Psychology, 56(6), 491-94.

Orem, D. (1995). Nursing: Concepts of practice (3rd ed.). New York: McGrawHill. 
Padonu, G., Homes-Rovner, M., Rothert, M., Schmitt, N., Kroll, J. Rovner, D. Talarczyk, G., Breer, L., Ransom, S., \& Gladney, E. (1996). African-American women's perception of menopause. American Journal of Health Behavior, 20(4), 242-251.

Patton, M.Q. (1990). Qualitative evaluation and research methods (2nd. ed.). Newbury Park: Sage Publications.

Pender, N.J. (1996). Health promotion in nursing practice (3rd ed.). Toronto: Appleton \& Lange.

Perlmutter, E., \& Bart, P. (1982). Changing views of "the change": A critical review and suggestions for an attributional approach. In A.M. Voda, M. Dinnerstein, \& S.R. O'Donnell (Eds.), Changing perspectives on menopause (pp. 187-199). Austin: Universty of Texas Press.

Polit. D.F. \& Hungler, B.P. (1995). Nursing research: Principles and methods (5th ed.). Philadelphia: J.B. Lippincott Company.

Popay, J. (1992). My health is all right, but I'm just tired all the time: Women's experinece of ill health. In H. Roberts (Ed.), Women's Health Matters (pp. 99-120). London: Routledge

Popay, J., Bartley, M. \& Owen, C. (1993). Gender inequalities in health: Social position, affective disorders and minor physical Morbidity. Social Science and Medicine, $36(1), 21-32$.

Postmenopausal Estrogen/Progestin Interventions Writing Group. (1995). Effects of estrogen or estrogen/progestin regimens on heart disease risk factors in postmenopausal women. Joumal of the American Medical Association, 273(3), 199-208. 
Presser, H.B. (1974). Temporal data relating to the human menstrual cycle. In M. Ferin, F. Halberg, R.M. Richart, \& R. Vande Wiele (Eds.), Biorhythms and human reproduction (pp. 145-160). Toronto: John Wiley \& Sons Incorporated.

Rachlis, M., \& Kushner, C. (1994). Strong medicine: How to save Canada's health care system. Toronto: Harper Perennial.

Reissman, C.K. (1990). Improving the health experiences of low income patients. In P. Conrad, \& R.Kern (Eds), The sociology of health and illness: Critical perspectives (3rd ed.), (pp. 419-432). New York: St. Martin's Press.

Riesch, S.K. (1988). Changes in the exercise of self-care agency. Westem Journal of Nursing Research, $10(3), 257-273$.

Robley, L.R. (1995). The ethics of qualitative nursing research, 迆mal of Professional Nursing, 11 (1), 45-48.

Rogers, M. (1980). Nursing: A science of unitary man. In J.P. Riehl \& C. Roy (Eds.), Conceptual models for nursing practice(2nd ed., pp. 329-337). New York: Appleton-Century-Crofts.

Rosenstock, I. (1974). The health belief model and preventive health behaviour. Health Education Monograph, 2 , 354-386.

Ross, D.P., Shillington, E.R., \& Lochhead, C. (1994). The Canadian fact book on poverty. Ottawa: The Canadian Council on Social Development.

Rothert, M.L., Rovner, D.R., Holmes, M.M., Schmitt, N., Talarczyk, G., Kroll, J., \& Cogate, J. (1990). Women's use of information regarding hormone replacement therapy. Research in Nursing and Health, 13, 355-366. 
Ryan, P.J, Harrison, R., Blake, G.M., \& Fogelman, I. (1992). Compliance with hormone replacement therapy (hrt) after screening for postmenopausal osteoporosis. British Journal of Obstetrics and Gynecology, 99(4), 325-328.

Sandelowski, M. (1995). Sample Size in Qualitative Research. Research in Nursing \& Health, 18, 179-183.

Sandelowski, M. (1986). The problem of rigor in qualitative research. Advances in Nursing Science, 8(3), 27-37.

Sandman, P.O., Norberg, A., Adolfsson, R., Axelsson, K., \& Hedly, V. (1986). Morning care of patients with Alzheimer-type dementia. A theoretical model based on direct observations. Journal of Advanced Nursing, 11, 369-378.

Schatzman, L., \& Strauss, A.L. (1973). Field research: Strategies for a natural sociology. Englewood Cliffs: Prentice-Hall, Inc.

Schmidt, P.J., \& Rubinow, D.R. (1991). Menopause -related affective disorders: A justification for further study. American Journal of Psychiatry, 148(7), 40-48.

Schein, V.E. (1995). Working from the margins: Voices of mothers in poverty. Ithaca: Cornell University Press.

Schiller, B.R. (1973). Empirical studies of welfare dependency: A survey. Journal of Human Resources, 8(supplement), 19-32.

Seibold, C., Richards, L., \& Simon, D. (1994). Feminist methods and qualitative research about midlife. Joumal of Advanced Nursing, 19 394-402.

Seyle, H. (1976). Stress in health and disease. Boston: Butterworths. 
Severne, L. (1982). Psychosocial aspects of the menopause. In A. M. Voda, M. Dinnerstein, \& S.R. O’Donnell (Eds.), Changing perspectives on menopause (pp. 239247). Austin: University of Texas Press.

Sheehy, G. (1993). Menopause: The silent passage. New York: Simon and Schuster.

Smart, J.F., \& Smart, D.W. (1994). The rehabilitation of Hispanics experiencing acculturative stress: Implications for practice, Journal of Rehabilitation, October/November/December, 8-12.

Smith, D.C., Prentice, R., Thompson, D.J., \& Herrmann, W.L. (1975). Association of exogenous estrogen and endometrial carcinoma. New England Journal of Medicine, 293(23), 1164-1167.

Smith, D.E. (1987). Women's perspective on a radical critique of sociology. In S. Harding (Ed.), Feminism and methodology (pp. 84-96). Bloomington: Indiana University Press.

Smith, J. (1981). The idea of health: A philosophical inquiry. Advances in Nursing Science, 3, 43-50.

Spradley, J.P. (1980). Participant observation. Toronto: Holt, Rinehart and Winston.

Stampfer, M.J., Willet, W.C., Coldiz, G.A., Rosner, B., Speizer, F.E., \& Hennekens, C.H. (1985). A prospective study of postmenopausal estrogen therapy and coronary heart disease. New England Journal of Medicine, 313. (17), 1044-1049. 
Standeven, M., Criqui, M.H., Klauber, M.R., Gabriel, S., \& Barrett-Connor, E. (1986). Correlates of change in postmenopausal estrogen use in a population-based study. American Journal of Epidemiology, 124(2), 268-274.

Standing, T.S., \& Glazer, G. (1992). Attitudes of low-income clinic patients toward menopause. Health Care for Women International, 13(3), 271-280.

Statistics Canada. (1995). Women in Canada: A statistical report (3rd. ed.). Ottawa: Minister of Industry.

Statistics Canada (1997). National overview: Population and dwelling counts (Catalogue No. 93-356-XPB). Ottawa: Author.

Stewart, M.J. (1993). Integrating social support in Nursing. Newbury Park, Ca.: Sage Publications.

Storm, D.S. \& Baumgartner, R.G. (1987). Achieving self-care in the ventilatordependent patient: A critical analysis of a case study. International Joumal of Nursing Studies, 24, 95-106.

Streubert, H.J., \& Carpenter, D.R. (1995). Qualitative research in nursing: Advancing the humanistic imperative. Philadelphia: J.B. Lippincott Company.

Streuernagel, G.A. (1990). Men do not do housework: The image of women in political science. In M. Paludi \& G.A. Streuernagel, G.A. (Eds.), Foundations for a feminist restructuring of the academic disciplines (pp. 167-184). New York: The Haworth Press.

Syme, S.L., \& Berkman, L.F. (1990). Social class, susceptibility, and sickness. In P. Conrad, \& R.Kern (Eds.), The sociology of health and illness: Critical perspectives (pp. 28-34). New York: St. Martin's Press. 
Thronton Dill, B. (1987). The dialectics of black womanhood. In S. Harding (Ed.), Eeminism and methodology (pp. 97-108). Bloomington: Indiana University Press.

Tebbets, R. (1982). Work: Its meaning for women's lives. In D. Belle (Ed.), Lives in stress: Women and depression (pp. 83-95). Beverly Hills: Sage Publications.

Thoits, P.A. (1982). Conceptual, methodological, and theoretical problems in studying soical support as a butter against life stress. Journal of Health and Social Behavior, 23, 145-159.

Traeuber, C.M. \& Allen, J. Women in our aging society: The demographic outlook. In J. Allen \& A. Pifer, (Eds.), Women on the front lines: Meeting the challenge of an aging America (pp. 11-45). Washington: The Urban Institute Press.

Treloar, A.E. (1982). Predicting the close of menstrual life. In A.M. Voda, M. Dinnerstein, \& S.R. O'Donnell (Eds.), Changing perspectives on menopause (pp. 289 304). Austin: Universty of Texas Press.

University of Regina. (1996). Women and poverty in Saskatchewan. Regina: Author.

Voda, A. (1982). Menopausal hot flash. In A.M. Voda, M. Dinnerstein, \& S.R. O’Donnell (Eds.), Changing perspectives on menopause (pp. 136-159). Austin: University of Texas Press.

Voda, A.M. \& George, T. (1986). Menopause. In H.H.H. Werley, J.J. Fitzpatrick, \& R.L. Taunton (Eds.), Annual review of nursing research (4th ed., pp. 55-75). New York: Springer.

Walker, S.N., Volkan, K., Sechrist, K.R. \& Pender, N.J. (1988). Health promoting lifestyles of older adults: Comparisons with young and middle aged adults, correlates and patterns. Advances in Nursing Science, 11 (1), 76-90. 
Wilbur, J., Miller, A., \& Montgomery, A. (1995). The influence of demographic characteristics, menopausal status, and symptoms on women's attitudes toward menopause. Women and Health, 23(3), 19-39.

Wilkinson, R.G. (1989). Class mortality differentials, income distribution and trends in poverty, 1921-1981. Journal of Social Policy 18(3), 307-335.

Wilkinson, R.G. (1992a). Income distribution and life expectancy. British Medical Joumal, 304, 165-168.

Wilkinson, R. G. (1992b). National mortality rates: the impact of inequality. American Joumal of Public Health. 82(8), 1082-1084.

Williamson, J.D., \& Danaher, K. (1978). Self-care in health. London: Croom Helm.

Wood Sherif, C. (1987). Bias in psychology. In S. Harding (Ed.), Feminism and methodology (pp. 37-56). Bloomington: Indiana University Press.

Woods, N.F. (1985). Self-care practices among young adult married women. Research in Nursing and Health, 8, 227-233.

Woods, N.F. (1989). Conceptualizations of self-care: Toward health-oriented models. Advances in Nursing Science, 12(1), 1-13.

Woods, N.F., \& Mitchell, E.S. (1997). Women's images of midlife: observations from the Seattle midlife women's health study. Health Care for Women International, 18 , 439-453.

Worell, J. (1990). Images of women in psychology. In M. Paludi \& G.A. Streuernagel, G.A. (Eds.), Foundations for a feminist restructuring of the academic disciplines (pp. 185-224). New York: The Haworth Press. 
World Health Organization. (1981). Research on the menopause (Technical Report, Series 670). Geneva, Switzerland: Author.

Zeil, H.K., \& Finkle, W.D. (1975). Increased risk of endometrial carcinoma among users of conjugated estrogens. New England Journal of Medicine, 293, $1167-$ 1170. 


\section{Appendix A}

Statistics Canada's Low Income Cut-offs

National Council of Welfare estimates of Statistics Canada's Low Income Cut-offs (1986 base) for 1998*

\begin{tabular}{cccccc}
\hline & & COMMUNITY & SIZE & & \\
FAMILY & Cities of & $\mathbf{1 0 0 , 0 0 0}$ & $\mathbf{3 0 , 0 0 0}$ & Less than & Rural \\
SIZE & $\mathbf{5 0 0 , 0 0 0 +}$ & $\mathbf{4 9 9 , 9 9 9}$ & $\mathbf{9 9 , 9 9 9}$ & $\mathbf{3 0 , 0 0 0}$ & Areas \\
\hline 1 & 16,565 & 14,550 & 14,214 & 12,957 & 11,277 \\
\hline 2 & 22,453 & 19,723 & 19,267 & 17,562 & 15,288 \\
\hline 3 & 28,541 & 25,071 & 24,490 & 22,324 & 19,430 \\
\hline 4 & 32,863 & 28,861 & 28,197 & 25,705 & 22,371 \\
\hline 5 & 35,904 & 31,534 & 30,806 & 28,083 & 24,443 \\
\hline 6 & & & & & \\
\hline $7+$ & 38,973 & 34,227 & 33,438 & 30,481 & 26,532 \\
\hline
\end{tabular}

* Based on estimate of 1.6 percent inflation in 1998.

(National Council of Welfare, 1998, p. 93). 


\section{APPENDIX B}

\section{Letter Requesting Access \\ to the $(\mathrm{xxxx})$}

October 15, 1998

$(\operatorname{xxxx})$

$(\mathrm{xxxx})$

Winnipeg, Manitoba

Dear

I am a graduate student in the Faculty of Nursing at the University of Manitoba. I am in the early planning stages of my thesis which will be investigating the self-care activities of low-income women at midlife. The purpose of this letter is to determine the feasibility of recruiting women between the ages of 40 and 51 from past participants of the $(\mathrm{xxxx})$ program for my study.

It would be helpful to know if the ( $\mathrm{xxxx}$ ) has policies around research as well as the process for ethical review to ensure acceptability of my proposal. This research proposal will be reviewed by the Ethical Review Committee of the Faculty of Nursing.

Participants will be expected to sign a consent form and all procedures for the protection of human subjects will be followed. I will be conducting in-depth semistructured interviews.

I am requesting to meet with you to discuss specific questions and procedures as outlined by (xxxx). The data collection is targeted for the late fall and winter of 1998/1999. Thank-you for your time and consideration. I will be calling you for an appointment. I look forward to meeting with you.

Sincerely

Patricia Gregory B.N., R.N.

Graduate Student

University of Manitoba 


\title{
APPENDIX C
}

\author{
Script for Recruiters
}

A project is being conducted on the self-care activities of women in middle-age. This project is being carried out by Pat Gregory, a Master of Nursing student at the University of Manitoba. She would like to talk with middle-aged women who are living on a low income, I was wondering if you would be interested in finding out more about this project. You will be asked what you do to care for yourself, about your experience with middle age, and what you see as your needs at this time. You will also be asked a few other questions about yourself, such as your age and education level. The project will involve an interview with Pat, in a place that is suitable to you. The interview will take about one and a half hours, and will be like an informal conversation. If you agree, I will provide Pat with your phone number and she will call you to discuss the project further.

Pat would then contact you within the week to provide you with more information. You do not have to take part in this project, it is entirely voluntary. You can decide whether or not you would like to take part when you talk to Pat. May I provide Pat with your name and phone number? 


\author{
APPENDIX D \\ Self-care Activities of Low-Income Women in Midlife \\ Telephone Explanation to Potential Participants
}

Hello, My name is Pat Gregory. Your name was given to me by (xxxx)of the $(x x x x)$. Is it a good time to talk? I am a student in the Faculty of Nursing at the University of Manitoba. I am doing a project titled "Self-care Activities of Low-income Women in Midlife" The goal of the project is to find out what women do to care for themselves in middle-age. This project is part of the Master of Nursing Degree. Because my project has certain requirements for potential participants I would like to ask you a few questions, may I go on?

1) I am interested in women between the ages of 40 and 51 . What is your age?

2) To minimize travel it is important that women live within the perimeter of Winnipeg. Where do you live?

3) I am a nurse at Youville Centre, it is important that women who take part in this project are not clients of Youville Centre. Have you ever used the services of Youville Centre?

4) The study is interested in women experiencing low-income, I would like

to

income? ask you what your household income is. What is your household How many people live in your household?

For women who do not meet the inclusion criteria: Because my project has certain requirements for participation, and (criterion) is not met I am not able to have you participate in the project. Thank you for letting me call you and thank you for your time.

For women who meet the inclusion criteria: You meet the requirements of this project. If you agree to take part, I will arrange to meet you in your home or other place that is suitable to you. You will be interviewed by me for about one and a half hours. You will be asked what you do to care for yourself, about your experience with middle age, and what you see as your needs at this time. You will also be asked a few other questions about yourself, such as your age and education level.

There are no benefits to you, other than you will be able to explore your own selfcare activities. The only risk to you in taking part in this project is that it may make you think about personally sensitive parts of your life.

The interview will be audio-taped and later typed. You may be contacted later to clarify any details. Your information will be analyzed along with information from other women. When the project is written up, the information will be grouped in such a way that it will not be possible to identify you. In addition I would like to contact three women by phone and ask them to review the summary of findings to make sure they accurately reflect the experiences of women such as yourself. You may agree or disagree to review the findings at that time. 
All information discussed during the interview will be kept confidential. Also, no one other than myself, the chair of my thesis committee, Dr. Karen Chalmers of the Faculty of Nursing, and the typist who will be typing the interviews will listen to the tapes. Dr. Wanda Chernomas, also of the Faculty of Nursing and Dr. Tuula Heinonen of the Faculty of Social Work, will have access to the typed copy of the interview only. No specific information will be shared with the $(\mathrm{xxxx})$ or the person who suggested your name. The project has been approved by the Ethical Review Committee of the Faculty of Nursing, University of Manitoba.

Your taking part in this project is totally your choice. If you agree to take part, you can stop and withdraw from the project whenever you like. You may decide not to answer certain questions, ask that the tape be turned off at any time.

Do you have any questions?

Are you interested in taking part in this project?

If no: Thank you for letting me call you and thank you for your time.

If yes: Can we set up a time to meet?

Thank-you for your interest in this project. I look forward to meeting you. 


\section{APPENDIX E}

Script for Request of Participants to Identify Other Eligible Women

Now that we have completed the interview, do you know of any other women who are between the ages of 40 and 51 experiencing low income who might be interested in taking part in the project? I am interested in women who live in Winnipeg, and who understand and speak English. Would you be willing to provide them with this information sheet and have them call me if they are interested in taking part?

Thank-you for your help in finding women who might be interested in taking part. 


\section{APPENDIX F \\ Information Sheet for Potential Participants \\ Self-care Activities of Low-Income Women in Midlife}

Pat Gregory is a registered nurse conducting a project on the selfcare activities of women experiencing low-income in middle-age. The goal of this project is to find out what women do to care of themselves as they go through this stage of life. This project is part of her Master of Nursing Degree at the University of Manitoba.

The project involves a meeting with you, for about one and one half hours in length which will focus on your experience with middle-age, what you see as your needs at this time, as well as what you do to care for yourself. The meeting will occur at a place and time that is convenient for you.

All information discussed during the meeting will be kept confidential. The project has been approved by the Ethical Review Committee of the Faculty of Nursing, University of Manitoba.

If you are a woman between 40 and 51 years of age, experiencing low-income and living in Winnipeg and are interested in receiving more information about the project please contact Pat at $X X X-X X X X$, please leave a message if no one is home.

Thank you for your interest! 


\section{APPENDIX G}

Demographic Questions

1. What is your Date of birth?

2. How many people live in your household?

Who lives in your household?

3. Do you have any children?

If yes, what are their ages?

4. What ethnic origin or descent do you identify yourself with?

5. What is your marital status?

6. What is your employment status

7. If employed, what is your occupation?

8. What is the highest level of education you completed? 


\section{APPENDIX H}

Interview Guide

Thank-you for meeting with me.

I want to remind you that you do not need to answer any questions that you are not comfortable answering. The tape recorder can be turned off at any time to "take a break" if you feel the need to. Specific information will not be shared with the (xxxx) or the person who suggested your name. All information will be kept confidential with the exception of any information that is reportable by law (e.g. child abuse). You may withdraw from the study at any time.

1. What does midlife or middle-age mean to you? What changes are you experiencing if any? Are you experiencing any changes in activities, roles you carry out and relationships within the family, at home, or at work?

Probe for: changes in - marital status

- employment

- caring for spouse, parents, children and/or grandchildren

- physical changes

- how you feel about yourself

2. What does caring for your self mean to you? What does self-care in midlife mean to you? What do you do to help you feel good?

3. What do you see as your personal needs at this time? How have your needs changed since you tumed 40 ?

4. How do you want this time of life to be for you? What conditions or situations are you trying to make or maintain for yourself in this stage of life? Is there anything that you are working at changing or trying to keep the same? Do you have any goals you are working towards?

Probe for: - health behaviours

- relationships

- life situation

- education

- employment

5. What kinds of things do you do to help make this time of life what you need it, or want it to be? Are you doing anything differently now to care for yourself than you did before? What do you do to help you through the changes? What activities have you found most helpful? 
6. How did you learn about the need to do these activities? How are you getting information to help you with the changes you are experiencing? What information did you use to help you with the changes you are experiencing?

Probe for: - reading

- talking with others

- observing others

7. To whom, or where do you go, for help in getting through this stage of life? How has this been helpful or not helpful? Do you have any ideas about the kind of things that would be helpful?

Probe for: - family

- friends

- other midlife women

- alternative healers

- physician

- nurse

- other community resources

8. What do you think you should be doing to help you at this time of life? How did you come to decide that these activities are important?

9. How did you come to choose the things that you do? How did you decide to do those things and not others that you think are important?

10. How do you fit these activities into your daily life. What helps you to do what you need to? What prevents you from doing what you need to do for yourself? What makes it impossible for you to carry out the things that you need to? What have you found are your personal strengths in coping with this stage of life?

11. What would help you to make this time of life what you need it or want it to be? In considering your experience with this stage of life, what suggestions do you have for health professionals in working with middle-aged women? How could the health care system make it easier for you to cope with this stage of life? How could a nurse working in your community, work with you to help you make this time of life what you are trying to make it or need it to be?

Probe for: - connections with other people and settings, example education, workplace, health care system

12. Is there anything else that you want to add that we haven't talked about in regard to middle-age and your needs at this time of life?

Do you have any questions?

Thank-you for providing me with the opportunity to talk to you about your experience with this stage of life.

I may need to call you again to make clear any details. Is this okay with you? In addition, once I have finished the interviews and put all of the findings together, I would like to review a summary of the findings with three women who have taken part in project. The 
main reason for this is to make sure they reflect the experiences of women such as yourself. Would it be okay if I call you. You could decide at that time if your want to meet and talk with me about the findings. 


\section{APPENDLX I \\ CONSENT FORM}

You are invited to take part in the project "Self-care Activities of Low-income Women in Midlife" being carried out by Pat Gregory, a Master of Nursing student from the University of Manitoba. The goal of the project is to find out what women experiencing low-income do to care for themselves in middle-age. If you agree to take part you will be interviewed for about one and a half hours. You will be asked about what you do to care for yourself, your experience with middle-age and what you see as your needs at this time. You will also be asked a few other questions about yourself, such as your age and education level.

The interview will be audio-taped and later typed. In addition, I may also write some notes to myself after our meeting about my observations. You may also be contacted at a later date to clarify any details. Your information will be analyzed along with information from other women. When the project is written up, the information will be grouped in such a way that it will not be possible to identify you. In addition I would like to contact three participants by phone and ask them to review the summary of findings to make sure they accurately reflect the experiences of women such as yourself. You may agree or disagree to review the findings at that time.

Your taking part in this project is totally your choice. If you agree to take part, you can stop and withdraw from the project whenever you like. You may decide not to answer certain questions, or ask that the tape be turned off at any time.

There are no benefits to you, other than you will be able to explore your own self-care activities. The only risk to you in taking part in this project is that it may make you think about personally sensitive parts of your life. Findings from the project may be published in a professional joumal.

All information discussed during the interview will be kept confidential with the exception of information that is reportable by law (e.g. child abuse). Also, no one other than Pat Gregory, the chair of her thesis committee, Dr. Karen Chalmers of the Faculty of Nursing, and the typist who will be typing the interviews will listen to the tapes. Dr. Wanda Chemomas, also of the Faculty of Nursing and Dr. Tuula Heinonen of the Faculty of Social Work, will have access to the typed copy of the interview only. No specific information will be shared with the (xxxx) or the person who suggested your name. Your name will not be used on any of the tapes, typed copies, reports, or in any publications. The tapes and typed copies will only be identified by a code number. The project has been approved by the Ethical Review Committee of the Faculty of Nursing, University of Manitoba. Your signature below indicates that you agree to take part in the project and that you have had all of your questions answered to your satisfaction You will be given a copy of this form. You may contact Pat $(261-4260)$ or her thesis committee chair, Dr. Karen Chalmers (474-7318) at any time, if you have any further questions about the project.

I, Women in Midlife. agree to take part in the project: Self-care Activities of Low-income

Signature: Date:

Researcher: Date: 
Would you like to receive a summary of the findings from this project once it is completed? yes no

If yes, please write you name and address below for the purposes of mailing. You can expect results in about four to six months. 


\section{APPENDIX J \\ Script for the Request of Participants for the Verification of Findings}

Hello, my name is Pat Gregory. I am a graduate student in the Master of Nursing program at the University of Manitoba. I met with you a few months ago to discuss your self-care activities in midlife. Is now a good time to talk? The reason for this call is to see if you would be interested in assisting me to verify or confirm a summary of the findings of my study. When I met with you, at the end of the meeting I asked if you might be interested in meeting with me again. The purpose of this process is to make sure that my examination of the data accurately reflects the self-care activities of women such as yourself. If you agree I will arrange to meet with you in-person to review a summary outlining the themes I have seen in the data. I will meet with you for about 20 to 30 minutes to discuss the findings. During our discussion I will be taking detailed notes on your reactions and opinions about the findings of the study. I want to assure you that confidentiality will be maintained. Data has been grouped so as to protect anyone who took part from being identified. Would you be interested in taking part in this part of the project?

Do you have any questions about this part of the project?

Can we set up a meeting time?

Thank you very much, I look forward to meeting with you again. 